\title{
Autistic Culture THE ARCHITECTURAL THERAPY
}

by

Thomas Mark Nemeskeri, B.A.S.

\author{
A thesis submitted to \\ The Faculty of Graduate Studies and Research \\ in the partial fulfillment of the requirements \\ for the degree of
}

MAster of ARCHITECTURE

M.ARCH (PROFESSIONAL)

Carleton University School of Architecture Ottawa, Ontario, Canada

(April, 2007) 


$\begin{array}{ll}\begin{array}{l}\text { Library and } \\ \text { Archives Canada }\end{array} & \begin{array}{l}\text { Bibliothèque et } \\ \text { Archives Canada }\end{array} \\ \begin{array}{l}\text { Published Heritage } \\ \text { Branch }\end{array} & \begin{array}{l}\text { Direction du } \\ \text { Patrimoine de l'édition }\end{array} \\ \begin{array}{l}\text { 395 Wellington Street } \\ \text { Ottawa ON K1A ON4 }\end{array} & \begin{array}{l}\text { 395, rue Wellington } \\ \text { Ottawa ON K1A ON4 }\end{array} \\ \text { Canada } & \text { Canada }\end{array}$

Yourfile Votre référence

ISBN: 978-0-494-26975-6

Ourfile Notre référence

ISBN: 978-0-494-26975-6

NOTICE:

The author has granted a nonexclusive license allowing Library and Archives Canada to reproduce, publish, archive, preserve, conserve, communicate to the public by telecommunication or on the Internet, loan, distribute and sell theses worldwide, for commercial or noncommercial purposes, in microform, paper, electronic and/or any other formats.

The author retains copyright ownership and moral rights in this thesis. Neither the thesis nor substantial extracts from it may be printed or otherwise reproduced without the author's permission.
AVIS:

L'auteur a accordé une licence non exclusive permettant à la Bibliothèque et Archives Canada de reproduire, publier, archiver, sauvegarder, conserver, transmettre au public par télécommunication ou par l'Internet, prêter, distribuer et vendre des thèses partout dans le monde, à des fins commerciales ou autres, sur support microforme, papier, électronique et/ou autres formats.

L'auteur conserve la propriété du droit d'auteur et des droits moraux qui protège cette thèse. $\mathrm{Ni}$ la thèse ni des extraits substantiels de celle-ci ne doivent être imprimés ou autrement reproduits sans son autorisation.
In compliance with the Canadian

Privacy Act some supporting forms may have been removed from this thesis.

While these forms may be included in the document page count, their removal does not represent any loss of content from the thesis.
Conformément à la loi canadienne sur la protection de la vie privée, quelques formulaires secondaires ont été enlevés de cette thèse.

Bien que ces formulaires aient inclus dans la pagination, il n'y aura aucun contenu manquant.

\section{Canadá}




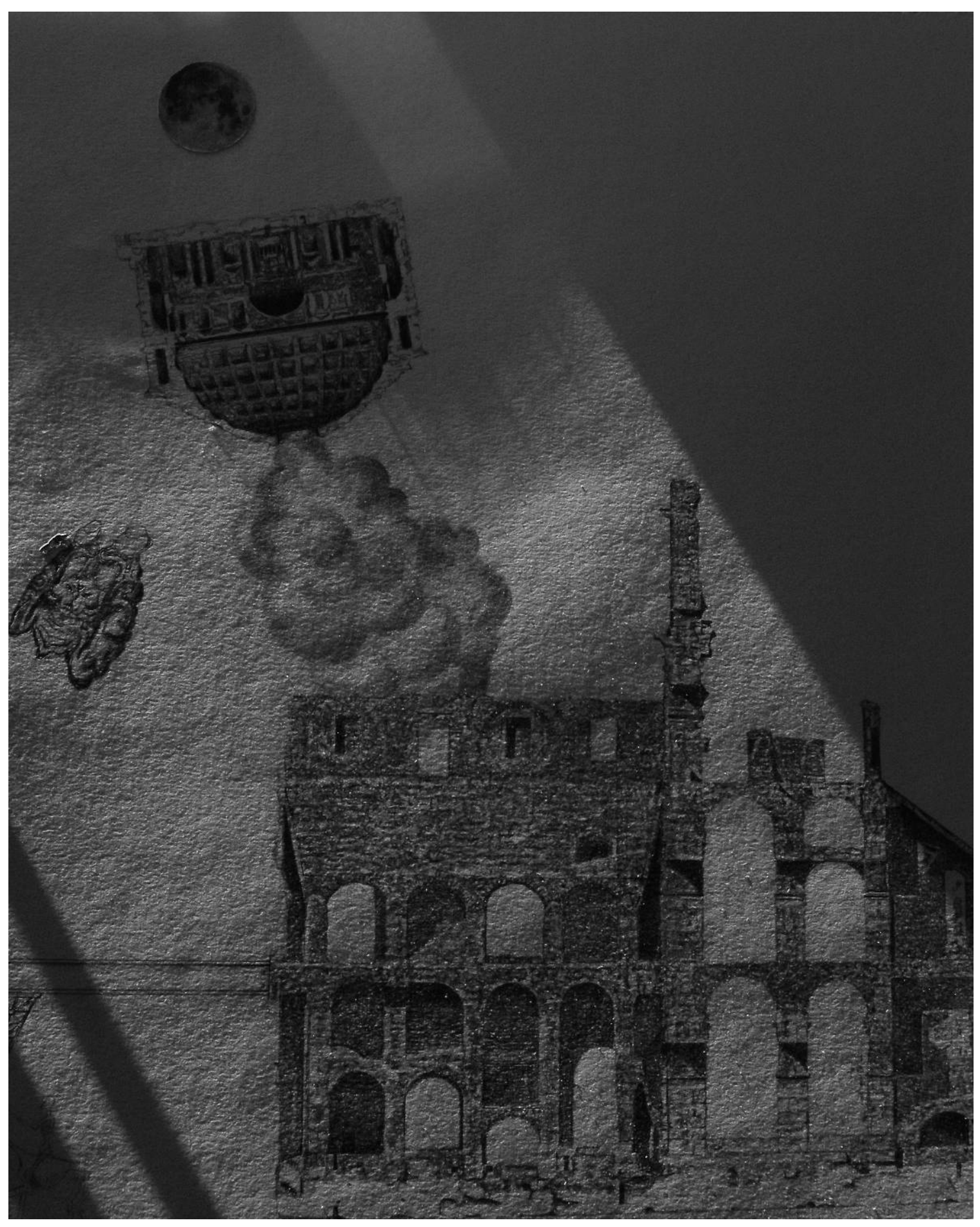




\section{ABSTRACT}

Binary logic can be described as one response to humanity's search for security from space and time. The primary means of this algorithmic'solution' is through the reduction of technology (technē) to a 'techno-logic' - a logic of instrumentalized means and ends that transmits through culture in such a way that the indeterminacy of our participatory role in the world becomes encompassed by meta-narratives rather than involvement in the communicative space of culture. As I will reveal, these discursively-generated narratives persist through the thoroughly technologically-oriented spectacle that is Autistic Culture. Autistic Culture reveals genetic biases of agency toward auto-poiēsis, facilitated by instrumentalized technology. I will argue that Autistic Culture is a condition which can most effectively be mediated through architecture; through its role of establishing 'spontaneous' heuristic fictions as a basis for revealing moral ontologies.

The intervention of a Laboratory for Human Prosthetics and Virtual Interfaces in the Lower Main of Montréal (St. Laurent Boulevard), in the context of those at the forefront of technological development, to coincide with the development of the area into an arts and cultural district is seen to be most apt as an Architectural Therapy to negotiate Autistic Culture, and is manifested by means of a twofold process; by one which engages the 'local technology' of its inhabitants, as a means of developing a relationality; and by another which deliberately engages their autistic tendencies, as a means of contrasting 'extension' with quotidian experience. 
I would like to thank Marco

Frascari, who provided me with insights, discipline and many architectural narratives as my thesis advisor.

I also wish to give thanks to my family for their support over the years, and to my friends for their wisdom and encouragement when I lacked any.

Finally, I wish to extend my thanks to Richard Lister, who helped me to understand the importance of architecture in a world worth caring for.

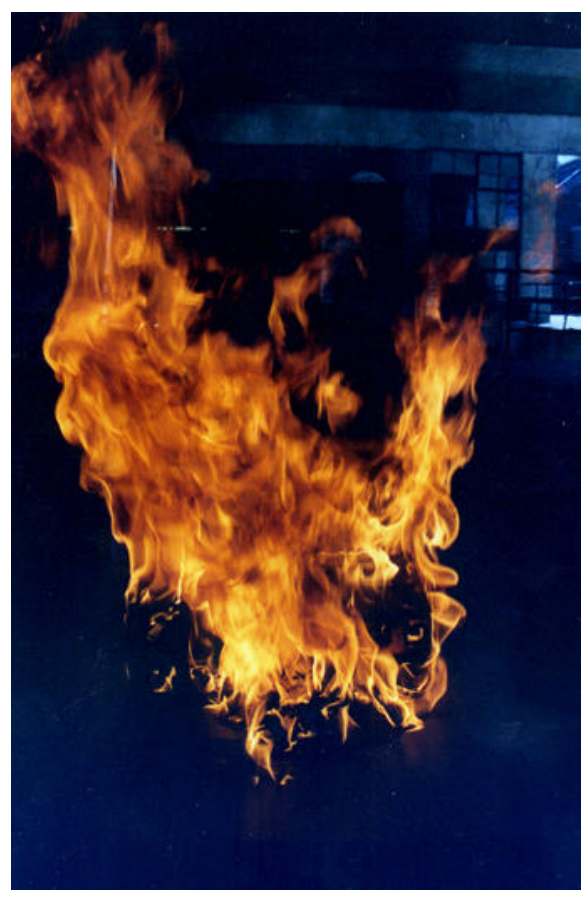




\section{TABLE OF CONTENTS}

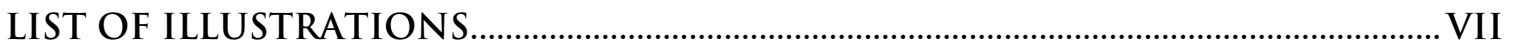

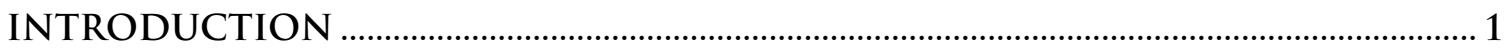

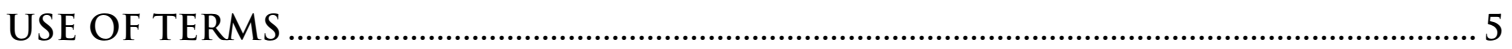

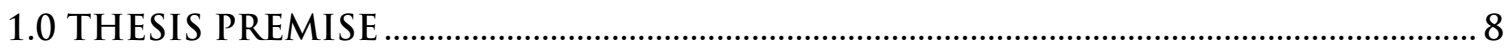

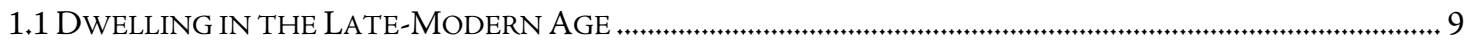

1.2 AUTISM VS. HYSTERIA: EXTREMES OF THE SYNAESTHESIAC ............................................................. 10

1.2.1 Epidemiology - The Case of Silicon Valley …………………………………………………………………..... 12

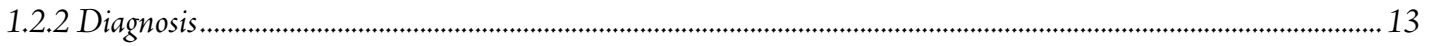

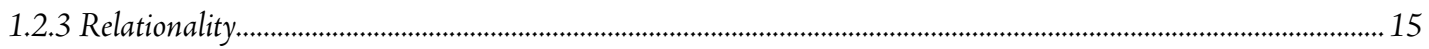

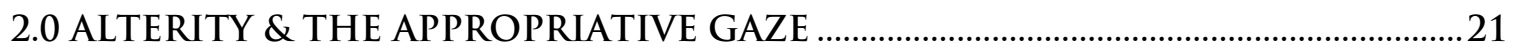

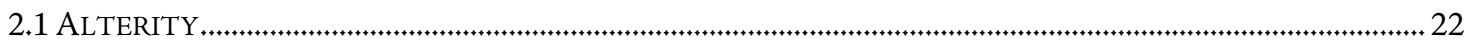

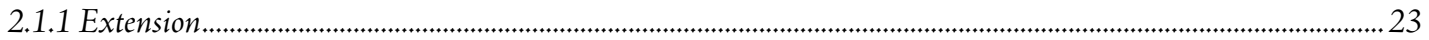

2.1.2 Theoria

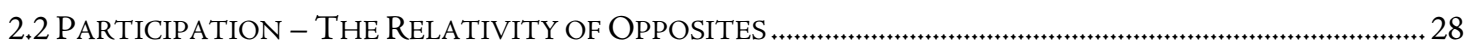

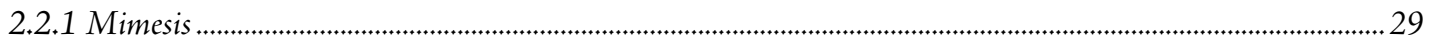

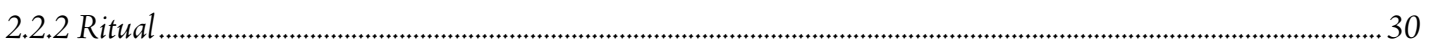

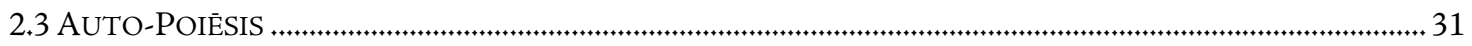

2.3.1 Appropriation - The Anthropocentric Dialectic.............................................................................................. 32

2.3.2 Epistemological Proceduralism ................................................................................................................ 34

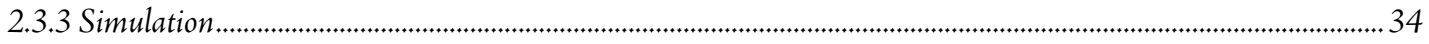

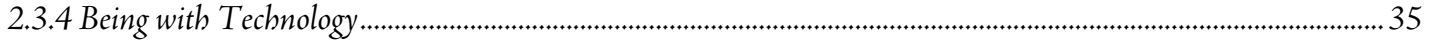

2.3.5 Divided Representation ……………………………………………………………………………………….... 38

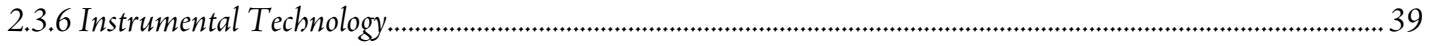

2.3.7 Ecologies and Prescriptive Disclosure ................................................................................................................ 41 


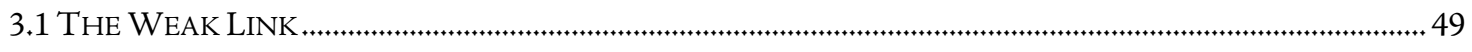

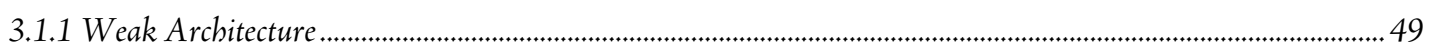

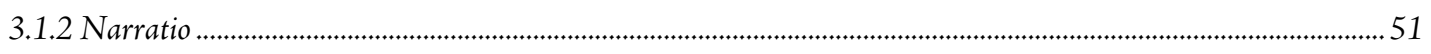

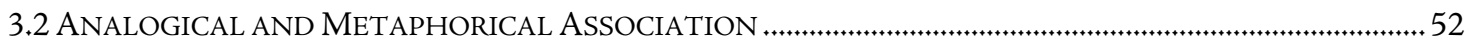

3.2.1 Prognosis - Eisenman's House VI ........................................................................................................................ 52

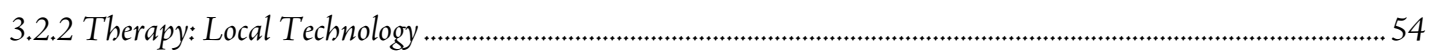

3.2.3 Technè: Revealing the Factum ……………………………………………………………………. 56

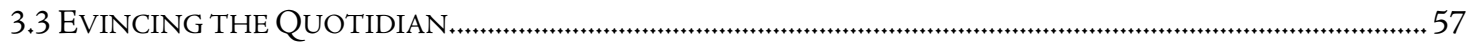

3.3.1 Situatedness........................................................................................................................................................... 57

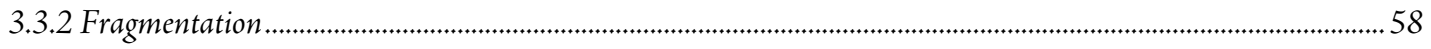

3.3.3 The Infra-ordinary: Michel de Certeau and Georges Perec ...................................................................61

3.3.4 Evincing the quotidian: Creative Resistance in Architecture...................................................................... 64

4.0 THE MAIN: CULTURAL PRODUCTION .......................................................................69

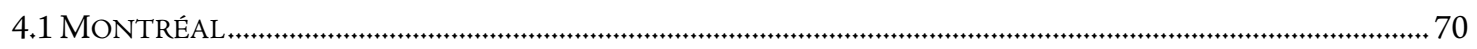

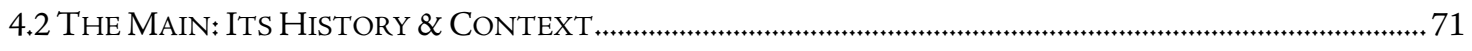

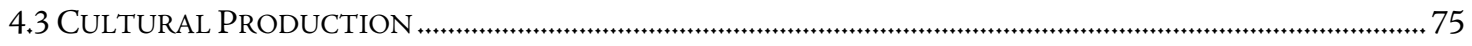

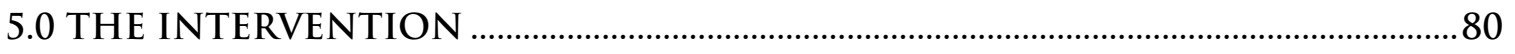

5.1 SITUATION

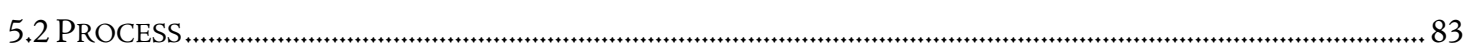

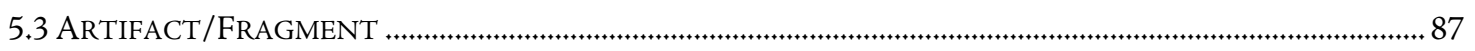

6.0 CONCLUSION

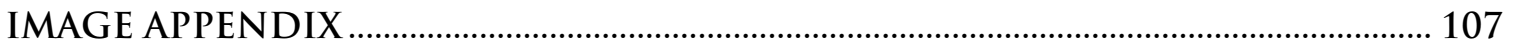

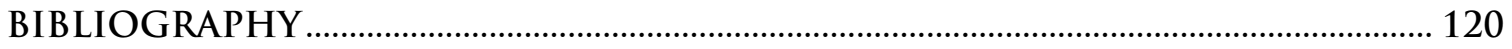




\section{LIST OF ILLUSTRATIONS}

ALL IMAGES COPYRIGHT OF THE AUTHOR UNLESS OTHERWISE NOTED.

Fig. 1 A drawing by a 3-year-old autistic child. A heightened focus on object inscription allows some to draw with great accuracy. Source: Lorna Selfe, Nadia: A case of extraordinary drawing ability in an autistic child. (London: Academic Press, 1977)

Fig. 2 An autistic child being embraced by a hugging machine. Source: http $: / /$ abclocal.go.com/kgo/story?section=edell\&id=3366089 (last accessed:2006-09-20) 16

Fig. 3 Johannes Kepler, Mysterium Cosmographicum (1596). Source:

http://upload.wikimedia.org/wikipedia/fr/1/10/Kepler_polyedres.jpg (last accessed: 200609-21)

Fig. 4 Versailles, France, under Louis XIV: the extension of the appropriative gaze as an aesthetic experience, as represented by Pierre Patel in 1668. Source (last accessed: 2006-0921): http://www.en.utexas.edu/Classes/Moore/neoclassical/images/gardens/large/PATEL230A.jpg.

Fig. 5 Extract from the frontispiece of the Encyclopédie (1772). The figure in the centre represents truth - surrounded by bright light (the central symbol of the Enlightenment). Two other figures on the right, reason and philosophy, are tearing the veil from truth. Drawn by Charles-Nicolas Cochin and engraved by Bonaventure-Louis Prévost. Source: http://en.wikipedia.org/wiki/Image:Encyclopedie_frontispice_full_473px.jpg (last accessed: 2005-05-05). 38

Fig. 6 Achille Leclere, The Pantheon, 1813 (left), and Alfred Nicolas Normand Monuments of the Roman Forum at the Foot of the Clivus Capitolinus from the end of the Reign of Septimus Severus, 1853 (right). Source: Cassanelli, Roberto... [et al.]. Ruins of Ancient Rome: the Drawings of French Architects Who Won the Prix de Rome, 1786 - 1924, p. $157 \& 70$ respectively.

Fig. 7 The curious contradictions of the 'revelatory' gaze. Da Vinci's "Vitruvian man" (Source: http://www.abc-people.com/data/leonardov/vitruvian-man.jpg [Last accesed 2005-11-15]), alongside "Monster Water, commonly called Thames Water" (Source: http://www.literarylondon.org/london-journal/march2004/Fig4.jpg [Last accessed: 2005$10-12])$ 
Fig. 8 Stills from Andrei Tarkovsky's films Stalker and Nostalghia. Sources:

http://www.hauntedink.com/uploaded_images/stalk4ae-740786.jpg (last accessed: 2006-08$11)$, and

http://www.acs.ucalgary.ca/ tstronds/nostalghia.com/graphics/photos_nostalghia.jpg (last

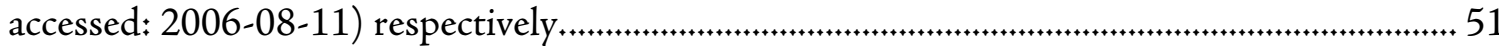

Fig. 9 The bed(s) of the master bedroom in Eisenman's House VI, before and after. Photograph by Dick Frank. Source: Frank, Susan. Peter Eisenman's House VI - The Clients

Response, p.61..... 52

Fig. 10 The poetic aspects of the typical construction site. Photographs by the author. 55

Fig. 11 The remains of Detroit's Central Station, circa 2005. Photographs by the author, .... 60

Fig. 12 Diogenetic Installation (Chiara Camposilvan, Thomas Nemeskeri); generated as an act of creative resistance in the Masters Studio of the Azrieli Pavilion, at Carleton University, 2006. Materials: tent, log, rodent bedding, maps. Photographs by the author.

Fig. 13 Dwellings expropriated for the construction of the Ville-Marie Expressway, May 1971. Photograph by Brian Merrett. Source: André Lortie, "Montréal 1960: The Singularities of a Metropolitan Archetype." Montréal Thinks Big. p.108.

Fig. 14 "St. Lawrence Boulevard, Montreal, QC, about 1910." Photograph by Neurdein Frères. Source: http://www.mccordmuseum.qc.ca/scripts/large.php?Lang=1\&accessnumber=MP-0000.816.1 (last accessed : 2006-03-15)

Fig. 15 Images of the current state of the Lower Main, including the Montreal Pool Room, where 80 year-old pool tables form eating surfaces for greasy-spoon dining. Photographs by the author.

Fig. 16 Artist's rendering of future site at the intersection of Ste-Catherine and St-Laurent, currently the site of a strip-club and pornography store. Source (last accessed : 2006-07-04): http://www.quartierdesspectacles.com/en/nouvelles/fichenouvelle.asp?id=11................... 75

Fig. 17 The proposed site - 1886-1896 St-Laurent Boulevard, Montréal, Québec; recalling its

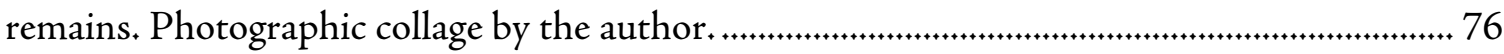

Fig. 18 Map depicting cultural centres within the vicinity of the site. Image by the author..... 77

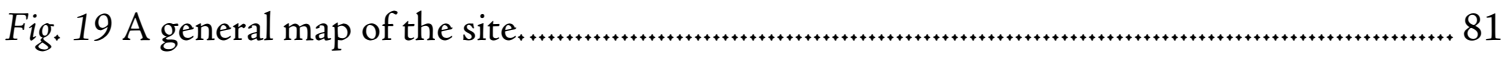

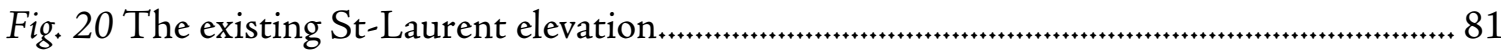

Fig. 21 The existing Clark St. elevation. 81 
Fig. 22 State of 1186-1196 St-Laurent, circa 2006. Photographs by the author. 82

Fig. 23 Rendering by the author; graphite and transfer on Stonehenge, 26" $x 40$ ". 84

Fig. 24 An unsuccessful iteration of the working surface, consisting of a plaster cast grafted to the underside of the birch table 85

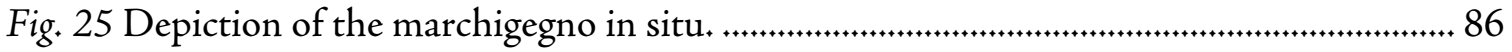

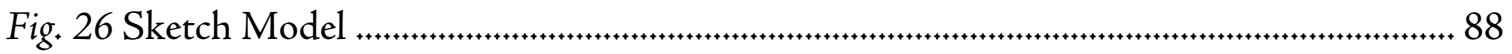

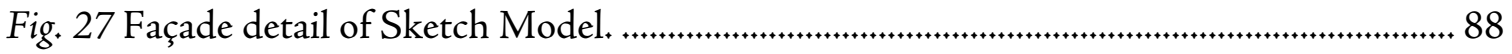

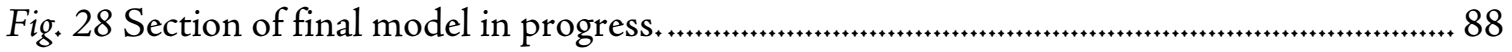

Fig. 29 Massing/Context site model, depicting new residential developments (red), lots to be developed according to the new development plan (white), and existing buildings to be redeveloped (black).

Fig. 30 Early sectional sketch.

Fig. 31 The Québec 'National' Archives, Montréal, Canada. Its glass floors date back to the original construction, at the turn of the 20th century. Photograph by the author

Fig. 32 Abstract of the proposed Laboratory.

Fig. 33 View of the Laboratory from St-Laurent Boulevard.................................................... 92

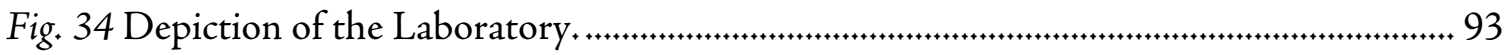

Fig. 35 Depiction of the circulation ramp and adjacent court.

Fig. 36 Depiction of the interstitial resource library and research carrels, adjacent to the

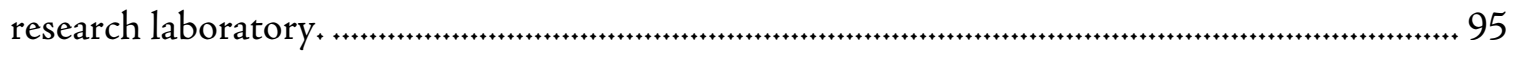

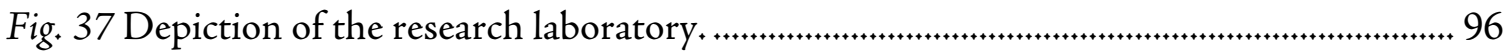

Fig. 38 Depiction of the nano-technology luminescent glass roof, above the uppermost

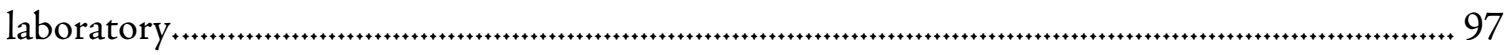

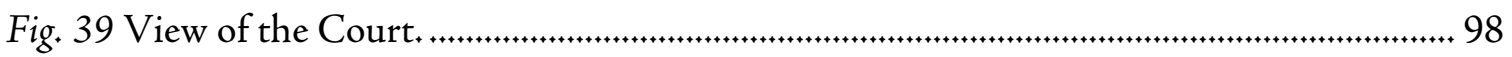

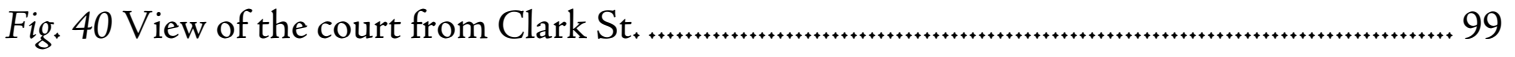

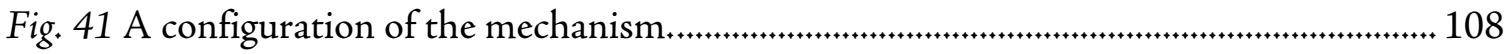

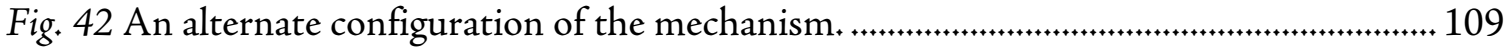




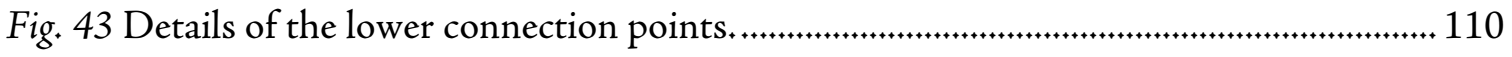

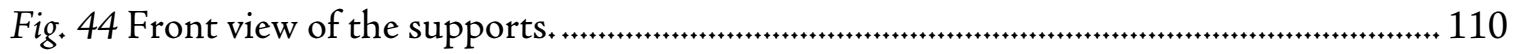

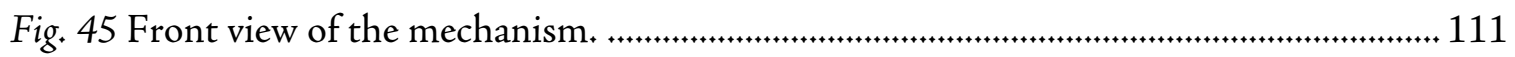

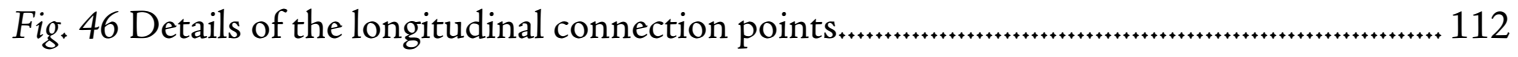

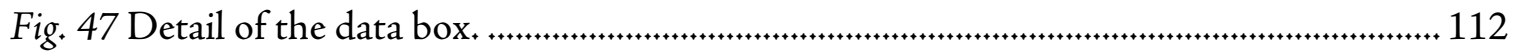

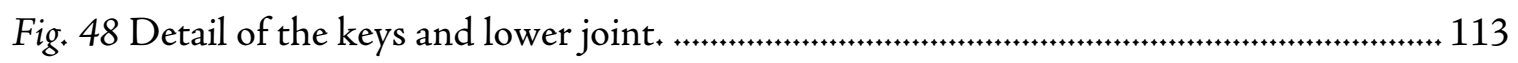

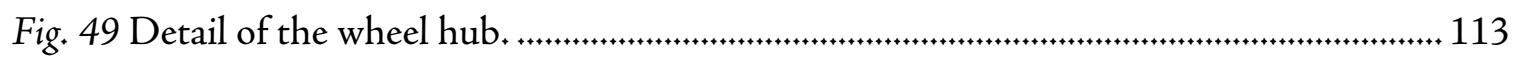

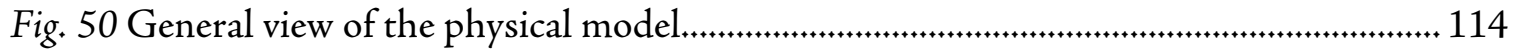

Fig. 51 Sectional view of the physical model; North-Eastern orientation................................ 115

Fig. 52 Sectional view of the physical model; South-Western orientation. ............................... 115

Fig. 53 Detail of the nano-technology-based glazing, and the emerging passive-solar mass. . 116

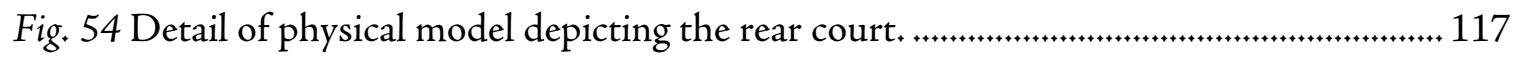

Fig. 55 Typical Plan of the Laboratory building

Fig. 56 North-Eastern Sectional diagram of the Laboratory. ................................................. 119

Fig. 57 South-Western Sectional Diagram of the Laboratory ............................................... 119 


\section{INTRODUCTION}

In developing a thesis with humanistic underpinnings, the question to the fore of my mind throughout the endeavour has been the question of sustaining humanity. Specifically, it poses how the well-being of humans can coincide with the well-being of the things which nurture and sustain us. This question - stemming from my will to know the world around me - has led me to many profound insights into praxis. What I have come to know through this thesis can be described as a moral ontology - a way of mediating the world. It recognizes aspects of the human condition, such as a persistent fear of time and space, and provides an implicit basis for mediating them. With this understanding, we can embrace our spatial and temporal orientation through a meaningful dialogue between our bodies and the spaces which conceive them.

Throughout this thesis, I argue that humanity's persistent fear of space and time necessitates systems of binary logic which increase the degree of auto-referentiality, while simultaneously limiting agency. The primary means of this algorithmic 'solution' is through the reduction of technology $($ techne $)$ to a techno-logic - a logic that permeates the field in such a way that the indeterminacy of our participatory role in the world becomes encompassed by meta-narratives. The purpose of this thesis is to bring to light critical issues in the question of technology - issues which place the hegemony of instrumental logic and meta-narratives 
under the scope of a Diogenetic eye. Under such a gaze, the role of technology as a mediational tool becomes a lens through which to consider the role of architecture in establishing the conditions for heuristic fictions (narratio) to be developed as expressions of human agency.

This thesis begins with a brief outline of the cultural symptoms of the late-modern age, beginning with a consideration of the hysteric and autistic conditions as extremes of the synaesthetic; in situating the symptoms as a question of embodiment, an association is made between cultural symptoms and corporeal symptoms. This is followed by an epidemiological account of Autistic Culture, to further punctuate the aforementioned association, followed by a diagnosis of the symptoms proper of autism, in which critical aspects of relationality are revealed as a platform for a discussion of alterity.

The following chapter, regarding alterity and the anthropocentric dialectic, provides a detailed account of the development of the appropriative gaze, beginning from first principles of alterity and extension, following Heidegger's theory of technology. This is followed by an account of the advent of epistemological proceduralism and auto-poiēsis, revealed as precursors to the development of Autistic Culture. This chapter culminates in a description of the effect of instrumentalization on representation and the shaping of discourses regarding our world, thereby transfiguring our relationality, and facilitating genetic proclivities towards autoreferentiality. In relating the development of alterity to the development of representation in architecture, an association is made between embodiment and architecture, thereby providing a basis for an understanding of the role of architecture in Autistic Culture.

This approach is then used in Chapter Three to propose a potential therapy to Autistic Culture, as a response to its self-producing, self-consuming tendencies, beginning with an account of a non-prescriptive methodology provided by Sola-Morales' work regarding 
Weak Architecture; his tangential description of a more visceral, subjective architectural experience is seen to be a primer for a critical response to Autistic Culture. This is contrasted by a prognostic account of Autistic Culture, as shown by Peter Eisenman's House VI. As an example of autistic architecture, House VI demonstrates auto-referential conditions in which the possibilities of negotiation are left primarily to the mind, thereby orienting disclosure through communicative space toward the self. With these two accounts in hand as a basis for negotiation (as a contrast between a rationality of relationality, and a calculus of relationality), I proceed to provide an orientation for an architectural therapy toward a situatedness within the quotidian. This orientation is reinforced with critiques of everyday life by Georges Perec and Michel de Certeau, and by the approaches of architects such as Louis Khan to build spaces imbued with a 'local technology.'

Following these strategic steps in the orientation of a dialogue concerning Autistic Culture, I proceed in Chapter Four to outline the basis for an intervention on Montreal's StLaurent Boulevard. By providing an account of the context and history of the site, and the eventual culmination in its transformation into an arts and cultural district, I am able to show how the intervention of a Laboratory for Human Prosthetics and Virtual Interfaces provides a critical response to the potential effects of gentrification in the area, and how the inclusion of a technologically-oriented facility within the district can be mutually beneficial to those at the fore of Autistic Culture, and to the artists within the district, such as those of the Society for Arts and Technology, immediately adjacent to the site.

In Chapter 5, I provide an account of the process of generating and representing this therapy, beginning with the manifestation of $1: 1$ construction conceived as a 'play structure,' or marchingegno, around which an architect can envision design of a project by implicating the 
user as a participant in the design process. Conceived as a device to reveal narratives based on heuristics of participation, the design of the building is generated through non-prescriptive processes derived from the immediate subjective experience of its participants. This condition is then transcribed in the generation of a duality of spaces; those which evince participatory heuristics by interrupting the ordinary, and those which deliberately mute such interruptive moments through their homogeneity. In such a way, symptomatic spaces of extension are contrasted with the quotidian, as a therapy to Autistic Culture.

The final chapter provides concluding remarks on the effectiveness of this thesis, beginning with remarks concerning the importance of architectural representation in generating opportunities to allow individual narratives to negotiate the tenuous nature of appropriation, wherein the possibilities of the copula between language, action and thought in developing agency through heuristic fictions are made present. I then re-assert that the discourse surrounding Autistic Culture belongs within the broader context of questioning what it is to sustain humanity; in building a thoroughly technological world, we are producing genetic biases of agency toward auto-poiessis. Finally, I dwell on the importance of creative disclosure of the circumstances which surround our everyday lives; by revealing the infraordinary aspects of our lives, the realm of extension becomes leveraged, allowing for a sustaining relationality to be developed. 


\section{USE OF TERMS}

The subject of this thesis is rendered through variety of lenses; though all reveal critical aspects about Autistic Culture, some are analytical while others are unsystematic. This approach yields a variety of unusual terms and concepts throughout this thesis, which require an introduction for the sake of clarity.

In this thesis, I use the term Autistic Culture as a reference to cultural phenomena with characteristics of auto-referentiality, which exist in parallel to medically prescribed symptoms. However, recent research about autism reveals contentious and sometimes contradictory understandings of the autistic spectrum, such that the field is divided between those that assert that autism is a genetic disorder (and subsequently believe in the possibility of a medically-defined cure for the condition), and those that assert that the autistic condition is in fact an evolution of the human species. ${ }^{1}$ For this reason, it is necessary appreciate Autistic Culture as that which encompasses such contentions.

Implicit within an understanding of Autistic Culture is an appreciation of medicine as a cultural trope. ${ }^{2}$ Because of this, I employ the term "therapy" through a definition of it as being a leverage to the persistence of instrumentality within the culture which it is defined by, and not as a medical cure. ${ }^{3}$ This approach evolves from a correlation between culturally-defined well-being and medically-defined well-being, where medical discourse is seen to discursively render a particularized view of phenomena. Such an understanding is easily expressed 
throughout medical history, as with the Oracles at Delphi; their spasmodic convulsions were thought to be brought about by contact with the gods, allowing them to divine aspects about the future. However, according to medical science, the subjects were undergoing epileptic convulsions brought about by the inhalation of gases emitted from fissures in Mount Parnassus, upon which the temple was built, after unusual behaviour was observed in grazing sheep. This twofold explanation provides a basis for an understanding that medicinal conceptions are bound by the culture in which the medicine is developed. The similarities between the medical explanations and cultural phenomena allow correlations to be drawn between the auto-referential characteristics as a cultural condition and autism as a medical condition. Furthermore, I assert that auto-referential proclivities persist through the anthropocentric dialectic, which is understood to be the dialectic between bumans and their alterity, or externality, which is rendered by agency through the circumstances of the human condition and environment.

Finally, I contend that auto-referential conditions within culture are rendered through a way of being with technology which instrumentalizes our relationship to the world, hereby understood as instrumentalized technology, which results in a dissociation between means and ends, wherein technology as a challenging, or bringing forth, becomes replaced with technology as a bringing about. ${ }^{4}$ This withdrawal is aptly explained by Aidan Davison, who notes a separation of the means of agency from "immediate bodily experience" ${ }^{5}$ through the efficacy of tool usage. As such, the mediator which I employ in response to this condition is one which regards Autistic Culture as being separate from the conditions which brought it about. 


\section{NOTES}

1. This assertion has prompted communities devoted to Autistic Pride, which celebrate the state through an annual parade, while seriously angering and disturbing parents of low-functioning autistics, who believe in one day curing autism. For an example of such contentious research, see Dawson, M.; Gernsbacher, M.A.; Goldsmith, H.H. Three Reasons Not to Believe in an Autism Epidemic, American Psychological Society. (Vol. 14, No. 2, 2005, 55-58).

2. For an introduction to this understanding, see Michel Foucault, The Birth of the Clinic; an Archaeology of Medical Perception. New York: Pantheon Books (1973).

3. A concept which itself is discursively-bound, producing the similar yet opposing techniques of Allopathic and Osteopathic medicine, as expressed through the Caduceus.

4. This concept is broadly discussed in Chapter Two of this document.

5. Aidan Davison, Technology and the Contested Meanings of Sustainability, p. 110. 
"In a secularized age, the dog architecture of machinedrawing hides our poetic selves from our technological selves - and reveals the same to the same - by a logic opposite that of personification. We are given the Pauline dyad of vision and blindness. Blindness to find, vision to know."

Donald Kunze, "Prolegomena to any future dog architecture.” (1989) ${ }^{1}$

\subsection{THESIS PREMISE}

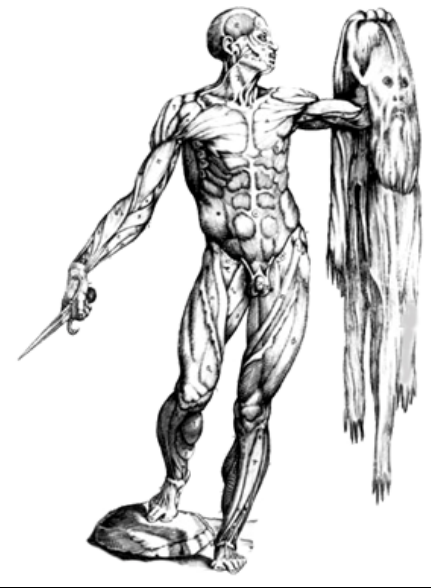




\subsection{Dwelling in the Late-Modern Age}

The nature of the research in this thesis is based upon the assertion that the act of dwelling - the means of mediating the world within and the world without - is subject to a crisis of representation and manifestation within the contemporary condition: the relationship between the abstracted realm of extension and the phenomenological world has become polarized under the hegemony of instrumental logic and meta-narratives, wherein any notion of mystery which might be had through mimetic modes of participation is shunned and undermined by the "tendency to replace participation by the appropriation and manipulation of the order-creating powers" ${ }^{2}$ of mathematical understanding and control, the extreme of which has led the sceptic-architect Rem Koolhaas to claim that "the cosmetic is the new cosmos." 3 This statement leads one to question the conditions under which such a claim could be made. According to Koolhaas, it would be under the hysteric, dystopic utopia (or the "heterotopia," ${ }^{4}$ according to Foucault) in which we live, which is best typified, to him, by the typical airport. To Koolhaas, the airport embodies the temporary, piecemeal nature of what were once spaces which embodied cultural production; now perpetually partially-renovated spaces - spaces of transition, in transition, concealed by vague, transient and disparate conditions. Throughout this thesis, I will argue that Autistic Culture plays an equal, if not greater part in the building of such a deformed world. The conditions described by Koolhaas are no doubt present in a context in which our spaces are often generated by economic imperatives, placing architecture under an instrumental aspect. Further, these conditions no doubt lend themselves in part to a cynical outlook on the world, though certainly not one that is productive. Such was the criticism of Donald Kunze, who reflected on Diogenes of Sinope to recall the original conception of cynicism, noting that Diogenes' role was to turn from 
convention (nomos) toward the "here and now" 5 of physis.

The convention of today lies within the anthropocentric dialectic. While this is a cynical thesis, it is one with an argute point directed at Autistic Culture, as a means of recovering what is productive about agency. To begin to demonstrate this, it is important to confine the specific conditions to which I am referring to - hysteria and autism - and to explain how they are extremes of a product of relationality known as synaesthesia.

\subsection{Autism vs. Hysteria: Extremes of the Synaesthesiac}

Synaesthesia exists as a foil to the symptoms of autism and hysteria; autism as being within the mind and hysteria as being without the body, synaesthesia merges the mind with the body (res cogitans and res extensa respectively) to generate a relationality. To elaborate, let us first take account of what these conditions imply. Autism, as will be elaborated throughout this thesis, is a genetically-based condition of auto-referentiality (hence its title), in which the subject is prone to self-orientation and anti-social behaviour, largely due to a heightened focus on object inscription. The autistic may therefore be seen to be 'locked' within themselves. On the other hand, hysteria can be seen as a condition of dis-embodiment. According to the etymology of the term, hysteria refers to a condition first diagnosed by the Egyptians, according to a purported dislocation of the uterus (bystera) from its moorings in the pelvis, while the hymen remains intact. The resulting wandering womb caused disturbances of the body as it floated about within the corpus, causing 'hysteric suffocation' for instance, when the bystera lodged in the upper thorax, thereby impeding the flow of air. ${ }^{6}$ Though anatomically unconvincing, the diagnosis does provide a productive insight into the nature of hysteria, specifically in its reference to a 
dislodgement or unmooring of the corpus from a homeostatic condition. Throughout its diagnostic history, hysteria had largely been referred to feminine conditions, most often to sexual dissatisfaction. However, the affliction eventually came to be associated with the male figure, such as in the case of post-war shell shock, though still a reflection of an exclusively female archetypal pattern. ${ }^{7}$ In the contemporary condition, it has come to be attributed, quite liberally, to the state of our relationship to the world without, as related by Baudrillard's explanation of the state of representation, for example, where hysteria takes effect as a disconnected, somnambulistic orientation toward the world as lived versus the world represented. ${ }^{8}$

In contrast to the conditions outlined above, the synaesthesiac embodies a unity of sensation, perception, and representation:

Known to medical science for almost three hundred years synaesthesia, a technical expression meaning crossing of the senses (Greek syn = together, and aisthesis $=$ sensation/perception) has been recently confirmed as a legitimate neurological condition. Synaesthesia occurs through the associations of two or more physical senses and other sense modalities. Called synaesthetes, the individuals with synaesthesia "smell" colors, "see" sounds and "feel" tastes. In these cross-modal associations, the elicited sensations are both emotional and noëtic and the phenomenon of synaesthesia interfaces virtual perceptions with normal sensory perception, rather than replacing one perceptual mode for another. ${ }^{9}$

This 'bringing together of the senses' - effectively joining the sensorial with the intellectual resides within the body's apprehension of the materiality of the world through an abductive process of reasoning; one that provides a set of relations which are not based upon or oriented towards ideal conclusions, but instead upon a 'clumsy heuristic' arrived at through participation. ${ }^{10}$ This heuristic process belies a state of embodiment - a state which stands in contrast to symptoms of our time, as they are manifested by the anthropocentric dialectic. 
1.2.1 Epidemiology - The Case of Silicon Valley

With a critical eye toward the anthropocentric dialectic, the continuing dilution of our embodied reality manifests itself as autistic symptoms. These assertions are concomitant with recent findings revealed by the medical community, which disclose the increasing incidence of autism within geographical proximity of technology-sectors such as Silicon Valley, California, where local industries invest in specific intellectual capacities. The offspring of the like-minded individuals in the area are increasingly showing signs of autism, and its milder occurrence, known as Aspergers Syndrome. ${ }^{11}$ These data suggest an association between the auto-referent behaviour of autism and the ability to think in highly abstract terms, beyond the conditions of embodiment.

An article printed in the December 2001 issue of Wired magazine posits an increase in assortative mating within tech-sectors as a cause of the radical increase in children being born with Autistic Spectrum Disorders, following a study by the University of California's Mind Institute. While autism was once considered a rare disorder, occurring in one out of every 10,000 births, the number has grown exponentially, reaching 'epidemic' proportions in California by 2001. ${ }^{12}$ This spike has prompted Microsoft to be one of the first major U.S. corporations to offer to compensation for behaviour therapy for its employees' autistic children. The assortative mating taking place within areas of higher learning was seen to be a result of the development of 'enclaves' of similar individuals who find it easier to converse through a computer about the latest news surrounding NGC 1232 (a galaxy), and increasingly so with the opposite sex, as more women have entered the workforce within these enclaves. This "Geek Syndrome," ${ }^{13}$ as it had been coined by the author of the article, reveals a trend in the changing demographics of individuals now at 
the forefront of technological development, who in the past considered themselves 'confirmed celibates,' or avoided forming any significant social bonds because of their 'complicated, unpredictable nature,' choosing instead to focus on the intricacies of binary scripts, or the apparently systematic logic of language.

While it has been argued that the increasing number of children diagnosed with Autistic Spectrum Disorder (ASD) has been a result of the difficulty in diagnosing the symptoms (which do not conform to earlier diagnostic criteria), or on the large shift of diagnoses from Schizophrenia and Hysteria into the relatively new category of ASD, it is now generally understood that ASD is a distinct disorder, with specific impairments in language and cognitive development, specifically as the number of instances of the disorder has grown. ${ }^{14}$ It is also understood that while environmental factors such as the development of 'enclaves' of like-minded individuals play a role in this autistic tendency, the source of the disorder is seen to be genetic, as parents who bring about one autistic child are exponentially more likely to give birth to another autistic child ${ }^{15}$ Further, following a genetic propensity, males are 4 to 5 times more likely to be autistic. ${ }^{16}$

\subsubsection{Diagnosis}

Autism is manifested initially as a communicative disorder, appearing most often around the age of two - when early language development is just beginning to effect the cognitive and conceptual development of a child. At this critical stage, a child's speech "ceases to be a signalling, and becomes a signifying function," ${ }^{17}$ thus becoming a tool for discerning. Prior to this stage, the use of a word is merely a means of negotiating the primary heuristics of spatial cognition and emotive development. For instance, the word "mom" might be used to signal anything from the direction of a food source to the impetus 
to play with a toy. Eventually, however, the will to discern becomes prevalent, and a cascade of events following the establishment of primary heuristics prompts the association of distinct words to distinct objects - a condition which allows for a comingling between action, language and thought to be developed, wherein language begins to be manipulated in the same way as the objects with which they are associated. According to Lev Vygotsky, these early associations develop from a syncretic speech of happenstance associations to a formal language following the narrative principle, based on the association of early instances of awareness. ${ }^{18}$ Having thus developed a relationality, language exists as a result of our will to manipulate the comprehensible world, while giving meaning to the suprahensible through heuristic fictions such as metaphor, which heighten our sense of reality by shattering and increasing our language.

What is unique to the autistic condition is that early narratives are never developed to allow for the generation of a platform for relationality. Often, a child may begin to develop these associations, only to lose the metonymical foundations of language as autism appears in the individual. In such conditions, the symptoms appear as those of an Aphasiac with a Contiguity Disorder, ${ }^{19}$ in which a meta-language persists, allowing only for quasi-metaphoric associations to be generated, such as the substitution of fire for gaslight; the potentially poetic is incapacitated by a lack of contexture. ${ }^{20}$ The linguistic associations between the Aphasiac and the Autistic individual are corroborated by Leo Kanner, whose studies were the first to note the auto-referential nature of a group of patients (thus labelling it Autism). ${ }^{21}$

According to Kanner, four criteria underlie the language impairment of the autistic: a "delay in, or total lack of, the development of spoken language [...], a marked 
impairment in the ability to initiate or sustain a conversation with others [...], stereotyped and repetitive use of language or idiosyncratic language [... , and a lack of varied, spontaneous make-believe play or social imitative play appropriate to developmental

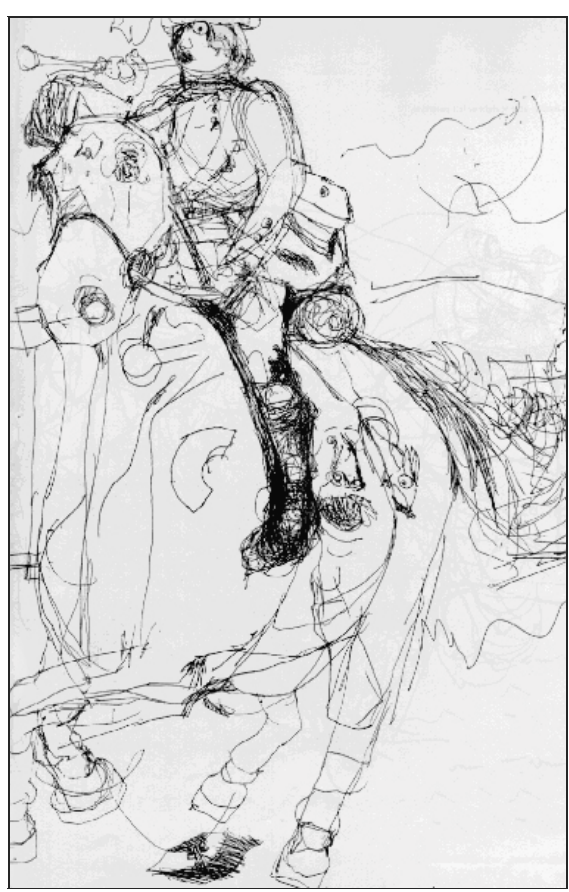

Fig. 1 A drawing by a 3-year-old autistic child. A heightened focus on object inscription allows some to draw with great accuracy. Source: Lorna Selfe, Nadia: A case of extraordinary drawing ability in an autistic child. (London: Academic Press, 1977) level." ${ }^{22}$ Following these communicative impairments, autistics tend towards flattened social hierarchies, an attraction to highly organized systems, and a disposition to highly abstracted, image-based thought processes. ${ }^{23}$ The objectivity of the autistic gaze is continued in their view of people as objects, which has been erroneously described by behavioural psychologists as a deliberate act of disobedience; in fact, the heightened focus on object inscription is preventing the autistic from negotiating between disparate sensorial information. Further, the resulting disruption in the generation of a relationality from primary heuristics develops into a propensity towards highly abstract systems, which act as a crutch to the lack of internal development. This is reflected in supposedly therapeutic methods of communication for the autistic, in which they are more able and more likely to communicate through computers (i.e. e-mail) than through verbal or written communication.

\subsubsection{Relationality}

The inhibited relationality of the autistic appears concomitant with various inscriptive disorders such as aphasia and agnosia - an association which reveals curious aspects of the role 
of inscription in agency; in the participatory nexus of language, action and thought. As explained by Vygotsky and his contemporaries, primary heuristics based on corporeality must ultimately lead to a relationality between action, language and thought, on the basis of narrative. Similarly, Marco Frascari suggests that corporeality must yield an imaginative and meaningful body-image which results from the coalescence of sensation, representation and perception. ${ }^{24}$ This similarity suggests a basis for the development of narrative within the negotiation of the body through space, wherein inscription takes place as a mimetic act - a

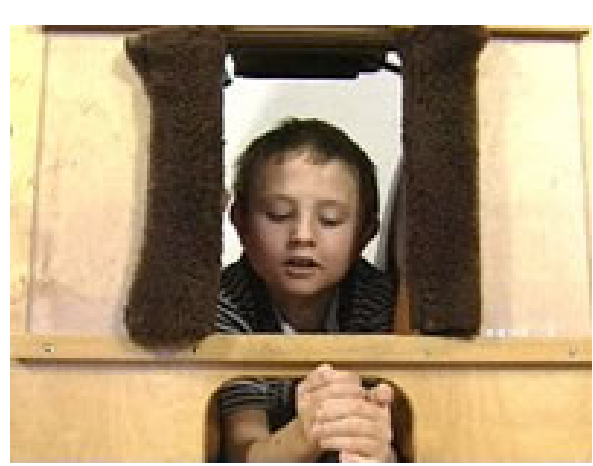

Fig. 2 An autistic child being embraced by a hugging machine. Source: http://abclocal.go.com/kgo/story?secti on $=$ edell\&id $=3366089$ (last accessed: 2006-09-20) similarity which is supported by current therapies to autism, which attempt to promote sensory integration by stimulating the senses. The usefulness of sensory stimulation as a therapy to autism is corroborated by the firsthand experiences of Dr. Temple Grandin, who developed a "squeezing machine" for herself at the age of eighteen. ${ }^{25}$ The device applies consistent pressure across the body in a manner similar to actual hugging, and provides a calming, self-reflective condition. The use of such devices has increased over the years, and has been shown to provide therapeutic results, particularly during adolescence. ${ }^{26}$

The autistic condition reveals to us a unique tendency toward object negotiation, where the possibility of breaking through literal association in language is undermined by the appropriative task of object inscription. This condition results in tendencies towards highly organized mechanical systems and abstract thought, which act as crutches to an inherent lack of relationality. This tendency is increasingly facilitated as our relationship to technology becomes ever more divorced from "the essence of human knowing and experience," ${ }^{27}$ so that 
the critical role of agency in developing relationality is challenged by a primacy of the mind over our bodies - a primacy through which genetic inclinations toward autistic symptoms are manifested with increasing prevalence. Thus, while it is understood that autism is a genetic condition, its increasing incidence relative to techno-centric regions reveals a tendency towards emancipation through technology - a relationship which aggravates the continuing dissolution of the role of agency in the relationship between the body and space. The autistic tendency to remain focused on the comprehensible world to extremes of abstraction suggests a dissociation from the participatory nature of dwelling, wherein the individual, confronted with the human condition, must define itself through projection into the world through mimetic acts. This projection is one in which the individual is confronted with its own condition - or conditioning, through the play of conflict and tension between the literal and metaphorical - thus producing a reflection on the world as lived, in a manner similar to current therapies for autism. It is understood that within this embodied being lie poetic, intangible characteristics which belie the current hubris of instrumental logic which permeates the field, and Architecture's critical role in the realm of 'first wisdom.'

This emancipatory tendency has lately been heavily criticized, as the appreciation that technology is imbued with a politic has come to the fore. Much, if not all theory in this field makes reference to Martin Heidegger's etymological studies surrounding the term 'dwelling,' as it was through his poetic insights into the role of dwelling in the negotiation of the transphysical that a critical theory of technology (extension) was developed ${ }^{28}$ In the following chapter, I will recount this emancipatory tendency, beginning from the first principles of alterity and extension, and culminating in a description of their effect on the representation of our world in the instrumentalization of technology. 


\section{NOTES}

1. Donald Kunze, "Prolegomena to any future dog architecture." Fifth Column, Vol. 7, No. 3, 1989, p. 26.

2. Dalibor Vesely, "Architecture and the Question of Technology," Educating Architects, p.46.

3. Rem Koolhaas, "Junkspace." Content, Köln : Taschen, [2004]. It is important here to note that although cosmetic and cosmos are singular in their etymology, Koolhaas is referring to a laminate condition, or the thinning of space from one dimension, to paraphrase Perez-Gomez.

4. Michel Foucault, Of Other Spaces, Website (last accessed: 2006-05-28):

http://foucault.info/documents/heteroTopia/foucault.heteroTopia.en.html

5. Donald Kunze, "Prolegomena to any future dog architecture." Fifth Column, Vol. 7, No. 3, 1989, p. 28.

6. Niel Micklem, The Nature of Hysteria, p. 9.

7. Ibid., p. 25.

8. See Jean Baudrillard. Simulacra and Simulation. (Ann Arbour: University of Michigan

Press, 1994.)

9. Marco Frascari. Architectural Synaesthesia: a bypothesis on the makeup of Scarpa's modernist architectural drawings. Website (last accessed: 2006-05-24):

http://art3idea.psu.edu/synesthesia/documents/synesthesia_frascari.html

10. See Marco Frascari, "Semiotica Ab Edendo, Taste in Architecture." Eating Architecture. (Cambridge: MIT Press, 2004.) pp. 191-203.

11. CBC: Autism. Website: http://www.cbc.ca/news/background/autism/history.html (last accessed: 2005-11-04)

12. See M.I.N.D. Institute. Report to the Legislature on the principal findings from The Epidemiology of Autism in California: A Comprehensive Pilot Study. Davis: University of California-Davis, 2002. 
13. Steve Silberman, “The Geek Syndrome," Wired. Website: http://www.wired.com/wired/archive/9.12/aspergers.html (last accessed: 2006-03-16). See also: M.I.N.D. Institute. Report to the Legislature on the principal findings from The Epidemiology of Autism in California: A Comprehensive Pilot Study. Davis: University of California-Davis, 2002.

14. This fact is further corroborated by Gary Mesibov, in Autism: Understanding the Disorder, p. 33.

15. Steve Silberman, op. cit.

16. Gary Mesibov, Autism: Understanding the Disorder, p. 33.

17. Frank R. Wilson, The Hand, p.192. After Vygotsky.

18. Ibid., p. 193. This process is summarized here by Wilson:

\begin{abstract}
"The World of objects, and knowledge of the action of those objects, will increase rapidly, and distinctive actions which can be taken with objects in the hand will also increase. In other words, the thought-language nexus is becoming a hand-thought-language nexus. The child learns with real objects, by trial and error, to make constructions that are inevitably composed as discrete events unified through a sequence if actions. Playing with anything to make something is always paralleled in cognition by the creation of a story." (The Hand, 195)
\end{abstract}

19. This similarity is corroborated by Rutter, in describing Developmental Receptive Aphasia; a language impairment effecting written language, sequencing and abstraction. (Gary Mesibov, Autism: Understanding the Disorder. p. 41).

20. Roman Jacobson, Fundamentals of Language, p. 72.

21. Leo Kanner developed the term "Autism," defined as being immersed within oneself, because he viewed social withdrawal as the primary feature of this new disability he defined:

"...he noted that children with autism did not show a preparatory response to being picked up, were content to play alone, and treated people as objects... along with an insistence on sameness [...] having observed that the children strictly followed many routines, becoming very upset at any changes in their rituals." (Gary Mesibov, Autism: Understanding the Disorder, p.5)

22. Ibid., p. 22.

23. A milder form of these symptoms was first diagnosed approximately at the same time by Hans Asperger, who later noted that the subjects he described were "(1) Not so disturbed, (2) more intelligent, (3) endowed with special abilities, (4) had a later onset [of this condition] and (5) started grammatical speech earlier." (Gary Mesibov, Autism: Understanding the Disorder, p. 36).

24. Marco Frascari, Monsters of Architecture: Anthropomorphism in Architectural Theory (Savage, Md.: Rowman \& Littlefield Publishers, Inc., 1991). 
25. Temple Grandin, An Inside View of Autism. Website (last accessed: 2006-09-10): http://www.autism.org/temple/inside.html. Temple Grandin, one of the more outspoken autistic persons in the field, has written many books on the subject of social interaction and sensory integration in autistics. She was diagnosed as an autistic at an early age, but was denied any appropriate treatment by a lack of therapeutic responses at the time.

26. See Lisa Graham, Does deep pressure touch improve attention in children with attention deficit byperactivity disorder? Website (last accessed: 2006-09-15):

http://www.rehab.queensu.ca/cats/PDFs/14.pdf

27. Aidan Davison, Technology and the Contested Meanings of Sustainability, p. 96.

28. See Martin Heidegger, Poetry, Language, Thought, pp. 143-159. According to Heidegger, the implications of technology can be traced back to the etymology of the word dwelling, which recalls its source in safeguarding. 
"Technology is not the neutral vebicle of human agency; it is the essence of human agency."

Aidan Davison, Technology and the Contested Meaning of Sustainability $(2001)^{1}$ 


\subsection{Alterity}

The current state of built space is largely defined by the intervention of Capital in the appropriation of space - which was originally a sacred act through which one mediated with the world without. This sacred act - that of dwelling - through its myriad epistemic and ontological means, existed as the foundation for cultures and civilizations for centuries. The appropriative gaze followed the succession of power, culminating in the ubiquitous and abstract 'appropriation' which defines the ends and means of Capital in today's global economy. By economizing space, as a means of generating commodity, the traditional notion of dwelling as a means of mediating the world's within and without becomes trivial; the fantasy projected by Capital entails that every individual be able to have, or participate in, the whole; engendering a notion of the ability to dwell within a placeless society. The current trend shows that this is anything but real, as individuals increasingly move towards 'subversive' means of dwelling, wherein individuals can express and mediate their mutual sentiments of loss and senselessness in a condition generated solely by the economic appropriation of space, both within and without their selves. ${ }^{2}$ While current trends in 'space making' move towards an integration of the means of Capital (the transmission of information), and the instrumental modes of representation within Architecture become more dependent and referential to these means (in delineating space, generating the virtually real'), it is critical to consider that the source, or purpose, of these means ultimately resides in the fundamental act of dwelling. This represents a genuine crux in the generation of our increasingly abstract, visually-oriented environments, and is crucial to understand if architecture is to generate responsible and responsive interventions within the environment. 
This critique of everyday life forms the basis for the argument that is to be laid out in this chapter. Beginning from first principles, an analysis of the act of dwelling is followed by explanations of its differentiation and eventual culmination in the disembodied world of the 'techno-logical.' This chapter then culminates in a description of the effect of instrumentalization on representation and the shaping of discourses regarding our world, thereby facilitating genetic proclivities towards autism. In relating the development of alterity to development of representation in architecture, an association is made between embodiment and architecture, thereby providing a basis for an understanding of the role of architecture in Autistic Culture.

\subsubsection{Extension}

According to Heidegger, in Poetry, Language, Thought, to dwell is to exist in the domain in which everything that is belongs. Its implications can be sourced in the etymology of the word dwelling: the German word, bauen, signifies to remain in place, to dwell, but a closer look at the word bauen reveals the verb buan, of which the imperative form is bis - to be. Therefore, the way in which humans are on earth is buan - dwelling.

The linguistic ties to the act of dwelling continue: the Old Saxon word wuon and the Gothic wunian, like bauen, mean to remain in place. Wunian means to be at peace; to be at peace means to be free - friede - to be safeguarded. "To free really means to spare. Real sparing is something positive that takes place when we leave something beforehand in its own nature, when we return it specifically to its being..." ${ }^{3}$ Thus, the fundamental nature of dwelling is to sustain.

To relate dwelling to the generation of space, Heidegger analyses the Greek root Peras - 
the space in which something has been made room for - specifically, the boundary in which something begins its presencing - as the horizon to the sky in the phenomenological realm in which we exist. The nearness or remoteness of the spaces in which things begin their presencing allows for a notion of distance, or stadion from Latin, which in turn leads to a notion of spation, or space. Once phenomenological space is related merely through distance - an abstraction of space, it then follows that space is no longer a space as we experience it, but one of extension. Thus, space no longer contains spaces, nor places, and only thus does the world without become appropriated within the realm of abstraction; our perception becomes that of extension:

To say that mortals are is to say that in dwelling they persist through spaces by virtue of their stay among things and locations. And only because mortals pervade, persist through, spaces by their very nature are they able to go through spaces. But in going through spaces we do not give up our standing in them. Rather, we always go through spaces in such a way that we already experience them by staying constantly with near and remote locations and things. When I go toward the door of the lecture hall, I am already there, and I could not go to it at all if I were not such that I am there. I am never here only, as this encapsulated body; rather, I am there, that is, I already pervade the room, and only thus can I go through it. ${ }^{4}$

\subsubsection{Theoria}

In analyzing this polarization of the world without and the world within, a notion of syntactic and semantic arise: the structure and meaning which is imposed upon everything which is cognizable, which is symptomatic of the increasing abstraction of space. The Mysterium Cosmographicum (1596 C.E.) of Johannes Kepler, demonstrates the extension of a geometric spatiality to the world without; specifically, in the form of the heliocentric cosmology which he posited along with Copernicus and Galileo, and outlined by planetary orbits of Pythagorean Solids, which themselves are grounded in their own 
distinct cosmological precedent of geometric extension on an elemental scale, but are now applied to a cosmological space, and thus frame an understanding of the world without. The intent of this exercise, though fanciful, signals a critical moment in the increasing abstraction of space, as its representation connotes the application of a specific understanding, or formulation, of the world without, based on applied reason, to the universe as a whole, and signals the eventual development of Newtonian Physics and ultimately Cartesian thought. ${ }^{5}$ These successive events allowed for a conception of abstract, geometrical space, which through mechanics and the development of technical knowledge allowed for an instrumental view of the world without to develop. Originally, geometry and number developed in Greek culture as mathesis ( $7^{\text {th }}$ century. B.C.E.), a reference to what could be taught and learned, and was a first step towards theoria, the apprehension of reality at a distance. ${ }^{6}$ Interestingly, mathesis was originally confined to the magician, where through mimesis, he was able to enact the world on a level separated from the physically real, and thus engage and manipulate in an illusory world of mystery. Thus, theoria was the first symbol of reality, which allowed humanity to successively disengage itself from its embodied being in ritual, existing instead in an independent universe of discourse.

This condition is extended by the work of Descartes and Kant, which sought to detach the subject from the object in demonstrating that one cannot apprehend anything unless one first experienced one's self as existing in the act of apprehending it. Specifically: "they presented consciousness... as the condition of there being anything at all; and the act of relating as the basis of relatedness." ${ }^{1}$ The separation of the cognizant individual from 


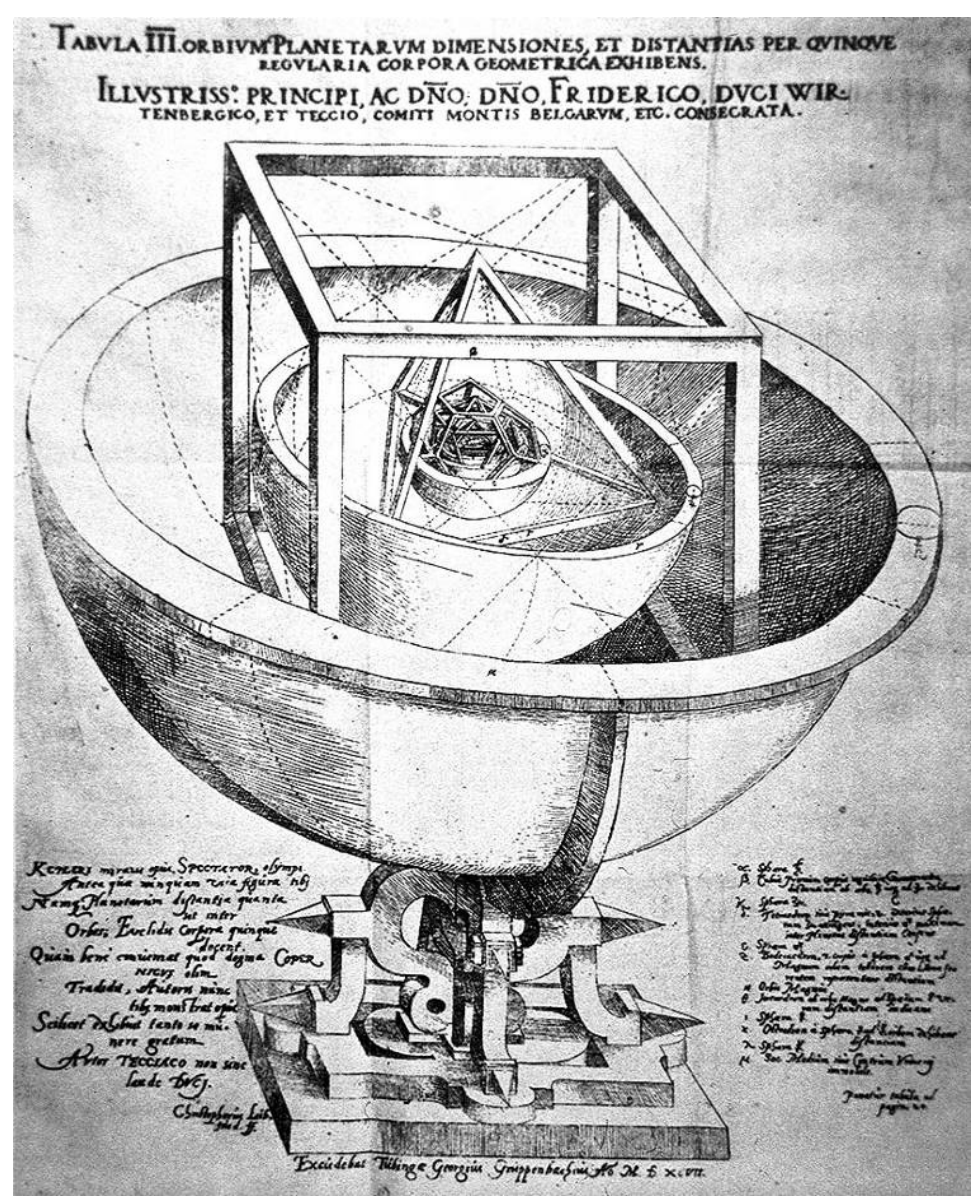

Fig. 3 Johannes Kepler, Mysterium Cosmographicum (1596). Source: http://upload.wikimedia.org/wikipedia/fr/1/10/Kepler_polyedre s.jpg (last accessed: 2006-09-21).

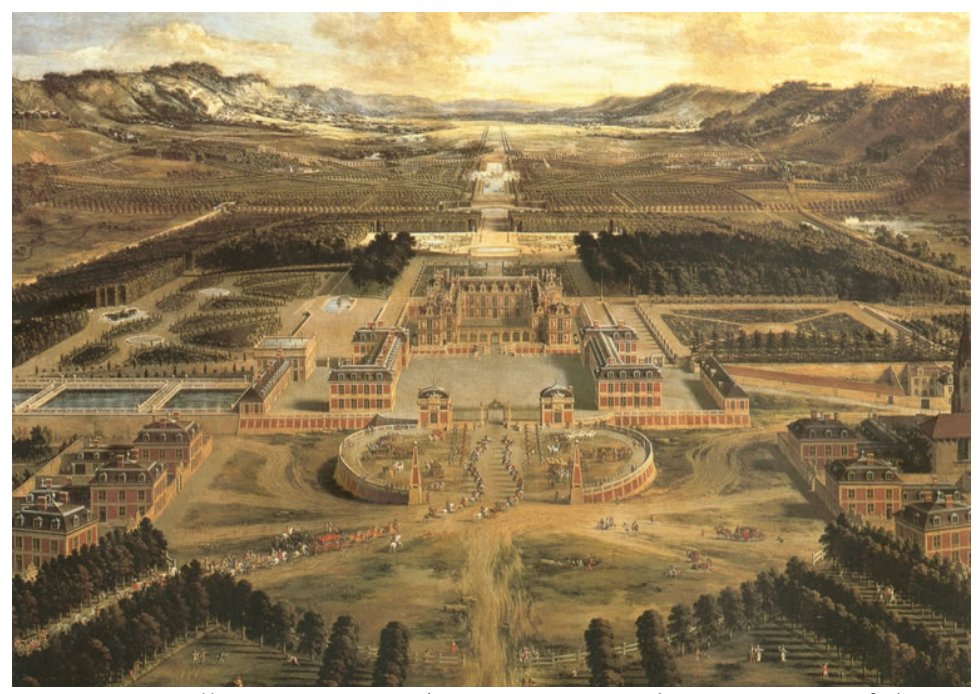

Fig. 4 Versailles, France, under Louis XIV: the extension of the appropriative gaze as an aesthetic experience, as represented by Pierre Patel in 1668. Source (last accessed: 2006-09-21): http://www.en.utexas.edu/Classes/Moore/neoclassical/images/g ardens/large/PATEL-230A.jpg. 
the phenomenological realm allowed for the artifactual (a condition of the human memory as a result of analytical reflection) to pervade as an entity within itself; that is, it allowed for the possibility of phenomena separated from the realm from which it is derived. It is the hegemony of this means of mediating the world ${ }^{8}$ which Dalibor Vesely describes as the "convergence of the infinity of will and the infinity of artifices," ${ }^{9}$ which allows for the ability to understand given reality as a priori - and thus project the mathematical certainty which substantiates it. This condition is illustrated by the landscape and geography of Versailles, which, under Louis XIV, the Sun King, presented an artificial representation of a cosmology of the world within in harmony with the world without. The intent of this work was clear: in extending the sitting of the project to continue to the horizon, the prospective gaze continued to infinity, mediated only by the earth and the sky. It was thus that Versailles came to be understood as the centre and source of the known world - now the cosmos itself - and that it was the Sun-King, in the new heliocentric cosmology, around which the realm of extension revolved. The logic was complete: that which was known was seen to be a direct abstraction of the world without, which itself was consumed by the appropriative gaze whose source lay in Versailles, where the Sun King, acting as God's hand on Earth, enacted this absolute knowledge, and thus absolute power. This demonstrative representation of absolute monarchic power appeared to reach its climax at this point, as the French Revolution which was to follow signalled the 'death of God' and the abstractive end of the Master-Slave dialectic, which was a seemingly inevitable conclusion to the development of the appropriative gaze in an increasingly abstracted cosmology, which had increasingly been associated with power. Incidentally, the notion of power had traditionally been associated with wisdom, which was considered as an 
understanding of the cosmos as a system, and was typically arrived at through close observation of the nature of things, which is typified by the Taoist methodology of dwelling.

\subsection{Participation - The Relativity of Opposites}

For the Taoists, careful mimesis of the natural world was considered a means of mediating the world within and the world without, while analytical logic (as with etiquette and morals) was seen as part of the artificial world of man:

[...] they were not interested in this world at all, but concentrated their attention fully on the observation of nature in order to discern the 'characteristics of the Tao.' They thus developed an attitude which was essentially scientific and only their deep mistrust of the analytic method prevented them from constructing proper scientific theories. Nevertheless, the careful observation of nature, combined with a strong mystical intuition, led the Taoists sages to profound insights which are confirmed by modern scientific theories $[\ldots]^{10}$

The will to observe prompted some classic Taoists to mimic common elements in their surrounding environment; camouflaged, the sages meditatively stood amongst trees and fauna for days, waiting for an aleatory instant of disclosure. What is most peculiar to the Taoists, specifically in the seminal Tao te Ching by Lao-Tse ${ }^{11}$ ( 600 B.C.E.), is a recognition of the relativity of opposites, in which the possibilities of disclosure are recognized to be dependent upon an appreciation of the common aspects of everyday life:

Being and non-being inter-depend in growth;

Difficult and easy inter-depend in completion;

Long and short inter-depend in contrast;

High and low inter-depend in position $[\ldots]^{12}$ 
This notion is mirrored in the work of Chuang-tse, also of the same era: " $[\mathrm{t}]$ here is nothing which is not this; there is nothing which is not that. [...] Division is the same as creation; creation is the same as destruction. There is no such thing as creation or destruction, for these conditions are again levelled together into One." ${ }^{13}$ In rejecting distinctions, the Taoists relegate mimesis to the "common and ordinary" in order to discern the qualities of the Tao. In remaining amongst the common, 'everyday' aspects of life, the classic Taoists kept tool usage to an immediate, non-appropriative realm - although this didn't prevent them from beings fastidious inventors, having generated mechanisms and techniques many hundreds of years before Western civilizations.

\subsubsection{Mimesis}

Dalibor Vesely's work differentiates between the world of mimesis (productive reinterpretation or creative synthesis), and the world of instrumental thinking as a means to establishing a foundation for technology, and as a means of clearing the illusion regarding the hegemony of technology. Specifically, he points out that the effective source of imagination in the art of making (technē) comes from "close contact with objects and tasks [that] could lead to the discovery of what is permanent in all of them." ${ }^{14}$ This experimentation (effectively an imitation of what happens in nature) leads to magic and to instrumental thinking. In the case of magic, a sense of mystery veils the reality of the situation, and makes magic seem to have a source in a mystical power:

The imitation of nature, in particular, is a creative process that contains a large residuum of mystery. The Greeks were very much aware of it and referred to it as chance (tyche). ${ }^{15}$ 
This understanding of chance and mimesis was fundamental to the Ancient Greek conception of the value of art, in that it brought forth knowledge out of the vastly mysterious and symbolically-charged world that existed at the time. Art differed from the magical in that the knowledge brought forth through the work of art was highly tenuous (through its dependence on the participatory act with which it was associated), while magic appropriated knowledge to develop it into a self-referent system, independent of the world from which it was drawn. Vesely shows that this appropriative behaviour is no different from that of an autistic individual, who appears to have internalized the entire world to the point that the individual is no longer able to interact with the world without. Specifically, magic (like autism) is an appropriative act, taking from the nature of things, as in the technical world. ${ }^{16}$ This condition is contrasted with the original conception of the mechanical: mechanisms were seen mimetically to be in harmony with the ultimate order, the cosmos.

\subsubsection{Ritual}

Vesely's notion of the "appropriative tendency of magic" 17 is clearly linked to the development of tool usage, and that of extension in general, and can be sourced historically to the Hellenistic period, when the disintegration of institutions of the polis ${ }^{18}$ led to the disintegration of traditional corporate rituals, which were the original means of the individual to participate in the overall order of things. This ritual act was related through dwelling; specifically, the phenomenological means in which the individual was able to exist within, and as a direct result of, the environment (the persistent elements which generate and comprise the human condition, such as the earth, the sky, and our mortality). As mentioned, this ritual 
behaviour was at the source of every action, as every act was imbued with a certain religious 'spirit,' which lent the act its meaning. This spiritual condition of existence can be revealed through the ritual acts of dwelling of the Greek and Roman civilizations, which, in its pagan rites, sought to relate the world within with the world without. The world without was that which could only be known through divine knowledge, and was acknowledged through the symbolic acts which defined the very act of dwelling: that of sighting one's self. This act of sighting was accomplished by two critical acts: acknowledging the centre of a point in space - a point where something began its presencing, and by delimiting the periphery in which the presencing was to be contained, which was connoted by the hearth - which gave and took life, and was thus known by the Romans as mundus, a word which has clear implications, even in its modern translation, in the intimate bond between the world within and the world without. For example, the sitting of a new house was traditionally delineated by the Romans in a ritual act of tilling the soil in an outline of the dwelling. Further rituals involved the placement of phalluses at the four corners of the dwelling, and the sacrifice of virgins on the land on which the dwelling was to reside. ${ }^{19}$ It was in such a manner that the individual was able to relate its vulgar life to the order of the cosmos, and thus mediate the inner and outer worlds. The notion of ritual is today re-asserted when used in the context of daily life (the daily 'ritual' of rising, eating, working, etc...), and follows the spectacularization of the ordinary when associated with religious rites.

\subsection{Auto-Poiēsis}

A further analysis of the advent of Capital in the world without signals a critical connection to the appropriative act sourced within dwelling, and is related as follows by 
Kojève's interpretation of the Hegelian Dialectic of the master and the slave, its generation of history, and the eventual end of history. ${ }^{20}$

\subsubsection{Appropriation - The Anthropocentric Dialectic}

First, the existing being, who does not confront the world actively, absorbs the world without through the passive admittance of it. The world thus remains an immediate 'world as lived,' and is not separate from the being which contemplates it. Secondly, the existing being, a biological being, 'experiences' hunger, thus becoming conscious of a desire for something in the world. In desiring, the being becomes conscious of an 'other,' which reveals a notion of individuality - that of being separate from the 'other,' which is different from the rest of being. This desire engenders an action which allows the object to be appropriated, and it is then that the existing being negates its original condition of Being that of passivity, although it ultimately returns to its original state of Being. Thirdly, the existing being, having been satisfied, desires that which is not, as the individual is now conscious of an 'I,' unique to the world without (as opposed to an animal, which merely falls back to its original state, having been sated). Fourthly, this existing being, now submitted to the void of its own existence, must direct its desire towards 'value;' specifically, as a mortal, toward the value of life. The existing being must risk his life to fulfil its desire, and in place of life, seeks to replace itself with that which is desired. In doing so, the individual seeks recognition for his capacity to overcome given-being, as an 'objective' gauge of its value. It is this situation which is the condition for 'anthropocentric action,' and the appropriation of the world without, as it requires the imposition of oneself on an 'other' to bring about self-recognition. This sequence is conditional on the existence 
of an 'other,' which being a desiring being, desires recognition as well, thus creating a conflict of intentions, and a struggle for life. Since the ensuing fight would be meaningless following the death of either or both, one individual succumbs to the recognition of the 'other,' and thus initiates the master-slave dialectic. Constantly aware of his life's jeopardy, the slave thus submits to facilitating the fulfilment of the desire of the master, but since the master does not risk his life in its desiring, it incessantly desires for that which does not exist. For the slave working against the 'Terror of Death,' its existence must be justified with notions of 'freedom' (that which is achieved through the responsibility of work), play (the 'idle negativity' that is the festival of consumption), and finally that of an oraganized religion such as Christianity (which, according to Kojève, justifies the contradictory existence of the slave in exchange for a genuine freedom, which exists in a suprabensible world, beyond the vulgar world of the sensible). This dialectic enacts itself as the generation of history itself (that is, history is generated by the actions of those who negated the present - through the act of desiring), and culminates in the overthrowing of the Master-Slave dialectic, the 'death of God,' and thus the complete abstraction and relativization of the world without brought about by the French Revolution. This condition of abstraction is appropriated by the Bourgeoisie, who are now at the seat of power through their appropriation of land in the legality which binds an individual to a parcel of land. This condition is thus appropriated under Capital, generating a world in which everything is commodity, and value is not absolute - value itself is instrumental. The most 'wise' individual (recalling the original meaning of the term) is now the individual who is able to manipulate the conditions of Capital (specifically, abstraction) to accrue power, and is enacted through the spectacle of 'idle negativity' that is the typical shopping mall, which pervades consumerist society. 


\subsubsection{Epistemological Proceduralism}

An analysis of the advent of capital in the world without signals a critical connection to the appropriative act sourced within dwelling. It is here critical to recognize the "epistemological proceduralism" ${ }^{21}$ which has rendered politics as a deductive exercise, effectively orienting practical reason toward principles beyond any human experience, into the realm of the ideal - that of 'pure' reason developed by Cartesian and Kantian attempts to situate human conscience as an ordering element utterly divided from the world without. What results is the systematic appropriation of the world without, allowing for the abstractive 'end of history;' the destruction of every referential, to be absorbed and manipulated as Capital. This condition renders culture itself an instrumental means for what Aidan Davison describes as "self-poiēsis" 22 (autopoiesis), wherein the individual, facilitated by technology, is able to focus on the self alone, re-presenting and orienting itself toward its own desires in a manner similar with what I have previously described as an aberration in the mediation of the trans-physical towards autistic tendencies, in the purely abstractive, instrumental use of technology, void of technē poièsis, under which

The only authentic goal of private life is to direct our moral awareness inwards, cultivating fidelity towards ourselves before all others [... $]$ Self-expression has become self-production in a world meaningful only to the extent that human production creates and sustains it. $^{23}$

\subsubsection{Simulation}

According to Jean Baudrillard, this spectacle is the simulated world which exists as a consequence of the 'death of God,' which Baudrillard notes to be a primer in the succession of phases in the dissolution of our relation to reality. ${ }^{24}$ Specifically: the image begins as a 
representation of a basic reality, which it then "masks and perverts," thus producing a representation which masks the absence of a basic reality (which is now only a representation of that reality), which then results in a representation that bears no relation to any reality - it is its own simulacrum.

In the realm of interpretation, the phases of our dissociation from reality lend themselves to struggles for power, and associations with Capital, as, according to Baudrillard, Capital was the first to feed off the destruction of every referential. The present condition is thus put into context: Capital employs simulacra for the fulfillment of its own ends; materialism - satisfaction of desire through the material, manifested, representational world, now ultimately void of any meaning but the meaning which is prescribed by the system of capital (a realm described by Baudrillard as that of the hyperreal). The resulting condition is one of apathy for the real, as it is perceived to be a simulacrum - a perfect medium for manipulation of meaning. ${ }^{25}$ The world without thus becomes the medium for the projection of commodity to satisfy desire. This appropriative act has reached its pinnacle in the 'new cosmos' defined by Tom Darby:

The new cosmos is the raw material to be forged into infinite novelty by the will of the selfanointed god. Thus cybernetics, the science of control, is the logical outgrowth and selfconscious expression of the self-referring circular process we call technology. The amount of effective control stands in direct relation to the amount of efficiency. Ultimate efficiency is systematization. Systematization increases with the level of self-referential or circuitry. This is why the most technological words in the English language, words we have increasingly used since the beginning of modernity, end in the suffix $i z e^{26}$

\subsubsection{Being with Technology}

In describing the development of technology as a way of revealing, Heidegger notes the 
act of "occasioning," which to the Greeks was effectively causality - a recognition of the conditions of bringing something forth into the world. In describing 'occasioning,' Heidegger points to the traditional causes of philosophy: the causa materialis (that of which everything is composed), the causa formalis (the form of which material objects are composed), the causa finalis (the end or purpose to which the form and matter serve), and the causa efficiens (that which brings about an effect). These causes are essentially a condition of being responsible for something else, and in such a way, predicate a way of being with technology:

The principle characteristic of being responsible is [...] starting something on its way into arrival. It is in the sense of such a starting something on its way into arrival that being responsible is an occasioning or an inducing to go forward..$^{27}$

What Heidegger here describes is no less than what the Greeks referred to as poiessis: the art of bringing forth. It is here that Heidegger notes that the current focus on instrumental logic is based upon the focus of causality as effecting; when something is brought forth, it is revealed - its truth is made present, and thus becomes a proponent of a way of being with technology understood as technē; however, enframing the world without challenges it to become abstracted and categorical. The realm of poiessis is thus subjugated, preventing a presencing, or occasioning from occurring. In fact, nothing is revealed, except for the effect which had already predicated by the causality of the "destined revealing;" 28 the crux of Being with Technology.

In relating the development of the enframing of the world without, Vesely establishes a differentiation between the 'relationality' of the phenomenological body, and the conventional understanding of space, which associates with primary coordinates 
(absolute space) and the primary orientation of the body (absolute body). In noting the phenomenological aspect of the body in space, Vesely notes (after Merleau-Ponty) that the orientation of the body as a system of possible conditions (relationality) generates a "virtual body," ${ }^{29}$ which is defined by its task and situation. This virtual body defines itself in relation to actual and possible structures of the surrounding world to which the human body belongs, which themselves are constituent of the references mediating between the explicit form of space and its implicit "deep structure." ${ }^{30}$ In re-presenting the world, this virtual body is constricted to a specific task as the built world presents an enframing. Thus, the orientation of the body in space becomes an element of its own extension.

This extension can be observed in the development of the perspectival. While the association of built space to perspectival clarity was still constituent of an embodied, ritualized life was part of the Baroque period, the objectivization of space only reached its fruition when the body and binocular vision had been left aside; now "assimilated with the geometric vanishing point - now truly a point at infinity." 31 The abstracted response of perspectiva artificialis was a mode of representation that was independent of our embodied condition, and could be universally applied, but was ultimately a duplication of the original, which could only result in divided representation. Descartes is associated with this "thinning and objectification of space," which, through the "consecration of perspectiva artificialis as the prime epistemological model led depth to lose its status as the 'first' dimension." ${ }^{32}$ It was thus through the objectification of the world without that the instrumentalization of technology was forged, creating a condition in which being in space was no longer an embodied experience. 


\subsubsection{Divided Representation}

Specifically, the "emancipation of the new mathematical science from the context of the natural world and the accompanying creating of a closed system of knowledge based on the Newtonian synthesis and its paradigm of intelligibility" ${ }^{33}$ appears to have been crucial in

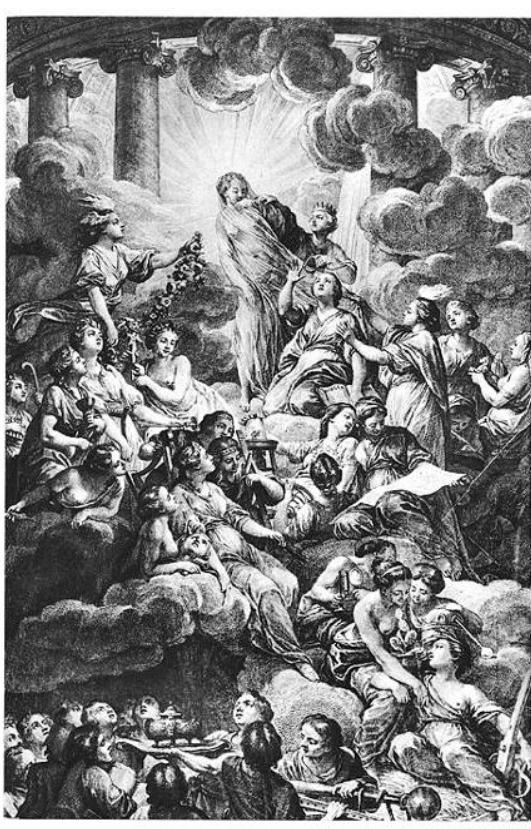

Fig. 5 Extract from the frontispiece of the Encyclopédie (1772). The figure in the centre represents truth surrounded by bright light (the central symbol of the Enlightenment). Two other figures on the right, reason and philosophy, are tearing the veil from truth. Drawn by CharlesNicolas Cochin and engraved by Bonaventure-Louis Prévost. Source: http //en.wikipedia.org/wiki/Image: Encyclopedie_frontispice_full_473px. jpg (last accessed: 2005-05-05). development of divided representation, as a process of the dissociation of human consciousness and the world without, elevating technē to a self-sufficient instrumentality. Importantly, the Newtonian model provided no real foundation for its prospects of progress and understanding of human nature, as it silenced whole areas of creativity and culture as outdated and irrelevant; the real consequences of this conditioning of reality were the separation of ideas and concepts from the body of language (hence the movement away from poiesis), followed by the separation of language itself from the practical world. This separation was understood as an evolution of knowledge (although this could only be applied to that which could be appropriated and taught as mathema). As this condition

developed, traditional guilds and lodges were replaced by academies, where architecture was taught with other disciplines such as civil engineering, mechanics, surveying, etc, as the reliance upon theoretical knowledge increased. 
What follows is a rationalization of form, in which the built space oscillates between "the real and the possible, the imaginative and the imaginary, the concrete and the abstract," ${ }^{34}$ which has its origin in the Aristotelian understanding of creativity in terms of matter and form; where matter is everything that can be formed, while form was seen as an idea, and thus perceived as an icon. It was in this era that representation through proportion was considered as being based in prejudice and custom, void of any 'absolute' certainty. Here arose the distinction between positive beauty and arbitrary beauty: arbitrary beauty, like fashion, was seen to have nothing positively likeable, while positive (actually Positivistic) beauty was seen to be based in inherent, convincing reasons; these distinctions are basically that of taste and that of numerical representation of true order (symbolic representation and technical reason respectively). It was during the transitional period of the Baroque that it was understood that "the true order of reality was mathematical, and that mathematical language thus provided the most adequate representation of reality." 35

\subsubsection{Instrumental Technology}

The condition of divided representation - between creative knowledge (technē) and symbolic representation (poiessis) - made possible the influence of instrumental representation. While instrumental thought played a great role in the development of Renaissance perspective, the majority of scientific approaches to built space were still considered part of the mechanical arts. As the theoretical basis for technology developed, and the "practical nature of the arts" was absorbed by instrumental thought, the technological will moved away from spontaneous creativity, toward goals of the 
maximization of economy and efficiency, ultimately motivated by the will to power through emancipation and autonomy. ${ }^{36}$ This condition has its roots in the development of theory; originally, geometry and number developed in Greek culture as mathesis $\left(7^{\text {th }}\right.$ century. B.C.), as a reference to what could be taught and learned, and was a first step towards theoria, the apprehension of reality at a distance, ${ }^{37}$ which allowed humanity to successively disengage itself from its embodied being in ritual, existing instead in an independent universe of discourse. The inception of theory-based knowledge has thus transformed the way we dwell, as things could now be known at a distance, separate from embodied reality, resulting in a categorized, fragmented reality in the development of scientific knowledge. Under the hegemony of instrumental logic, any notion of mystery or tyche which might be had through mimesis (the means of relating to the ultimate order of the cosmos, typically through ritual) is shunned and undermined by the "tendency to replace participation by the appropriation and manipulation of the order-creating powers" 38 of mathematical understanding and control.

This transformation can be expressed by the works of the Beaux-Arts Schools of the $19^{\text {th }}$ Century, in which the works of keen student architects of the time, vying for the Prix de Rome, represented the Ruins of Ancient Rome, following their Grand Tours, ${ }^{39}$ in a manner which was both analytical, and pseudo-symbolic of the grandeur of the age in which they lived. Their drawings vividly re-present the works in an imagined original context, while sectional and diagrammatic representations depict the construction techniques which were employed in the original works, now revealed by their decrepit state. 

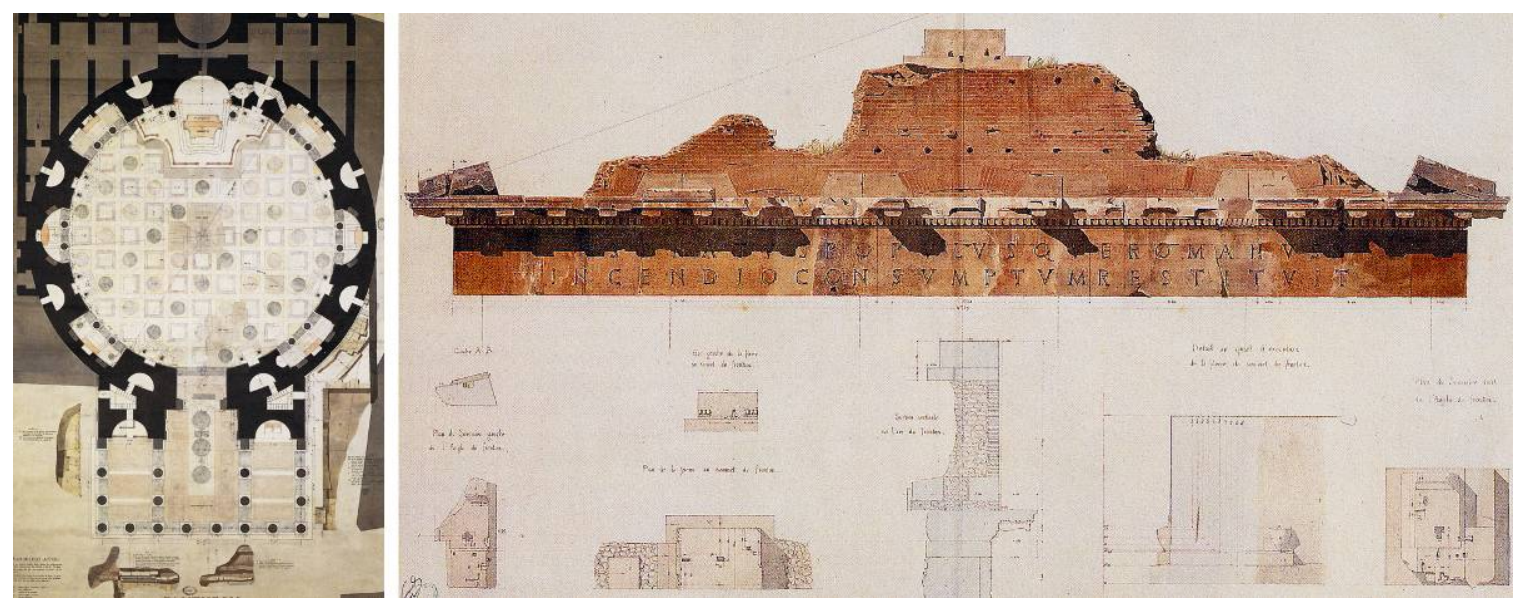

Fig. 6 Achille Leclere, The Pantheon, 1813 (left), and Alfred Nicolas Normand Monuments of the Roman Forum at the Foot of the Clivus Capitolinus from the end of the Reign of Septimus Severus, 1853 (right). Source: Cassanelli, Roberto... [et al.]. Ruins of Ancient Rome: the Drawings of French Architects Who Won the Prix de Rome, 1786 - 1924, p. $157 \& 70$ respectively.

The didactic nature of the representations intend to show us the original works through a genuinely theoretical gaze, utterly disengaged from the symbolic representations which gave rise to the works; elaborate architraves are set alongside sectional diagrams, which represent the structure that the façades 'betrayed.' This example typifies the new 'age of reason' which had dominated the $18^{\text {th }}$ and $19^{\text {th }}$ Century, during which architectural representation, at the cusp of the modern era, began to take the form of devices for auto-referentiality, as an auto-poiēsis.

\subsubsection{Ecologies and Prescriptive Disclosure}

The development of auto-poiesis (autism) as a cultural phenomenon points to the curious and contested basis of sustaining humanity, in which value-laden prescriptions of technological negotiation provide the basis of supplying meaning in our lives. It appears that the impression of these technological imperatives has been fuelled largely by Promethean discourses, which rely implicitly on the primacy of instrumental logic in the establishment and negotiation of ecologies. Within these Promethean conceptions, 
scientific determinism is established as the definitive means of negotiating the tenuous nature of object inscription, thus providing the basis for the development of Capital. What is critical to appreciate at this point, are the implicit, prescriptive values within the legitimation of knowledge, which serve as frameworks in the discourses surrounding the promulgation of a given position (hereby understood as being discursive). This process is well described through Kuhn's Law, ${ }^{40}$ which provides a legitimate foundation for the understanding that science is proffered through its own mechanisms, which are in turn dependent upon the values of those scientists that perform research. According to Max Oeschlaeger, this largely unquestioned methodology is demonstrated by Resourcism, which in its dependence on Capital claims that:

- Natural systems are no more than collections of parts.

- Homo sapiens is related externally to the Ecomachine.

- The Ecomachine can be engineered to produce desired outcomes and prevent undesired concequences.

- The market objectively determines worth and value of all things, cultural and natural.

- The national and per capita income amounts are the ideal measure of social well being.

- Progress can be determined according to the utilitarian formula of the greatest good for the greatest number. ${ }^{41}$

This methodology is manifested in strangely divergent paths, wherein a canyon might be viewed for its aesthetic value in representing 'nature,' or for the value of the mineral which might be mined from it. These values are compounded by economic imperatives, as demonstrated by George Bush Jr.'s stance on the harvesting of forest in his country's National Parks. 

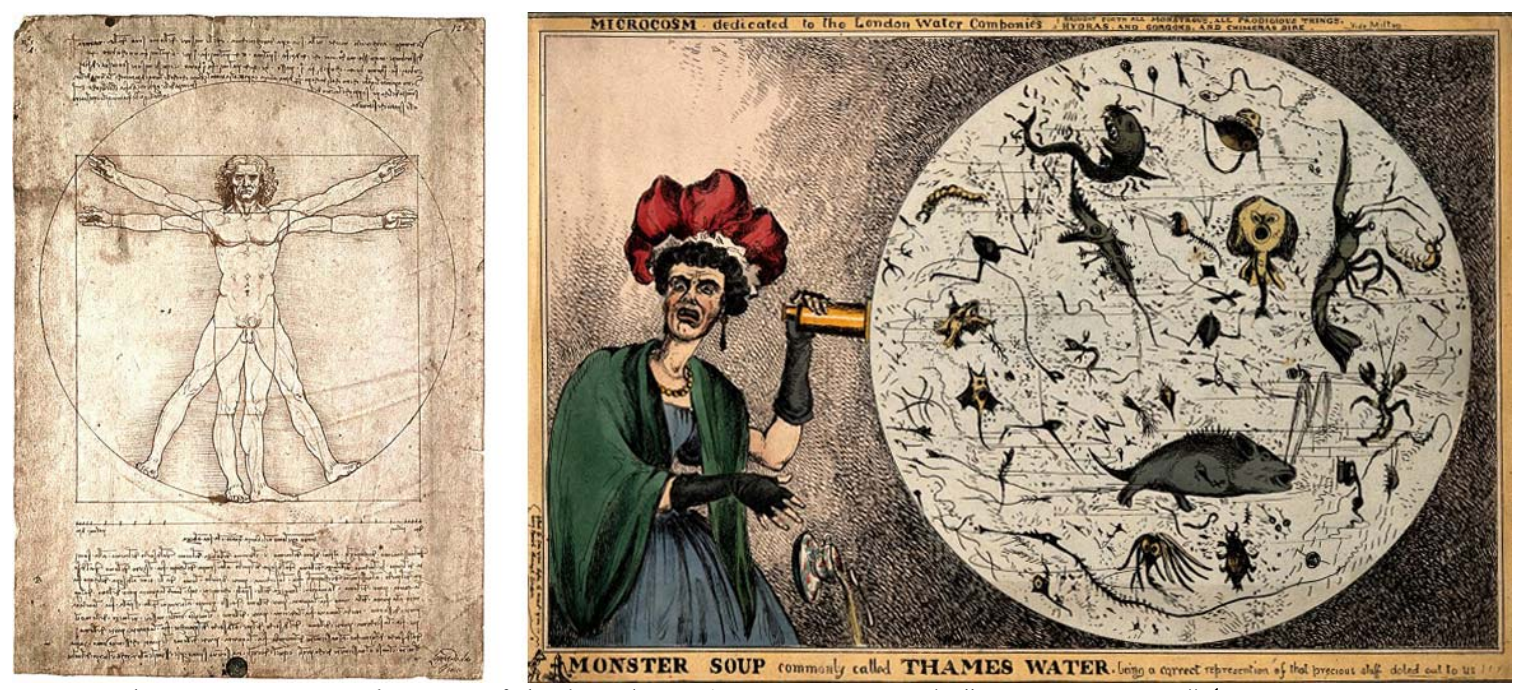

Fig. 7 The curious contradictions of the 'revelatory' gaze. Da Vinci's "Vitruvian man" (Source: http://www.abc-people.com/data/leonardov/vitruvian-man.jpg [Last accessed 2005-11-15]), alongside "Monster Water, commonly called Thames Water" (Source: http://www.literarylondon.org/londonjournal/march2004/Fig4.jpg [Last accessed: 2005-10-12]).

These moral ontologies are contrasted by those on the other end of the spectrum; by

Eco-Feminists, who according to Oeschlaeger, claim that:

- Mother Earth is a nurturing home for all life and should be revered and loved as in pre-modern societies.

- Ecosystemic malaise and abuse is rooted in Androcentric concepts, values, and institutions.

- Relations of complementarity rather than superiority between culture and nature, the human and the non-human and male and female are desirable.

- The many problems of human relations, and relations between the human and nonhuman worlds, will not be resolved until androcentric institutions, values, and ideology are eradicated. ${ }^{42}$

The Eco-Feminist attitude toward values tends towards the disclosure of many socio-cultural institutions as being based on Androcentric conceptions, including that of Judeo-Christian thought, and finds a curious ally in the proclivity of males towards autistic symptoms. Considering prevailing socio-cultural thought, this attitude has the dubious 
position of being considered peripheral to any question of technology. Interestingly, the ecofeminist's stance is corollary to the convictions of the Taoists, who proclaim an embracing of both the feminine (the valley) and the masculine (the mountain) in order to further understand the 'way.' Furthermore, in recent architectural theory, the notion of a nondominant or 'weak architecture' has developed in a curious parallel to deepening conceptions of ecology, which is what I will elaborate in the following chapter, as I dwell on a potential therapy to Autistic Culture. 


\section{NOTES}

1. Aidan Davison, Technology and the Contested Meanings of Sustainability, p. 101.

2. Consider, for instance, the rise in urban exploration communities throughout populated centers, similar to early Détournements, or variants of the Situationist movement.

3. Martin Heidegger, Poetry, Language, Thought, p. 149.

4. Ibid., p. 157.

5. Dalibor Vesely, Architecture in the Age of Divided Representation. p. 192.

6. Alberto Pérez-Gómez, Architecture and the Crisis of Modern Science. p. 8.

7. Maurice Merlau-Ponty, Phenomenology of Perception, p. x.

8. Specifically, through the Positivist notion that the world without can be known entirely through our senses - the abstraction of empirical evidence. The hegemony of this perspective has allowed for the instrumentalization of technology.

9. Dalibor Vesely, op. cit.

10. Fritjof Capra, The Tao of Physics, p. 126. This harmony is also clearly sought after by Maurice Merlau-Ponty in the Phenomenology of Perception, where a point is made of a return to the phenomenological realm of the world as lived (Lebenswelt), or a return to things in themselves, which:

"... is to return to that world which precedes knowledge, of which knowledge always speaks, and in relation to which every scientific schematization is an abstract and derivative sign-language, as is geography in relation to the countryside in which we have learned beforehand what a forest, a prairie or a river is." (Maurice MerlauPonty, Phenomenlogy of Perception. p. x)

11. In particular, see Chapters 2 and 40 of the Tao Te Ching. (London: Penguin Books, 1963.)

12. Lin Yutang, Wisdom of Lao-Tzu, p. 47. 
13. Ibid., pp. 48-50.

14. Dalibor Vesely, "Architecture and the Question of Technology," Educating Architects, p. 45.

15. Ibid. p. 45 .

16. See Chapter 6 of Dalibor Vesely, Architecture in the Age of Divided Representation, specifically pp. 288-290. Specifically:

"[T]he domination by will has one essential condition: before the world can be thus controlled it must be transferred inward and man must take it into himself. He can actually dominate it only when it has in this way become an inner realm. For this reason all magic is autism, or living within oneself." (G. van der Leeuw, Religion in Essence and Manifestation, trans. J.E. Turner. 2:248)

17. Dalibor Vesely, op. cit. , p. 46.

18. A word sourced within the Greek civilization: a manifested expression of place, itself a unified community in harmony with itself and its surroundings.

19. Rykwert, Joseph, The Idea of a Town, pp. 97-162.

20. Thomas Darby, The Feast: Meditations on Time and Politics, pp.102-107.

21. Aidan Davison, Technology and the Contested Meanings of Sustainability, p. 155.

22. Ibid., p. 157.

23. Ibid., p. 157.

24. Jean Baudrillard, Simulacra and Simulation. (Ann Arbour: University of Michigan

Press, 1994.) These would be the successive phases of the image related by Baudriallard:

a. It is the reflection of a basic reality.

b. It masks and perverts a basic reality.

c. It masks the absence of a basic reality.

d. It bears no relation to any reality whatever: it is its own pure simulacrum.

25. From a further analysis: the notion of diversion is related by Baudrillard in his example of Disneyland, where the simulation of the fantastical exists only as a diversion to the real simulation that of Capital as a whole. This notion is resonant because of its implications in regards to built space, as it considers what happens to built space through an architecture of nothingness, or idle negativity (i.e.: the suburban shopping mall).

26. Thomas Darby, Soujourns in the New World, p. 10. 
27. Martin Heidegger, The Question Concerning Technology and other Essays, p. 9.

28. Ibid., pp. 23-33.

29. Dalibor Vesely, Architecture in the Age of Divided Representation, p. 48.

30. Ibid., p. 49.

31. Alberto Pérez-Gómez, Chora, p.19.

32. Ibid., p. 19.

33. Dalibor Vesely, op. cit., p. 230.

34. Ibid., p. 237.

35. Ibid., p. 238.

36. Ibid., p. 282. This will to power and emancipation through technology is further explained by Vesely:

"We have reached a point at which it does not much matter what we call ourselves and who does what, as long as we understand that the higher we what to build, the deeper the foundations must be, that the notion of technological autonomy is only an idea, and that coming to terms with technology is possible only be coming to terms with the conditions of our earthbound cultural existence." (Vesely, 308)

37. Alberto Pérez-Gómez, Architecture and the Crisis of Modern Science, p. 8.

38. Dalibor Vesely, "Architecture and the Question of Technology," Educating Architects, p. 46.

39. See Roberto Cassanelli... [et al.]. Ruins of Ancient Rome: the Drawings of French Architects Who Won the Prix de Rome, 1786 - 1924. Ed. by Massimiliano David. Los Angeles : J. Paul Getty Museum, 2002.

40. See T.S Kuhn. The Structure of Scientific Revolutions, (Chicago: University of Chicago Press, 1962), specifically Chapter IX.

41. Max Oeschlaeger, The Idea of Wilderness, p. 287.

42. Ibid, p. 310 . 
"The thinking poet reaches toward a presence obscured by the obvious, toward what is absent because of its concealment bebind language, behind opinion, behind ideology: the wilderness poet calls forth being."

Max Oeschlaeger, The Idea of Wilderness $(1991)^{1}$

\subsection{NARRATIO: THE WEAK LINK}

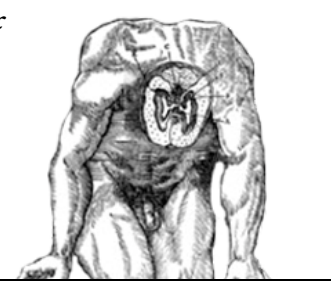




\subsection{The Weak Link}

It is useful at this point to consider a potential therapy to the condition which I have described in the previous chapters. What presently seems most crucial is the provision of a basis for the articulation of the participatory nexus within architecture - a position which appears forsaken under the instrumental gaze. As Ben Highmore reminds us, "if everyday life is going to challenge us into new ways of thinking and new ways of perceiving, then it will need to practice a kind of heuristic approach to social life that does not start out with pre-designated outcomes." 2 This is a notion which can be most aptly introduced through Ignasi de Sola-Morales' appreciation of the tangential and nonprescriptive in architecture.

\subsubsection{Weak Architecture}

In Sola-Morales' work, the notion of a liquid or weak architecture is posited as an architecture of non-prescriptive disclosure - as a corollary to Gianni Vattimo's weak thought. Specifically, Morales calls for an appreciation of visceral experience in the creation of architecture - in response to the modern era's search for universal subjectivism as a replacement to the 'death of God,' describing Le Corbursier's promenade architectural, for example, as "an itinerary that admits the possibility of control." This is a far cry from the Flâneurs of today, who in their urban détournements, seek to disclose the rift between their subjective experience and that of the built world, indirectly negating prescriptive modes of inhabitation. Recalling the implications of extension on the conception of space and time as a system, Morales posits that weak architecture is based in genuine subjective experience, in an event in which he notes: 
$[\mathfrak{t}]$ emporality does not present itself as a system, but as an aleatory instant that, responding above all to chance, is produced in an unforeseeable place and moment. In certain works of contemporary art, in dance, in music, in installation, the experience of the temporal event, occurring once and then gone forever, ably explicates a notion of temporality that finds the event in its fullest form of expression. ${ }^{4}$

Within this conception of temporality, Morales recalls Deleuze's position that the subjective and objective are constitutive of a fold in a single reality, which "emerges as a continuum in which the time of the subject and the time of external objects go round together on the same looped tape, with the encounter of objective and subjective only occurring when this continuous reality folds over in a disruption of its own continuity." With these conceptions of space and time, Morales posits that weak architecture is always decorative, in that the decoration is a "pulling back to a function that projects beyond the hypothetical ground of things," 6 and into the encounter between subject and object, within the participatory nexus which I have previously described as being crucial to the development of a relationality. Finally, Morales dwells on the monumental characteristic of weak architecture, in which he recalls the root term monitu, or recollection, to describe the characteristic of weak architecture as being a reference to the individual heuristics brought about by subjective experience, in which the monumental is "bound up with the lingering resonance of poetry after it has been heard, with the recollection of architecture after it has been seen."7

As such, Morales' text on weak architecture makes no prescriptive claims towards a deliberate type of architecture, but instead provides an account which might leave a lingering resonance within the reader. It is, however, deliberate in its rejection of an architecture which does not yield to the sensual experience of its inhabitants; of buildings never built in 
the synaesthestics of their culture. While Morales takes account of contemporary rejections of any possibility of Heideggerian dwelling in the present context, he notes that the instrumentalization of technology has prompted the most common aspects of reality - "that which is felt as being experience in itself" ${ }^{8}$ - to exist within a peripheral position, and although marginal, the experiential possesses a privileged, paradigmatic value, revealed through works of art. Thus, the possibilities of technology as a revealing remain, but are conflagrated within the heterogeneous nature of everyday life.

\subsubsection{Narratio}

The notion of an individual heuristic in Morales' work on weak architecture finds many analogues within the arts, such as those found in the 'happenings' of the Fluxus Movement, or in the works of Andrei Tarkovsky, who's evocative films create a deliberate distance between image and narrative, with the intention of weakening the logic of the story; by "creating an associative field of clustered images," ${ }^{9}$ which are then related through heurism. Essentially, Tarkovsky's metonymical constructions allow for auto-didactic instances based on the clumsy heuristics of his cinematographic projections.
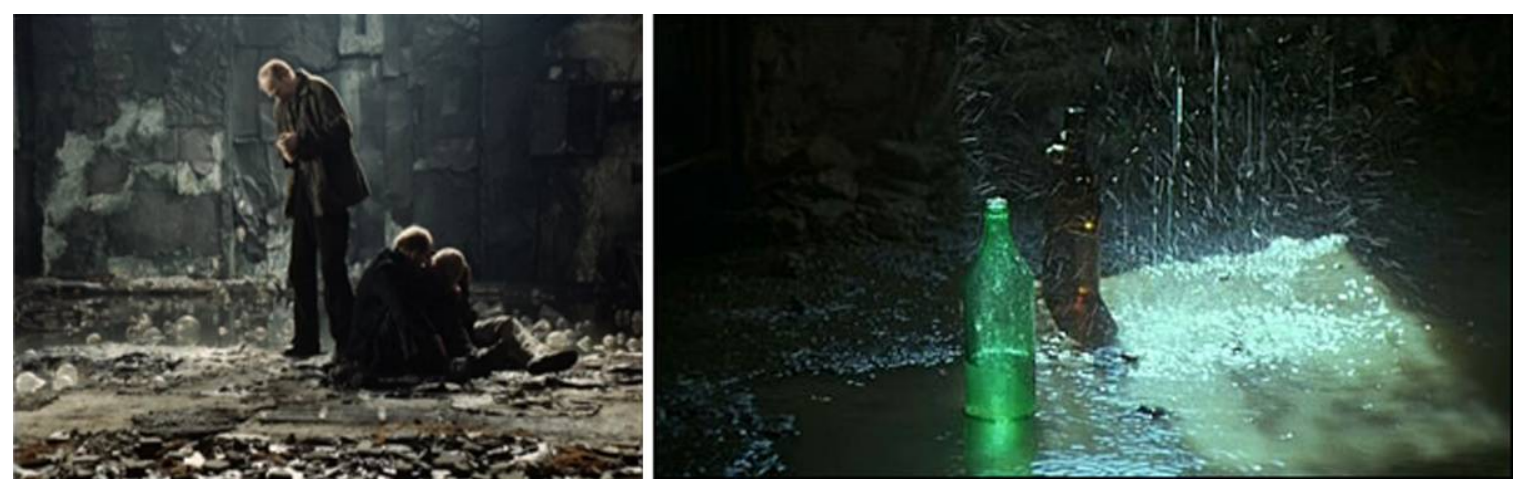

Fig. 8 Stills from Andrei Tarkovsky's films Stalker and Nostalghia. Sources: http://www.hauntedink.com/uploaded_images/stalk4ae-740786.jpg (last accessed: 2006-08-11), and http://www.acs.ucalgary.ca/ tstronds/nostalghia.com/graphics/photos_nostalghia.jpg (last accessed: 2006-08-11) respectively. 
Through these heuristic fictions, the possibilities of individual narratives in negotiating object inscription (through the association of images) are employed as selfreflective plot devices, thereby placing importance on agency. The weak image is here reflected on by Juhanni Pallasmaa:

The idea of weak image in architecture seems to run parallel with the idea of 'weak force' in physics, as well as the weak processes of nature when compared to the use of excessive physical violence in our technological processes. ${ }^{10}$

3.2 Analogical and Metaphorical Association

3.2.1 Prognosis - Eisenman's House VI

Currently, attitudes toward technology tend toward the negation of the pragmatic nature of everyday negotiation, as the primacy of mind over body develops. This condition

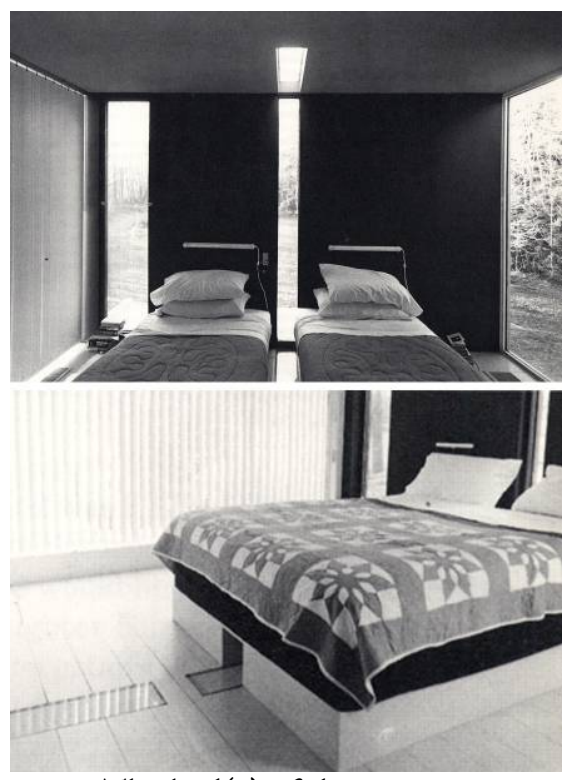

Fig. 9 The bed(s) of the master bedroom in Eisenman's House VI, before and after. Photograph by Dick Frank. Source: Frank, Susan. Peter Eisenman's House VI - The Clients Response, p.61. is compounded by changing attitudes around the role of representation in the ideation and construction of architecture towards more instrumental orientations.

This tendency has resulted in extreme examples of Autistic Architecture, such as Peter Eisenman's House VI, in which the diagrams of the house are symbiotic with its reality. ${ }^{11}$ House VI lacks any appreciation of the pragmatic; a fact that has resulted in a master bed being divided by structural cues to the overall order of the house, or the placement of the bathroom in what appears to be a closet. In the original drawings, the 
house had no bedroom; the bed was to be rolled out of a closet at night. Even when a bedroom was made, it had no door or any other concession to privacy in the family's small cottage. Only after 15 years of habitation was a supplementary bed designed to span the slot in the floor, so that the couple might sleep together once again. Conceived as a realization of the dialectic between virtual space and real space, the house ultimately negated a genuine dialectic, despite claims to having removed all symbolic references (the potentiality of structure had originally always been developed symbolically). Its extremity towards objectivity is therefore ironic. However, House VI remains the subject of the narratives developed by its inhabitants, as it is they who have had to negotiate the Autistic nature of its construction.

Through Eisenman's House VI, a fundamental concept can be understood: relationality is revealed through the narratives told about them, in which the disparate interests and values associated with an artifactual element are negotiated through the consensus arrived at through the act of recounting the narrative itself. Jean-Francois Lyotard's account of the modern state of knowledge reveals a critical view of the role of narrative in negotiating the post-modern condition, through an analysis of the disjunction between knowledge as transmitted and proffered through narrative means, and knowledge as investigated through the positivist means of scientific inquiry. Specifically, as an analysis of the post-modern condition, Lyotard points to attempts to seam the gap between narrative knowledge (dwelled knowledge) and scientific knowledge (paradigmatic knowledge); defining post-modern as an "incredulity towards metanarratives," ${ }^{12}$ devised through the attempt to legitimize scientific knowledge. Seen in this light, Eisenman's House VI persists as a poignant example of Autistic Architecture, acting as a beacon in 
the prognosis of Autistic Culture. In developing space as a product of its own representation, Eisenman generates auto-referential conditions in which the possibilities of negotiation are left primarily to the mind, thereby orienting disclosure through communicative space toward the self. This condition is here summarized by Eisenman himself:

In House VI [... ] a particular juxtaposition of solids and voids produces a situation that is only resolved by the mind's finding the need to change the position of the elements [...] This produces a tension within the mind, a sense of tension or a compression in a particular space that is not created through the juxtaposition of real wall, but is instead our conception of their potential location. ${ }^{13}$

\subsubsection{Therapyः Local Technology}

What I now propose is an Architectural Therapy to the autistic symptoms in culture, wherein narrative is developed through the physical negotiation of space through mimesis. Within this conception, the thaumaturgical properties of architecture are made evident by "rendering visible the invisible," 14 as explained by Frascari. The capacity of architecture of developing these conditions rests on our ability to represent the entire spectrum of relationality - from the sacred to the profane - thereby revealing the poetic qualities of our existence; a process which Vesely describes as a situatedness of representation in the communicative space of culture. ${ }^{15}$ This situatedness is contingent upon a 'local-technology' of self-reflexive or heuristic action, wherein the disclosure of relationality takes place through what Heidegger reminds us of as techne; a fundamentally creative and individual act which (re)reveals the qualities of everyday life - a circumstance which his most aptly revealed by architecture, as we will come to see. 

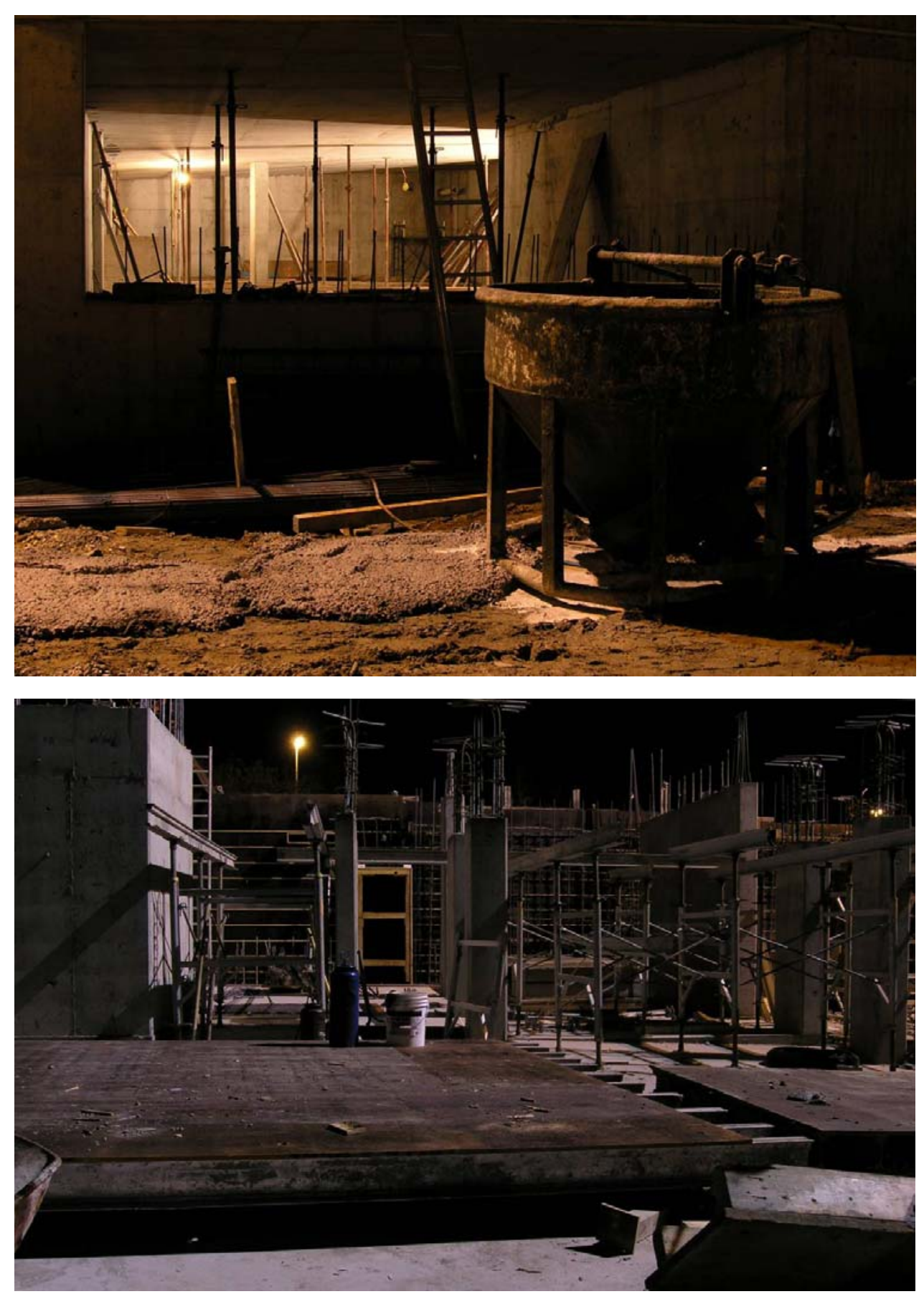

Fig. 10 The poetic aspects of the typical construction site. Photographs by the author. 


\subsubsection{Technē: Revealing the Factum}

What is critical to the theory at hand is Heidegger's recognition of the purpose and use of technology relative to the human condition; that technology is an application of knowledge which has been revealed from the world without; that technology, enacted through techne, is a poetic means of revealing what is central to the human condition - it is the means of human agency in mediating the world without and the world within.

According to Heidegger, in his essay The Question Concerning Technology, the term technē refers to a revealing of that which does not already exist; an un-concealment of the mystery of existence. The term is thus associated with episteme, as it brings forth elements to be grasped and known. ${ }^{16}$ As Davison points out, methods of un-concealment such as technology and language have the dubious nature of confounding the revelation of truth, since their tendencies towards abstraction fail to embody the myriad nature of reality, resulting in mere glimpses of the essence of things. ${ }^{17}$ Under the hegemony of instrumental logic, we have found a polarization of these worlds, wherein the notion of dwelling as a reference to the world without becomes disjunctive, as mimesis no longer occurs within the tactile realm of phenomenology, and must instead refer to the abstract realm developed by the 'I,' which exists distinct from the world without. In this condition of instrumentality, the world without is seen solely as a means of securing the prospect of freedom, in the understanding that instrumentality can reveal the same meaning, or value, to the world without as can symbolic re-presentation:

In disciplines such as architecture, most believe, even today, that instrumentality can be brought into harmony with symbolism, that a balance can be established between them, that instrumentality can produce its own symbolism, or that the two can exist independently. The 
absurdity of such a belief becomes clear in the view that instrumentality (technē) must always be subordinated to symbolic representation (poiēsis), because technē refers to only a small segment of reality, while poiēsis refers to reality as a whole. ${ }^{18}$

It should be understood that techne, in its original situation, was understood as techne poiēsis - translated as creative knowledge through symbolic representation, and was constituent of an embodied reality, which was given meaning through the rites of mimesis/participation and ritual. That is to say, the 'art of making' was a creative way of meaningful making, and was fundamental to a way of being with technology.

The usefulness of recalling the importance of technē is also found within the etymology of the descriptive factura. The Latin word factura is derived from facere - "to make;" at once an action and a result. Factura is more than a feature of the thing presented for understanding; "it implies an original, material attachment to a subject, and as such, it is as well a recuperative optic and a nostalgic ideal." ${ }^{19}$ In simultaneously denoting a way of looking, as well as being an aspect of 'the thing,' factura presents opportunities for an implicit relationality between the artifactual and the individual, by means of its explicit "made-ness." In doing so, factura - as a way of making and a way of seeing - can begin to reflect the creative potentialities within technology.

\subsection{Evincing the Quotidian}

\subsubsection{Situatedness}

When considering the representative task of architecture in the world without, it is critical to appreciate the limitations of instrumental thought, relative to what Vesely describes as situatedness: 
[...] what characterizes a way of making as poetic is the situatedness of the results in the communicative space of culture. The phenomenon of situatedness stands in clear contrast to the instrumental thinking and to the subjective experience of aesthetics. It represents deep respect for the given reality of the natural world, manifested in the rich articulation of typical situations. ${ }^{20}$

In Vesely's terms, the "articulation of typical situations" involves the formulation of a limited set of creative principles, and to articulate its content and structure through influence from the metaphorical and analogical structure of the visible world; that is, by embracing the poetic qualities of reality. It is this re-presentational quality that Harries describes in the orientation of the human condition relative to space and time. Specifically, Harries argues that what could broadly be defined as 'ornament' should possess a representational function of recalling us to "a more genuine dwelling," 21 oriented around the fundamental aspects of the human condition (dwelling, as mortals, mediating the earth and the sky) - one which embraces our mortality as opposed to avoiding the death of the human conscience through the search for security.

\subsubsection{Fragmentation}

Within this condition of increasing autonomy, the question of re-orientation within a thoroughly fragmented reality becomes paramount. The question of orientation comes at the hands of a curious phenomenon in architectural re-presentation, wherein the artifactual element - the fragment - begins to reveal aspects which can begin to re-instate a sense of dwelling; an often Romantic condition wherein architecture is reflected through memory and imagination as a 'ruin,' ultimately revealing the temporal aspect of dwelling, 
here described by Karsten Harries:

The artificial ruin betrays a crisis in the confidence that architecture is able, or should even attempt, to provide anything like Heideggerian dwelling. This suspicion of architecture figures a deeper distrust of the Cartesian dream that reason will render us the master and possessors of nature. $^{22}$

This attitude toward fragmentation reveals a response to the will to power which belies Cartesian dualism, which seeks to overcome its own "terror of time" 23 through the manipulation of the world without in an attempt to establish security over death. In representing architecture as a ruin, the fragment reveals the inevitability of death as an essential component of dwelling; it exposes architecture to the conditions which define our existence, and thus relate it back to the realm of first wisdom. Implicit within this is a paradoxical condition; while architecture provides sustained shelter through reasoned structural elements which respond to the vicissitudes of the environment, the architectural fragment simultaneously re-presents itself as being fallible - a fallacy which suggests a sense of the sublime. This condition is epitomized in The Notebooks of Malte Laurids Brigge, by Rainer Maria Rilke, who presents a poetic description of the remains of a demolished house:

There stood the middays and the sicknesses and the exhaled breath and the smoke of years, and the sweat that breaks out under armpits and makes clothes heavy, and the stale breath of mouths, and the fusel odour of sweltering feet. There stood the tang of urine and the burn of soot and the grey reek of potatoes, and the heavy, smooth stench of ageing grease. The sweet, lingering smell of neglected infants was there, and the fearsmell of children who go to school, and the sultriness out of the beds of nubile youths. ${ }^{24}$ 

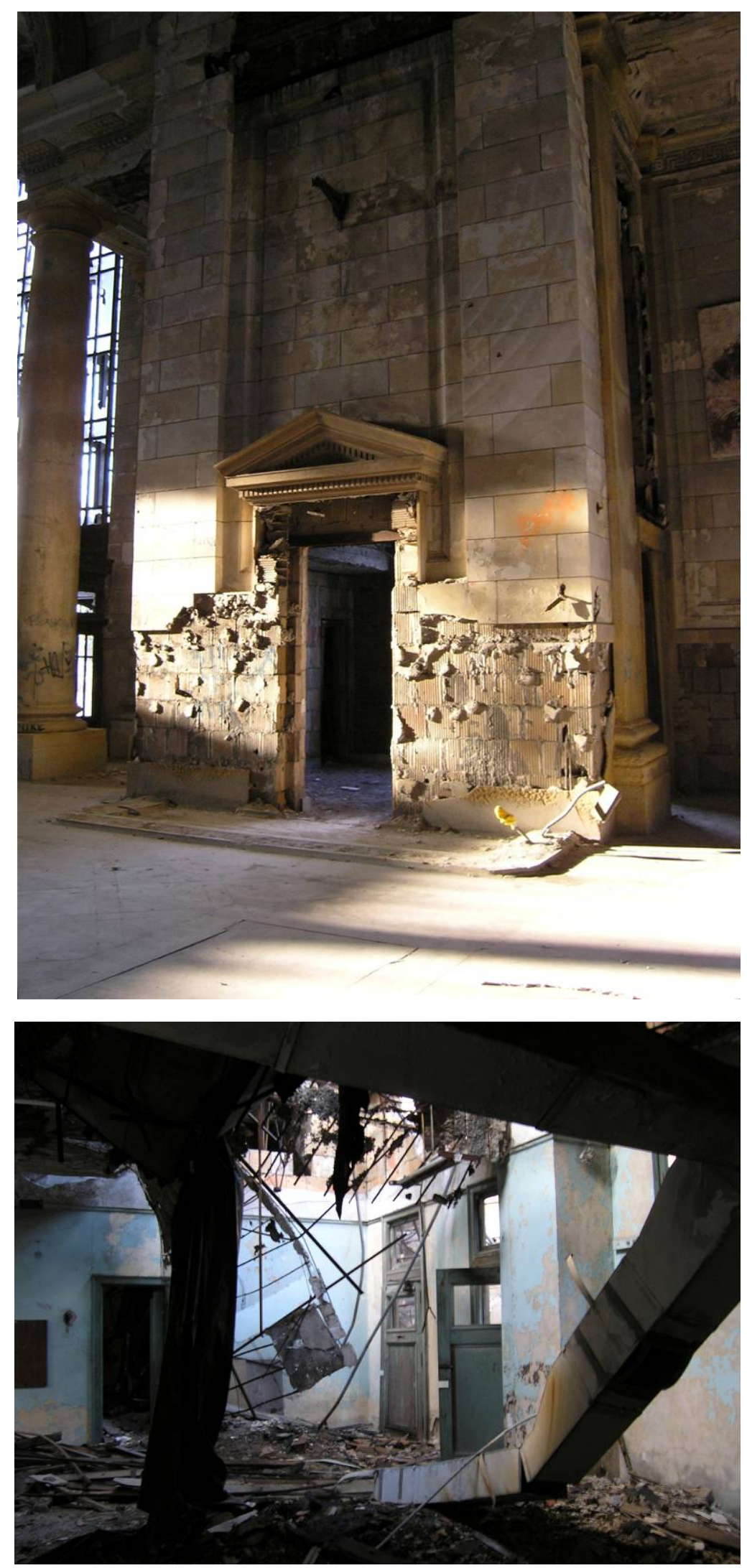

Fig. 11 The remains of Detroit's Central Station, circa 2005. Photographs by the author. 
The origins of the fragment in representation can be seen as an inevitable result of modern knowledge, and traced back to the development of perspectival representation, wherein reality is represented as an object, and experienced by a single subject. The development of the fragment followed the appropriative gaze through the succession of power; first as spoils, then as curiosities, reaching a peak in the "cult and poetics" 25 of the ruin, peaking in the eighteenth century. The de-contextualization of an object has the effect of revealing symbolic meaning which could not have been gleaned had the object remained in its original context, and is a process which occurs parallel to the projective, categorical gaze. However, the fragment, while a condition of extension, also has the property of being in dialogue with the sublime - the tension between the "potential presence of the infinite and the finitude of our sensible experience," ${ }^{26}$ which has the effect of restoring meaning through poiessis, as it reveals the dialectical nature of our perception. As in Maria Rilke's poetic description of the ruins of a domicile, where architectural fallibility is the equivalent of human fallibility, it is understood that within the condition of fragmentation lies the possibility of restoring communicative space in the establishment of metaphorical, representative ties to what is essential to dwelling. The poetic example is here also seen to exemplify a condition of situatedness in the quotidian world to allow for such an experience to take place.

\subsubsection{The Infra-ordinary: Michel de Certeau and Georges Perec}

The strategy of an 'articulation of typical situations' marks a decisive point in the articulation of this thesis, as it reveals a circumstance that can directly effect how participation takes place within the strictures of Autistic Culture. Michel de Certeau, in his work The Practice of Everyday Life, recounts the importance of agency through the act 
of creative resistance. Specifically, de Certeau proposes the extension of science toward an understanding of the everyday; as a means of disclosing an ethnology of consumerist society:

As unrecognized producers, poets of their own acts, silent discoverers of their own paths in the jungle of functionalist rationality, consumers produce through their signifying practices something that might be considered similar to the "wandering lines" ("lignes derre") drawn by the autistic children studied by F. Deligny: "indirect" or "errant" trajectories obeying their own logic. ${ }^{27}$

Michel de Certeau points out critical distinctions between strategies and tactics in describing the trajectory of a creative resistance to the repressive aspects of modern society; defining strategy as a "calculus of force-relationships which becomes possible when a subject of will and power (a proprietor, an enterprise, a city, a scientific institution) can be isolated from an 'environment;" 28 and tactic as a "calculus which cannot count on a "proper" (a spatial or institutional localization), nor thus on a borderline distinguishing the other as a visible totality." ${ }^{29}$ While strategies are employed by power structures to institute a set of relations for official ends, tactics are employed by the subjugated as opportunistic actions 'within the moment.' The tactical, as a way of producing without capitalizing, employs a deliberate estrangement from everyday practices in order to react creatively; it poses questions such as: "We live, true, we breathe, true; we talk, we open doors, we go down staircases, we sit at a table in order to eat, we lie down on a bed in order to sleep. How? Where? When? Why?" 30 The opportunity to acknowledge these everyday aspects, as revealed by Georges Perec, lie in a surrealistic approach to the quotidian; his descriptions of the everyday suggest the poetic potential to what may lie behind one's wallpaper, or within the space of the page. ${ }^{31}$ 

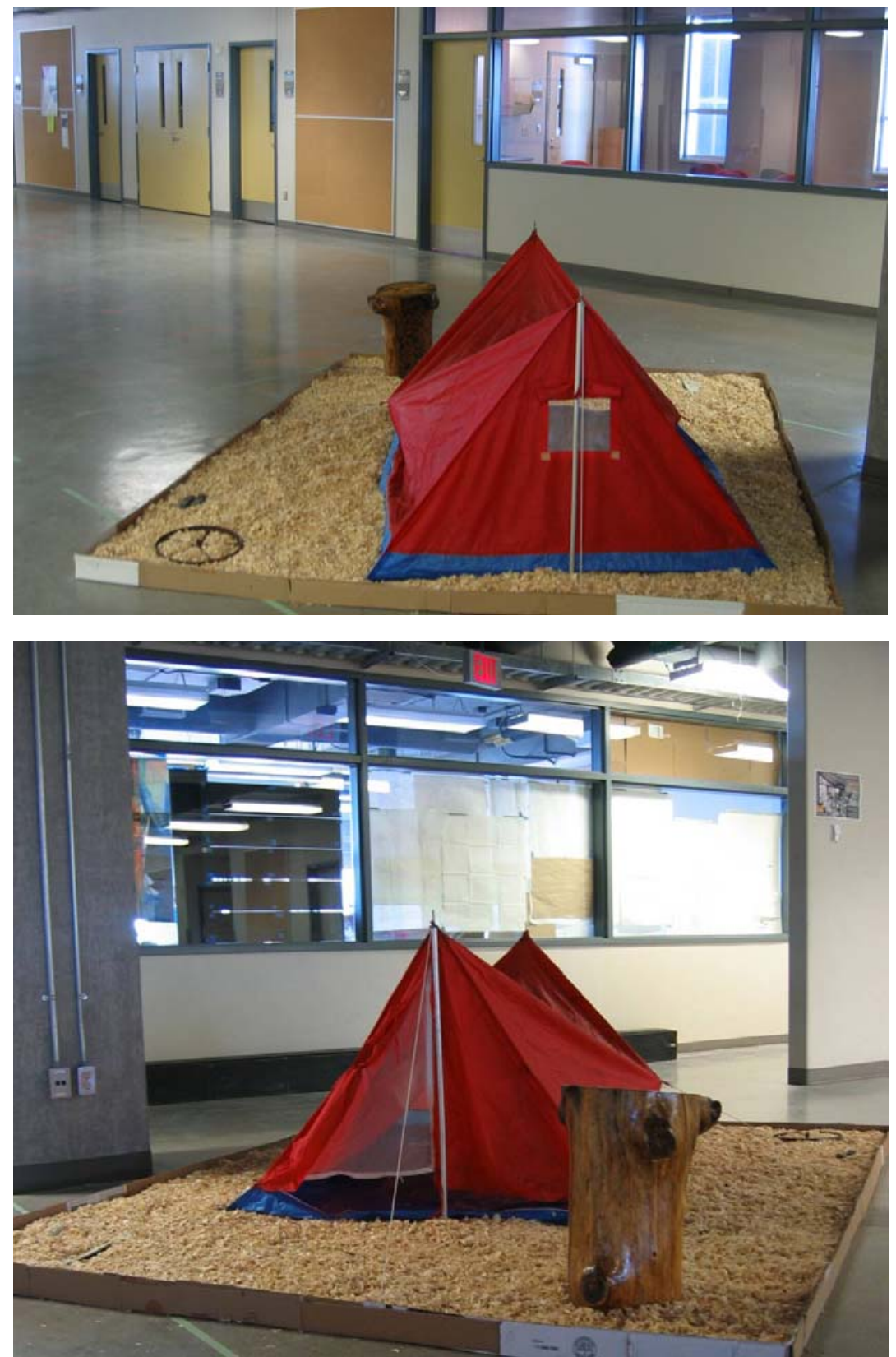

Fig. 12 Diogenetic Installation (Chiara Camposilvan, Thomas

Nemeskeri); generated as an act of creative resistance in the Masters Studio of the Azrieli Pavilion, at Carleton University, 2006. Materials: tent, log, rodent bedding, maps. Photographs by the author. 
The techniques of estrangement are most aptly revealed by Ben Highmore, who states: "[if] everyday life is what continually threatens to drop below a level of visibility, collage practices allow the everyday to become vivid again by making the ordinary strange through transferring it to surprising contexts and placing it in unusual situations." 32

\subsubsection{Evincing the quotidian: Creative Resistance in Architecture}

These techniques are manifested in divergent methods of architectural representation. For instance, the works of Diller $\&$ Scofidio point to how an individual might begin to mediate the enframing effect of technology through the experience of real-time and virtual situations in contrast to their existing situation in space, as a means of critiquing the public realm through 'immediate' representations and narratives of media (thereby suggesting spontaneous heuristic possibilities). In doing so, an individual is presented with a different way of understanding their situation relative to built and ideological edifices. This 'local technology' is employed differently in the works of John Hejduk, specifically in his Wall House studies, which employ figuration in the generation of walls to heighten the experience of frontality and movement, as a means of transposing narrative possibilities. As a tie to the usefulness of factura in generating a situatedness, the work of Louis Kahn is resonant. In expressing how a building is manifested (though not entirely as a functional imperative), Kahn creates moments where the explicit order of a building reveals an implicit dynamic of materials, systems and structure:

I believe that in architecture, as in all art, the artist instinctively keeps the marks which reveal how a thing was done [... ] Structures should be devised which can harbour the mechanical needs of rooms and spaces [... ] It would follow that the passing over of the construction, of lighting, and acoustic material, the burying of tortured, unwanted ducts, conduits, and pipe lines, would become intolerable. ${ }^{33}$ 
In considering the techniques which recall the phenomenal, poetic qualities that constitute a condition of situatedness, it is critical to appreciate a means of meditating the technological realm through the application of practical reason - what Davison refers to as "rationality of relationality." 34 This understanding of rationality is based on an ethical mediation of the world (a moral ontology), but differs from a calculus of rationality (through the hegemony of the appropriative gaze) in its approach to the establishment of what practical reason holds before us. Specifically, the dualistic approach (a calculus of relationality) asserts that practical reason (now considered pure reason) is the seat of categorical imperatives, utterly disengaged from our local embodiment (such as social practice). This Kantian approach, now widely instrumentalized, orients morality relative only to what the mind can establish as being true, in the belief that the mind is the measure of all things. The antithesis to this approach (a rationality of relationality) asserts the futility of disembodying ourselves from the things which nourish us in the search for security; that we cannot assume a neutrality to the vehicle of our will - technology - in establishing this security from the world without, but that we do have the capacity to represent it in a manner that gives meaning to our lives, through a moral ontology. Within this poetic mediation, we embrace our orientation in space and time through a meaningful dialogue between our bodies and the spaces which conceive them. In so doing, this re-assertion-through-re-presentation becomes emblematic of what is fulfilling in our lives, while establishing a basis for the role of human agency in the development of narratio, thereby mediating the autistic nature of contemporary culture. 


\section{NOTES}

1. Max Oeschlaeger, The Idea of Wilderness, p. 279.

2. Ben Highmore, The Everyday Life Reader, p. 3.

3. Ignasi de Sola-Morales, Weak Architecture, p. 68.

4. Ibid., p. 68.

5. Ibid., p. 69.

6. Ibid., p. 70 .

7. Ibid., p. 71.

8. Ibid., p. 60 .

9. Juhani Pallasmaa, "Hapticity and Time," High Beam Research. Website:

http://www.highbeam.com/library/docFree.asp?DOCID=1G1:64720968 (last accessed: 2006-09$05)$.

10. Ibid.

11. Suzanne Frank, Peter Eisenman's House VI - The Clients Response, p. 23.

12. Jean-François Lyotard, A Report on Knowledge: The Post-Modern Condition, p. xxiv.

13. Suzanne Frank, op. cit., p. 23.

14. Marco Frascari, Monsters of Architecture: Anthropomorphism in Architectural Theory. (Savage, Md.: Rowman \& Littlefield Publishers, Inc., 1991).

15. Dalibor Vesely, Architecture in the Age of Divided Representation, p. 387. 
16. Martin Heidegger, The Question Concerning Technology and other Essays, p.13. It is here where Heidegger points out the effective purpose of technē:

"...what is decisive in techne does not lie at all in making and manipulating nor in the using of means, but rather in [...] revealing. It is as revealing, and not as manufacturing, that technē is a bringing forth." (Heidegger, 13)

17. Aidan Davison, Technology and the Contested Meanings of Sustainability, p. 118.

18. Dalibor Vesely, op. cit., p. 242.

19. Joseph Leo Koener, "Factura." Res, Vol. 36, p. 10.

20. Dalibor Vesely, op. cit., p. 386.

21. Karsten Harries, The Ethical Function of Architecture, p. 239.

22. Ibid., p. 242.

23. Ibid., p. 228.

24. Rainer Maria Rilke, The Notebooks of Male Laurids Brigge, trans. MD Herter Norton, WW Norton \& Co. (New York \& London), 1992, pp. 47-48.

25. Dalibor Vesely, op. cit., p.322.

26. Ibid., p. 334.

27. Michel de Certeau, The Practice of Everyday Life, Website (last accessed: 2006-03-21): http://www.ubu.com/papers/de_certeau.html.

28. Ibid.

29. Ibid.

30. Georges Perec, “Approaches to What?," The Everyday Life Reader, p. 178.

31. See Georges Perec, Species of Spaces and Other Pieces, ed. and trans. John Sturrock (London: Penguin, 1997 [1974]).

32. Ben Highmore, Everyday Life and Cultural Theory: and introduction, p.45.

33. Louis Kahn, “Toward a Plan for Midtown Philadelphia," Perspecta 2 (1953), p. 23. 
34. Aidan Davison, op. cit., p.169. It is here where Davison describes the specific situatedness which we must embrace, as a means to overcome the hegemony of instrumental reason. 
"To tell the truth, the city didn't exist. In its place, a big, buge, monstrous thing that had never been given a name sprawled around a mountain and ended by dwindling into suburbs: east, west, north, a few scattered slums... In the centre, glass and girders. An artificial heart. Here and there, banks, offices, headquarters, insurance companies, wide sidewalks, and a bus line. Under those conditions, it was hard to talk about it as a city. And in fact, people didn't talk about it: they lived in it."

Pierre Gravel, À perte de temps (1969) ${ }^{1}$

\section{${ }_{4.0}$ The MAin: CUltural Production}




\subsection{Montréal}

The preceeding excerpt exemplifies most reactionary perspectives on how the quest for modernity, manifested most prominently during the 1960's, had transformed people's relationships to Montréal, in what appears to be the culmination of a process which had begun when the settlers first occupied the shore of the St-Laurent, at a routine portage stop. In the middle of this issue was the Main, a thoroughfare which both divides and bonds the diverse population of Montréal. Indeed, the most singular development of St. Laurent Boulevard (The Main) consisted of the construction of the Ville-Marie Expressway through the heart of Montréal - a master plan which enveloped the city under a grand narrative of modernity. The grand narrative at hand had been fostered by Keynesian economic imperatives, ${ }^{2}$ whereby downtown Montréal was to be modernized to an international level of commoditization by government-run planning initiatives thought to be a new panacea in the development of a genuinely Canadian identity. ${ }^{3}$ The development of mega-complexes - which internalized multiple programmatic functions within a highly ordered and collapsed entity - was typical of the periods' high-modernist aspirations. This development coincided, and was largely spurred by, the mega-structures of Expo '67, which presented a "pragmatic utopia" 4 that carried over to the city in the spirit of the Metabolists, Archigram and Team X, to name a few avant-garde visionaries of the time. The resulting mega-complexes of Place Bonaventure, Place des Arts, and Place Ville Marie, amongst many other infrastructural projects such as the metro, solidified the vision of Montréal as a thoroughly modern metropolis. Throughout the execution of this vision, planning initiatives prompted the destruction of many examples of Montreal's built heritage, to make way for real-estate developments which only partly came to fruition 
under much more random developments in the decades to follow. While the rear-guard reactions to the developments occurring at the time were fostered by divisive sentiments

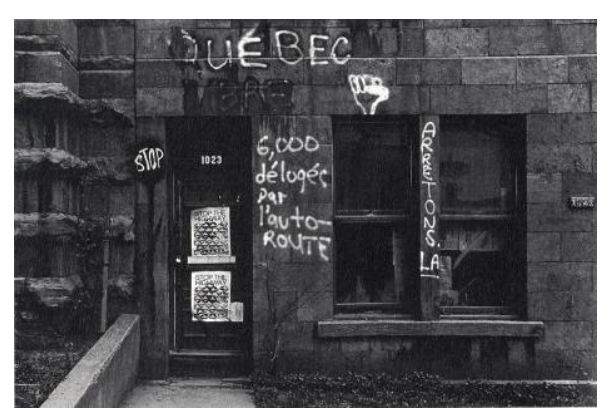

Fig. 13 Dwellings expropriated for the construction of the Ville-Marie Expressway, May 1971. Photograph by Brian Merrett. Source: André Lortie, "Montréal 1960: The Singularities of a Metropolitan Archetype." Montréal Thinks Big. p.108. between the French and English populations, the general citizenry was initially receptive to the transformation of their neighbourhoods, unaware of their ultimate impact. Following the referendum of 1995 - the end of a period during which Montréal's economy plummeted - the downtown has seen much revitalization; a process which has culminated in such developments as the "Quartier des Spectacles" the proposal around which the intervention of a Laboratory for Human Prosthetics and Virtual Interfaces is to be made, as a non-prescriptive foil to the Quartier's move toward gentrification.

\subsection{The Main: Its History \& Context}

The history of the Main dates back to the first settlers of Montréal, as the settlement pattern of the street reflects the settling of Montréal as a whole. Initially just a thoroughfare with dime-a-night hotels and brothels for visiting sailors, many grander buildings were erected along the Main after The Great Fire of 1852. They were wider than they were deep, allowing for a carriageway to pass through to an inner courtyard. Within the courtyard, wooden galleries ran along the back at each level, where respective neighbours would meet to converse, since shops typically occupied the frontages. Nearing the turn of the $19^{\text {th }}$ Century, real-estate came into demand, following the advent of public transportation in Montréal in 1861, forcing 
lots onto street frontages, and increasing the heights of buildings. By the turn of the century, street-cars and their associated tracks were included in the streetscape. Much of the

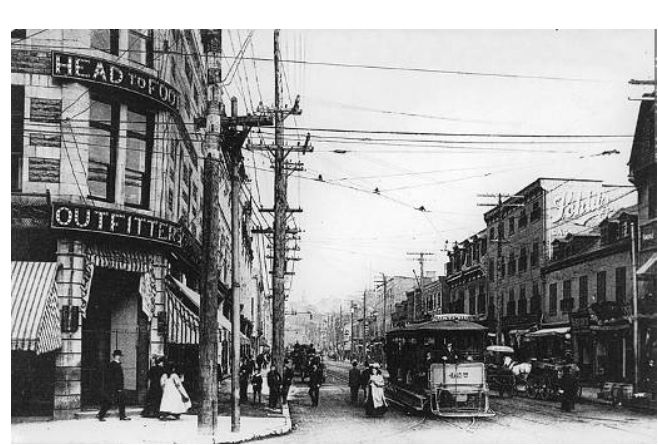

Fig. 14 "St. Lawrence Boulevard, Montreal, QC, about 1910." Photograph by Neurdein Frères. Source: http://www.mccordmuseum.qc.ca/scripts/large.php?Lang=1\&a ccessnumber $=$ MP -0000.816 .1 (last accessed : 2006-03-15) architecture at the turn of the century reflected the grandeur attributed to the new Boulevard, meant to rival those found in Europe. Much inspiration stemmed from the Romanesque-revival designs initiated by Henry Hobson Richardson (known as Richardsonian Romanesque). The Monument National of 1894 was seen as leading the new design movement at the time, while the buildings

surrounding the Monument National were also of a higher architectural calibre.

Following the outbreak of World War I, development on the Main was halted, leaving "a mixture of the grand and the unpretentious." 5 The presence of Chinese immigrants beginning in the 1880's only made an impact during the 1920's, when the locality had finally been settled, after having changed from French and English settlers to those in Ukraine and Russia. ${ }^{6}$ Further up the Main, a Jewish population filled in the empty spaces left behind after the push to generate a new 'Champ Élysées' came to a halt, particularly in the period during World War II. These changes came to define the heterogeneous morphology of the area.

Violence which had become a part of the seedy club scene during the 1960's on StLaurent was halted by Mayor Jean Drapeau's work, which was based on an election campaign promise. These developments were no doubt realized following the construction of the expressway, which relegated the Main to a peripheral condition, and effectively cut it 
off from its historic source in the Old Port, into which writers, poets and artists now moved into. ${ }^{7}$ While the development of the expressway through the heart of the city was ultimately seen as a major point of contention between the residents of the area and the government, the resulting scheme was no smaller than any of the other developments to come out of the 1960's. Past Dorchester (now René Levesque Boulevard) the immigrants remained, and fostered a genuine sense of community, which has been recounted by many authors, such as Mordechai Richler ${ }^{8}$ who was born in the area.
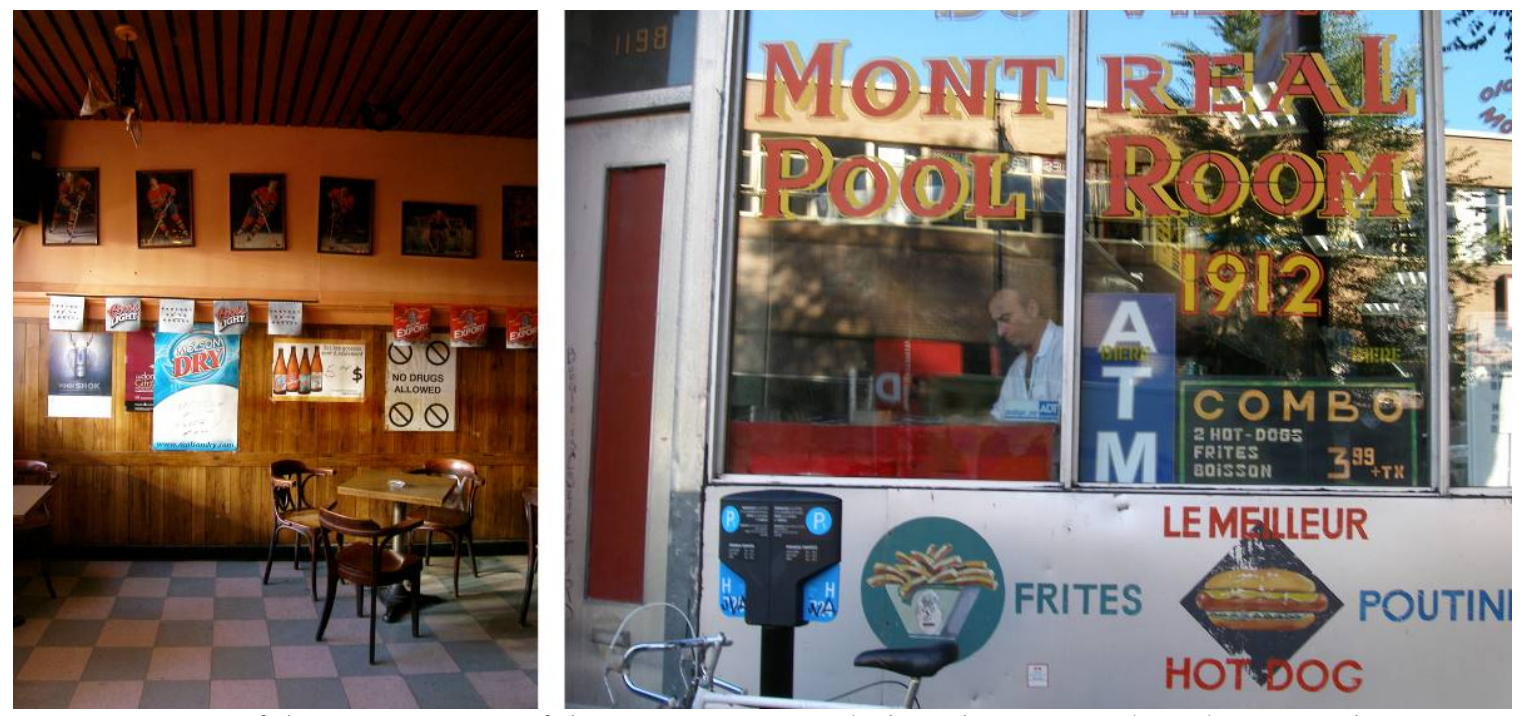

Fig. 15 Images of the current state of the Lower Main, including the Montreal Pool Room, where 80 year-old pool tables form eating surfaces for 'greasy-spoon' dining. Photographs by the author.

Since the late 1990's, the area has been the subject of numerous redevelopment schemes of gentrification, though only of late have any credible plans been put forward. In 2002, the Main was officially labelled as a National Historic Site, in recognition for its critical role in the lives of immigrants who came to inhabit the street over the course of four centuries. Along the first six kilometres, the patterns of habitation of the Île de Montréal are vividly etched into its fabric by varying patterns of European, Arabic, and Asian settlers. The historical declaration doesn't prevent developers from destroying any of the historical 
fabric, but the decaying site next to the Monument National, for example, has been maintained at least superficially, to represent the historical character of the area. ${ }^{9}$ In 2002 , a scheme to develop an arts district in the downtown area was proposed by private partnerships at the Montréal Summit, with the aim of economic and cultural development. The development scheme was approved, and the Partenariat du Quartier des Spectacles (PDQS) was formed by representatives of the city of Montréal, the Ministry of Municipal Affairs, local businesses and the real-estate and educational sectors, ${ }^{10}$ with the aim of developing buildings in the Quartier with a strong cultural and heritage component. Furthermore, implicit in this is an intention to unite commerce and the arts, using "culture as a lever for development." 11 The 'remedial' proposal of the PDQS aims largely to balance the developments of the 1960's, wherein Montréal saw its most radical changes. During that period, the singular developments, such as the construction of the Ville-Marie Expressway and the associated development of high-rise office blocks, transformed the character of downtown, and relegated the Main to a peripheral circumstance. Further, its original architectural connections to the old port were severed in the process, effectively disrupting both the historical continuity and the cultural ties. With the re-orientation of the district into a cultural area, following a combination of artistic and commercial vectors, the "Quartier des Spectacles" promises a re-invigoration of the area. ${ }^{12}$ The potential of this thesis in contributing to this trajectory lays in its orientation toward the possibilities of technē in the development of a Laboratory for Human Prosthetics and Virtual Interfaces - by mediating a technologically-oriented environment with an artistic and culturally-oriented environment - a circumstance which is both conducive and necessary to the area's intended development. 


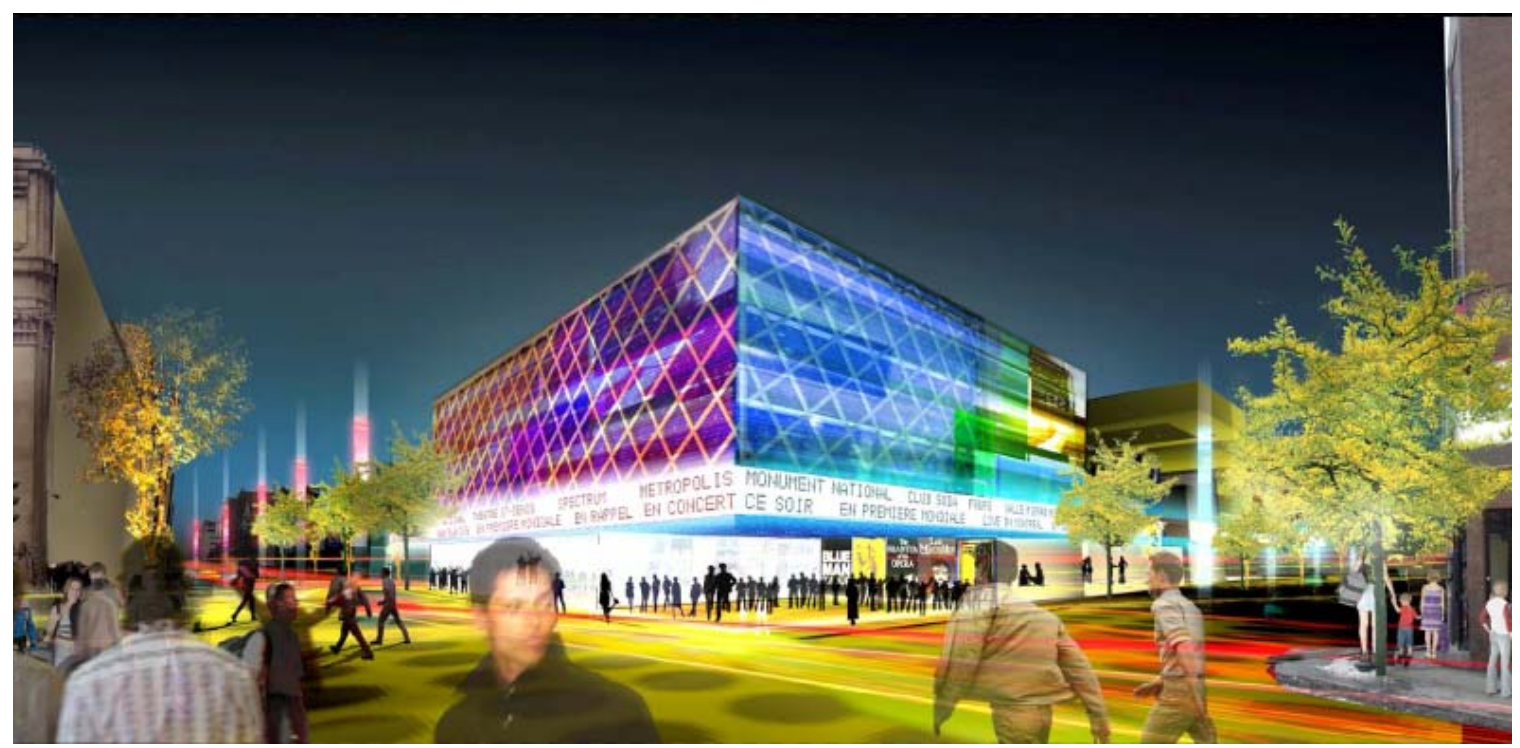

Fig. 16 Artist's rendering of future site at the intersection of Ste-Catherine and St-Laurent, currently the site of a strip-club and pornography store. Source (last accessed: 2006-07-04): http://www.quartierdesspectacles.com/en/nouvelles/fichenouvelle.asp?id=11

\subsection{Cultural Production}

The proposed site for the project, between 1186-1196 St-Laurent, holds the remains of a building which had been gutted by fire in the 1990's. The heritage of the site is reflected in the remaining façade, which is at present structurally supported by steel reinforcements. The original design dates from 1890, and is of the Richardsonian Romanesque manner, as are many other significant works of architecture along the Main, including the Monument National, immediately adjacent to the site. This heritage is the result of a construction boom which occurred at the turn of the $19^{\text {th }}$ Century, during which a significant faith in the potential grandeur of the new Boulevard prompted planners to envisage a contender to the Elysian fields of Paris. The momentum behind the transformation abated, however, during the advent of World War I, during which the area was populated by immigrants from various countries across Europe. This added to the variegated character of the neighbourhood. Across the century, artists and poets populated the lower Main, 


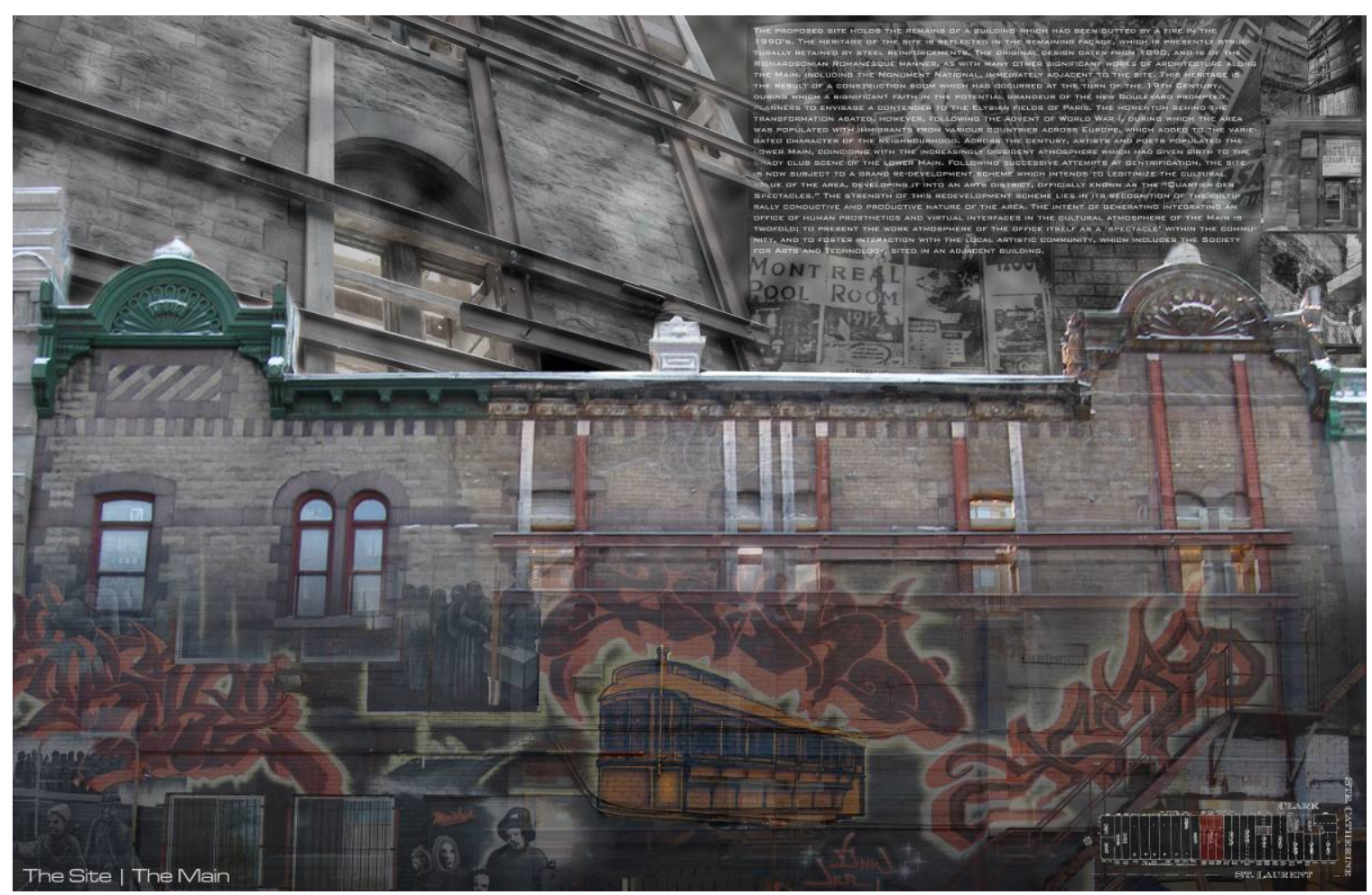

Fig. 17 The proposed site - 1886-1896 St-Laurent Boulevard, Montréal, Québec; recalling its remains. Photographic collage by the author.

coinciding with the increasingly dissident atmosphere which had given birth to the shady club scene of the lower Main. Following successive attempts at gentrification, the site is now subject to the grand re-development scheme of the PDQS, with the intent to legitimize the cultural value of the area in developing it into a cultural district. The strength of this redevelopment scheme lies in its recognition of the culturally conductive and productive nature of the area, which is likely due to its highly variegated socio-economic platform. The intent of integrating a Laboratory of Human Prosthetics and Virtual Interfaces in the cultural atmosphere of the Main is twofold; to engender the work atmosphere of the office itself as a 'spectacle' within the community, and to foster interaction with the local artistic community, which includes the Society for Arts and Technology in an adjacent building - a transdisciplinary centre "dedicated to research, creation, production, presentation, education 
and conservation in the field of digital culture." ${ }^{13}$ Within these strategies is the prospect of remedying the derelict, though culturally-rich condition, by re-establishing ties to the communicative space of its culture, while re-orienting built space to respond to larger environmental challenges than its immediate context.

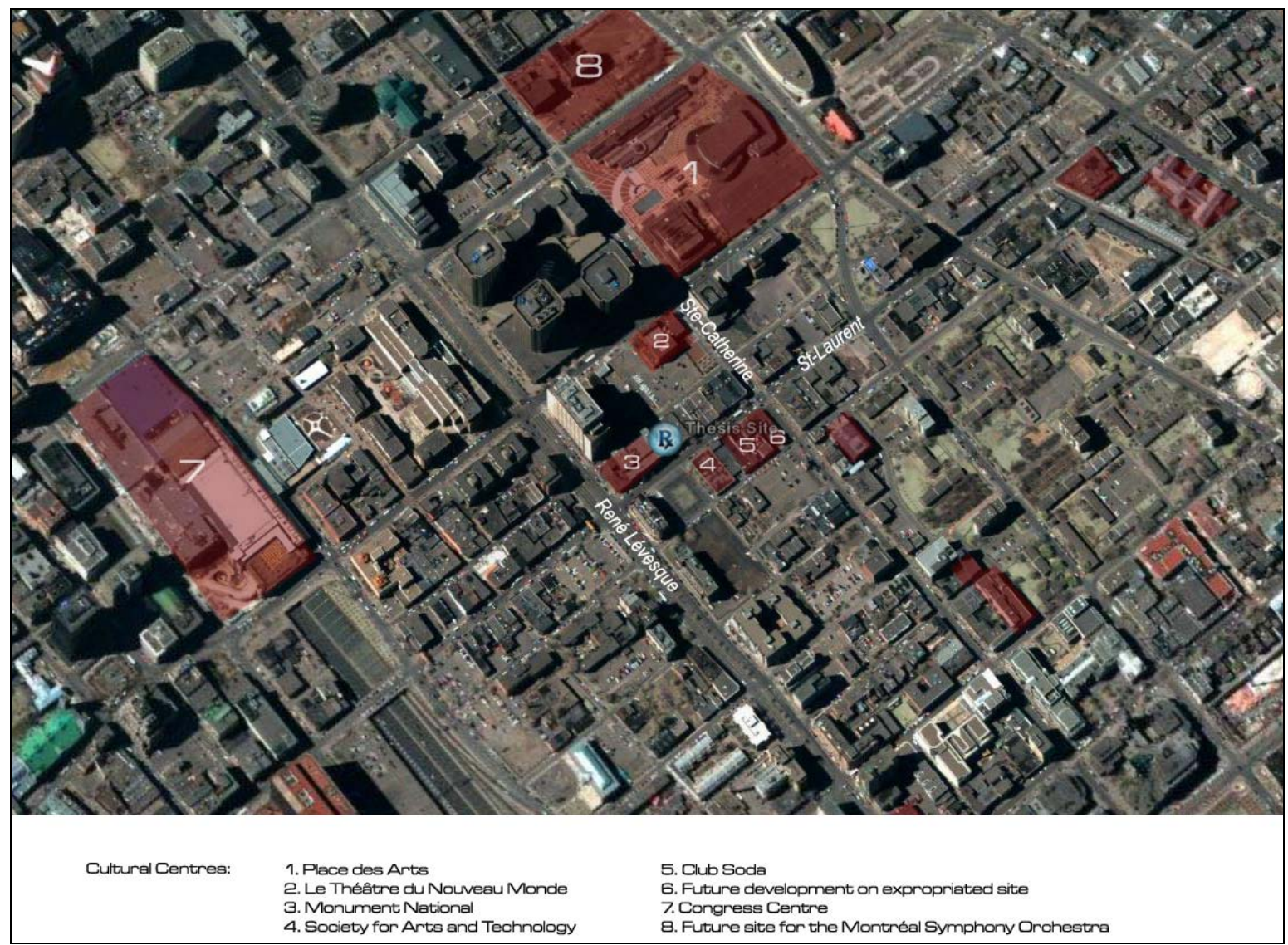

Fig. 18 Map depicting cultural centres within the vicinity of the site. Image by the author. 


\section{NOTES}

1. Pierre Gravel. À perte de temps (Toronto: Anansi, Montréal, Parti pris, 1969), p 26.

2. André Lortie, "Montréal 1960: The Singularities of a Metropolitan Archetype." Montréal thinks big, p.75.

3. Ibid., p.76.

4. Ibid., p.112.

5. Aline Gubbay, A Street Called the Main, p. 54.

6. Ibid., p. 62.

7. This disconnection is being addressed by the city, according to the 2004 Master Plan for the city of Montreal, in an attempt to re-establish links to the Faubourg Saint-Laurent. See the Montreal Master Plan, p. 81 (last accessed: 2006-08-21):

http://ville.montreal.qc.ca/portal/page?_pageid=2762,3099643\&_dad=portal\&_schema=PORT $\mathrm{AL}$

8. See Mordecai Richler, The Street. (Toronto: McLelland and Stewart, 1969).

9. Graeme Hamilton, "The Main acknowledged as historic site." The National Post. Sect. A5. Sept. $28^{\text {th }} 2002$.

10. Helga Loverseed, "Property Report/Quartier des Spectacles. “The Globe and Mail. Sect. B6. January $4^{\text {th }}, 2005$.

11. The full intention of the Quartier des Spectacles can be found at the following address: http://www.quartierdesspectacles.com/en/partenariat/vision/ (last accessed: 2006-04-11)

12. See Montreal Master Plan, Section 4.22. Website (last accessed: 2006-08-21): http://ville.montreal.qc.ca/portal/page?_pageid=2762,3099643\&_dad=portal\&_schema=PORT $\mathrm{AL}$ 
13. The SAT "brings together creators who work with digital technologies, fostering collaboration among diverse artistic and scientific disciplines, establishing partnerships with industry and educational institutions and promoting its members at home and abroad." Source: http://www.sat.qc.ca/page.php?id=52\&lang=en (last accessed: 2006-04-14) 


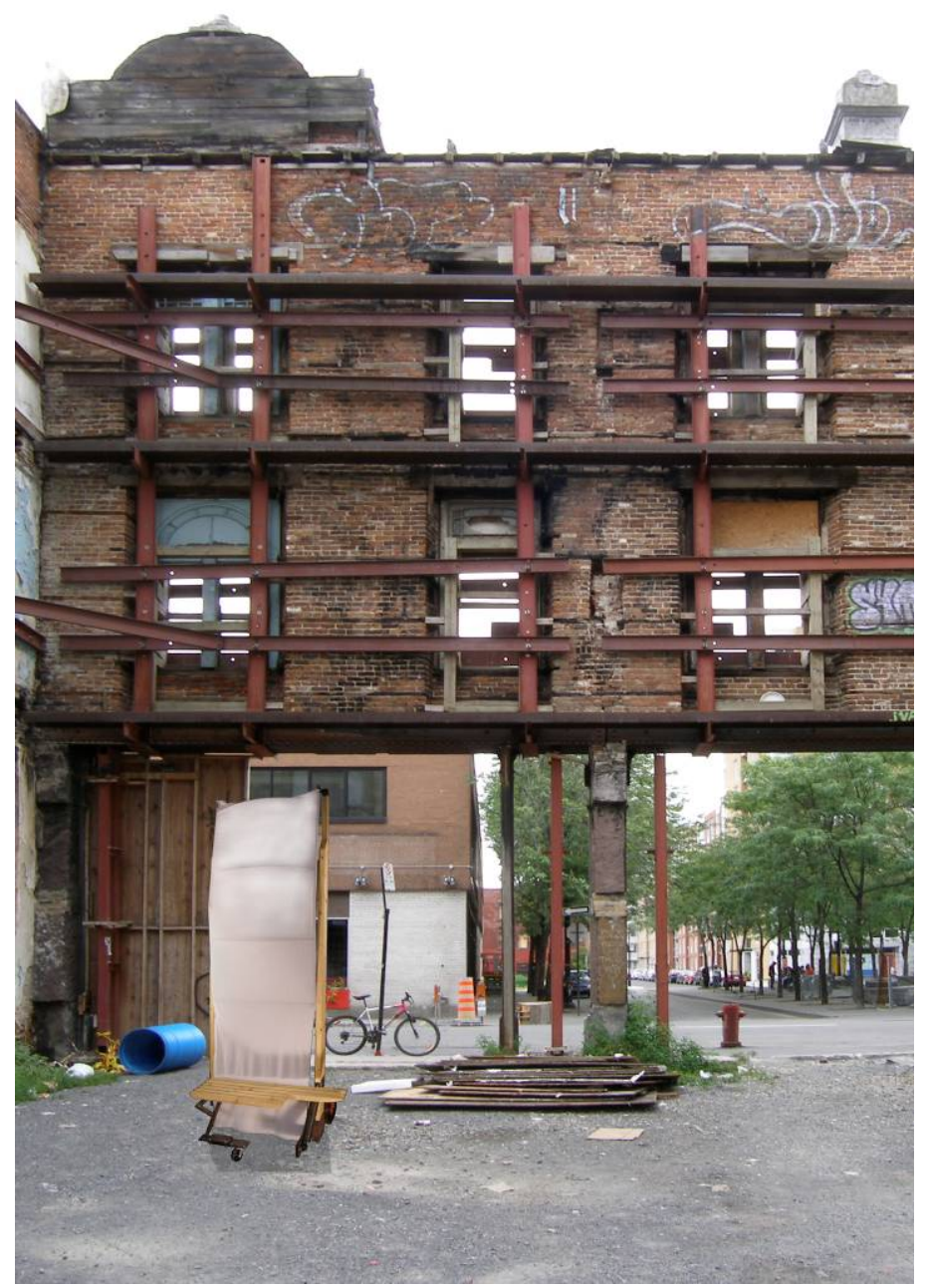

5.0 THE INTERVENTION 


\subsection{Situation}

The site of intervention exists in the

middle of the six-kilometre stretch of St-Laurent, now recognized as a National Historic Site. St-

Laurent Boulevard runs roughly in the direction of North/North-West, so the St-Laurent elevation (facing North-East) receives light in the morning, while the Clark St, elevation (facing South/SouthWest) receives great amounts of light in the afternoon. The shadows cast by the Hydro Québec and the Complexe Desjardins buildings are negligible, particularly in the summer months. Future developments would project construction to the immediate north along Clark St., which will not interfere with the reception of sunlight. The frontage along Clark St. consists of warehouse-like façades, recalling that the street has existed largely as a logistical alley way to St-Laurent Boulevard, and is therefore not pedestrian-oriented. The StLaurent frontage, conversely, is highly pedestrianoriented, with variegated massing and appropriate scales.

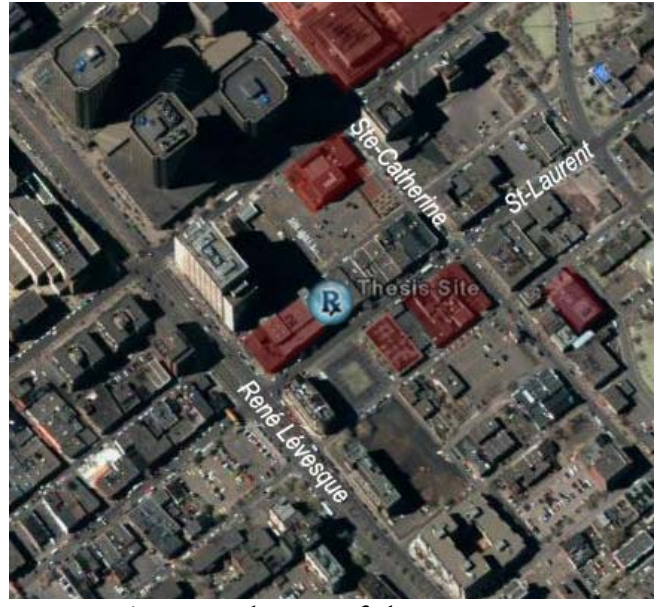

Fig. 19 A general map of the site.

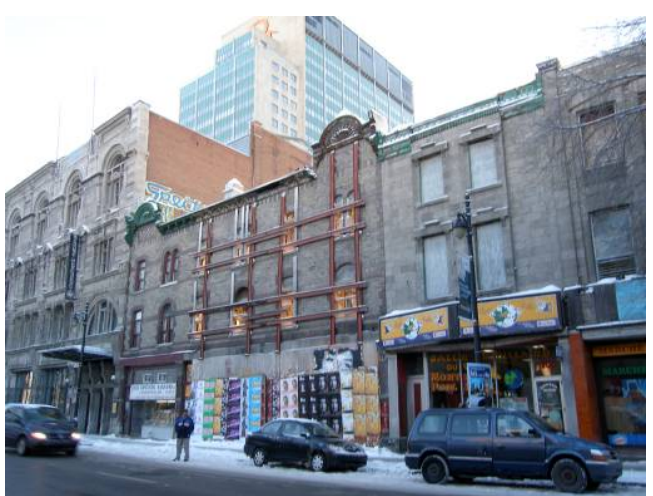

Fig. 20 The existing St-Laurent elevation.

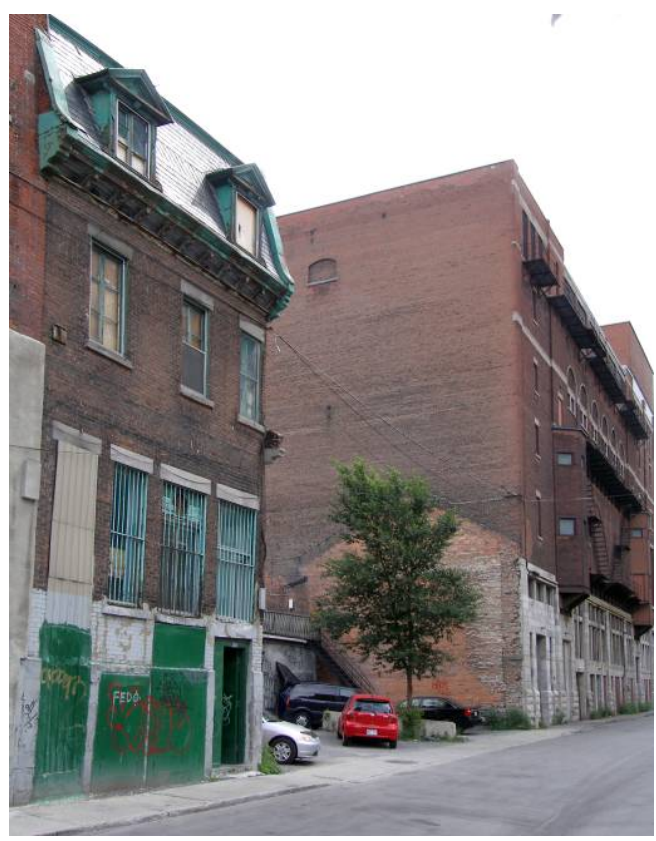

Fig. 21 The existing Clark St. elevation. 

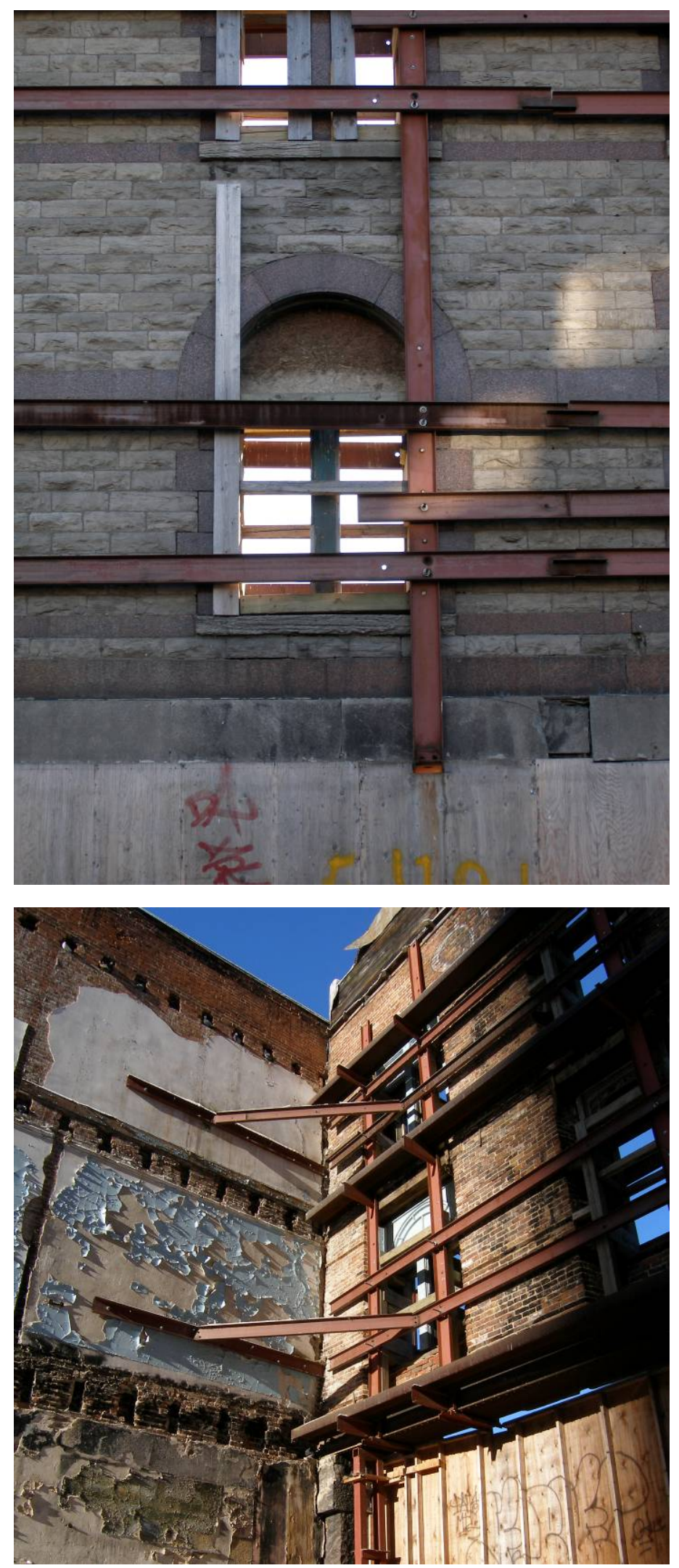

Fig. 22 State of 1186-1196 St-Laurent, circa 2006. Photographs by the author. 
The programme for a Laboratory for Human Prosthetics and Virtual Interfaces calls for a variety of circumstances - from highly-controlled immersive environments and hermetic laboratories, to research carols and network environments. The hybrid nature of the program precludes a lack of precedents, until only recently. However, the concept is fairly straightforward:

$\begin{array}{ll}\text { Public Related: } & \text { Media centre } \\ & \text { Office/Administration area } \\ & \text { Commercial/Restaurant area } \\ \text { Research and Development: } & \text { Research Laboratories } \\ & \text { Visualization Laboratories (Immersive environments) } \\ & \text { Research carols } \\ & \text { Library/Resource Centre } \\ & \text { Archive } \\ & \text { Network \& CPU areas } \\ \text { Logistical: } & \text { Mechanical and Service areas } \\ & \text { Fabrication Laboratories } \\ & \text { Underground Parking }\end{array}$

The total area, over seven floors, is approximately $4400 \mathrm{~m}^{2}$.

5.2 Process

A tableau depicting the symptoms of autistic culture was a preliminary step in the realization of this thesis. Devised as a summation of my position toward Autistic Culture, the tableau reflects a fragmented, disjunctive representation. To the right of the tableau, a sectional 'diagram' of the Pantheon is seen lifting off, as a space-craft, from behind the ruins of a classical forum. As it lifts toward the sky, a plume of smoke is emitted through the oculus of its dome. Below, a scene depicting Bill Gates - dressed in a monks robe and sporting Nike 
runners - is seen laughing, or perhaps giving his blessing, to Diogenes of Sinope below him. ${ }^{1}$ Bill Gates, the founder of Microsoft and the world's richest man, is thought by many to suffer from Aspergers Syndrome; he has often been seen rocking and tends to speak in monotones. Toward the center of the tableau, a fragmented subject is seen watching his brain reach towards the departing Pantheon. Below are depictions of analytical and auto-referential fantasies. Toward the right of the tableau is a scene depicting the poetics of construction and manifestation, where the potential of material deformations is seen to hold potential for creative knowledge, as a therapy to Autistic Culture.

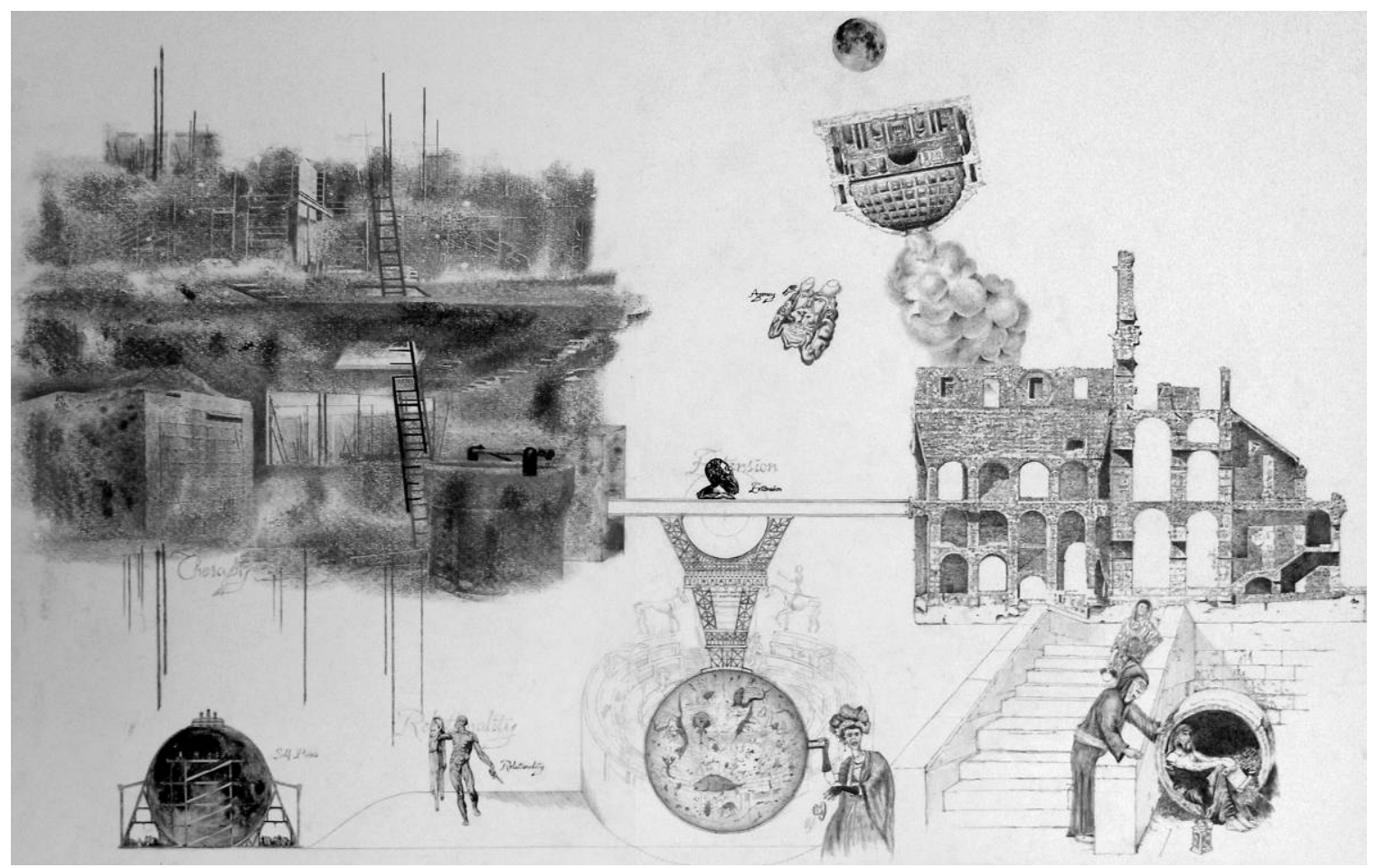

Fig. 23 Rendering by the author; graphite and transfer on Stonehenge, 26"x40".

The second development was the generation of a marchingegno; a 1:1 scale construction conceived as a 'play structure,' around which an architect can envision design of a project by implicating the user as a participant in the design process. Essentially, the device is a configurable, mobile platform, over which building elements 
and conceptual devices can be placed. In making the device mobile, it can be transported amongst and within sites to frame specific moments. The configurability of the device allows it to be transformed to suit different functions, in keeping with design responses

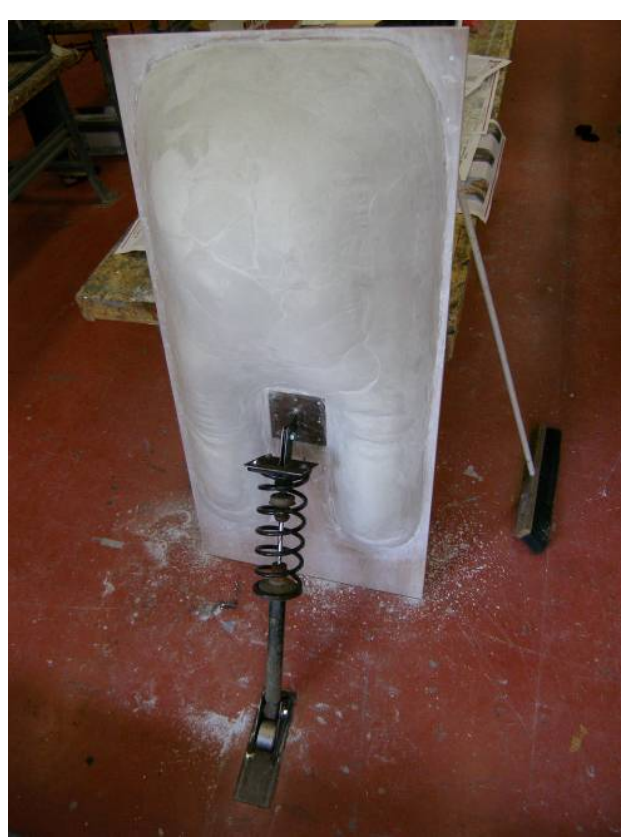

Fig. 24 An unsuccessful iteration of the working surface, consisting of a plaster cast grafted to the underside of the birch table. to critiques of everyday life. ${ }^{2}$ For instance, the seating surface can be rotated to provide bench seating, with or without a canopy extended above. Furthermore, a work surface can be added as an alternative configuration. In keeping with the overall theme of this thesis, the structure was devised through a heuristic process guided by the manufacturing process and the general conception of a participatory device. As such, certain parts were generated only to be removed later; a sympathetic form on the underside of the table,

for instance, while generated as a cantilever to the mass of the frame, proved to be too massive after causing deformations in the table, despite having been reinforced. Other parts, such as the lower leg assemblies, were developed with an appreciation of the deformation of the structure under the weight of its users. Conceived as both architecture and machine, its participants can gain a vantage over their surroundings through interaction with the device. For example, an extension of the shading fabric of the canopy beyond its structure is allowed to blow around with the wind, allowing for happenstance associations; thereby, a relationality can be developed, as forerunner to participatory cues within the building. 


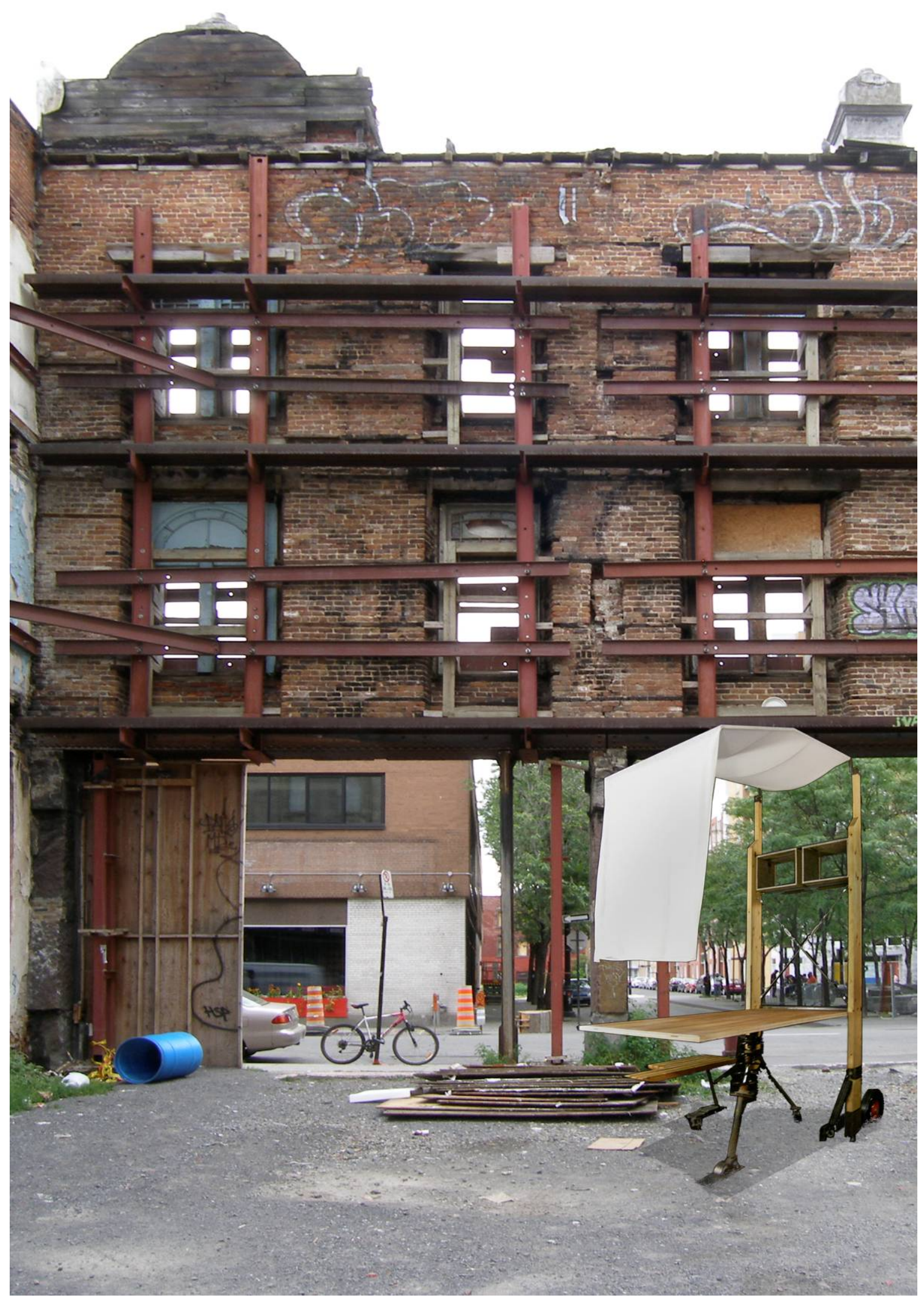

Fig. 25 Depiction of the marchigegno in situ. 


\subsection{Artifact/Fragment}

Approaching the St. Laurent Boulevard façade of the building, one sees a recessed entrance behind the original stone frontage of the building, composed of a glue-laminated plywood, as a reference to the materiality of the original masonry façade. Within this epoché, a wall of high-reflectivity glazing open to the offices beyond alternates with a floor to ceiling video screen that projects CCTV-captured images of local pedestrians, at a 1:1 scale, into images of static immersive environments, standing in contrast to the office beyond. To the left of the laboratory entrance is a separate entrance for the restaurant. A stainless steel mesh is lowered at night to screen the entrance at night, while the restaurant façade remains open to the public. A distinct material and tectonic separation exists between the existing façade and the intervention, creating a framing effect between the two elements. Passing through the entrance, one notices a bifurcation within the building, around an exterior court which opens to the Clark St. elevation. To the left the restaurant facilities continue, and terminate at a large rain-water collection cistern. To the right, a passive-solar stone wall is set within the Canadian Shield, which rests immediately below the site. This stone wall - composed of Canadian limestone - is oriented to maximize solar exposure, and runs from the rear of the site within the north-eastern arm of the building. The mass was conceived as an opportunity to consider the presence of a 'joint' between the body's presence in the space which the body is negotiating; the inclusion of a solar mass in this sun-bathed orientation provides a condition to render visible the often hidden presence of solar radiation. This stone mass contains the major services of the building; including emergency exists, elevators, lavatories, and a geothermal regeneration system, which aids in regulating the temperature of the building. Accordingly, circulation ramps 
encircle and punch through this mass on the lower floors, as the majority of the circulation within the building will occur between the office spaces and research laboratories and carrels. These ramps are slightly stepped at irregular intervals, requiring a slow, attentive pace to negotiate. On the uppermost floors of the bifurcation are the immersive environments of

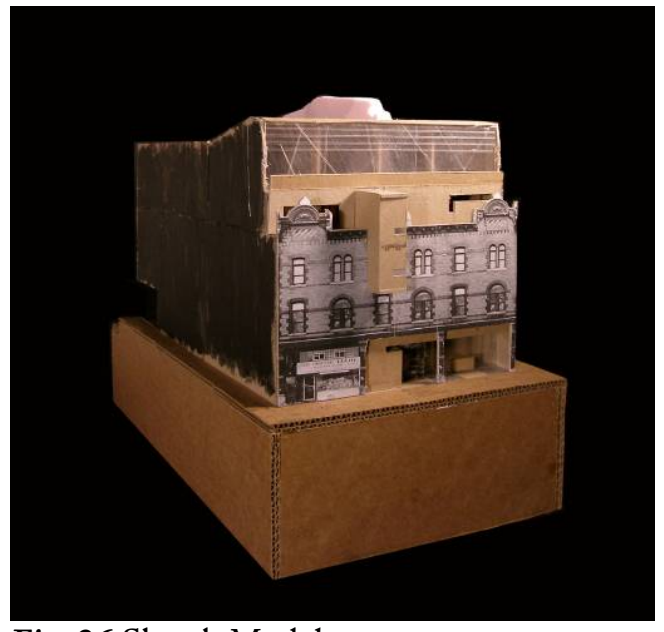

Fig. 26 Sketch Model

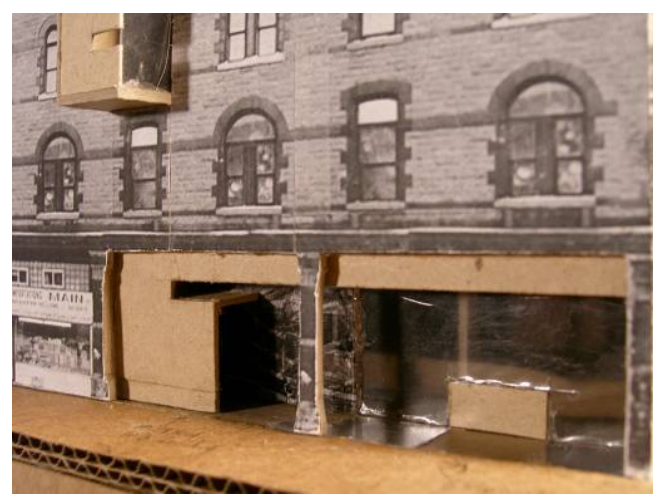

Fig. 27 Façade detail of Sketch Model.

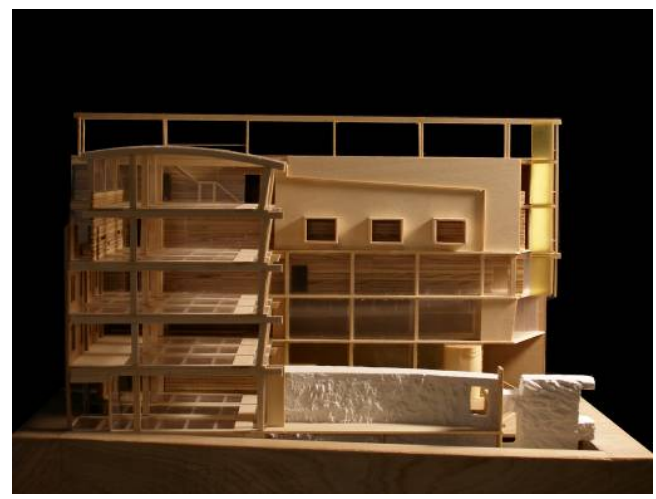

Fig. 28 Section of final model in progress. flooring is not merely an abstract plane, but exists as a system in harmony with the rest of the structure; the floors/ceilings in the offices and research $\&$ development areas alternate between tempered glass flooring and glue-laminate beams. A 1.2 meter cap above each beam, coinciding with the glass flooring, allows for 
mechanical and electrical systems to be distributed.

The southern orientation of the exterior glazing

allows a maximum amount of light to diffuse

throughout these areas, including the archival area of

the first basement level, creating conditions where

the technologically-oriented employees cannot fail to

recognize the sun. On overcast days, and during the

evening, light-emitting-diodes placed along the

perimeter of each plate of glass create a soft, diffused

glow within the floor. The use of glass flooring finds

a surprising precedent in the Québec National

Archives, also in Montreal, which was constructed at

the turn of the $20^{\text {th }}$ century.

A portion of the glue-laminate structure

protrudes out of the existing façade along the upper

floors, acting as a marquee to the Quartier des

Spectacles beyond. In this curious inversion, the

near-autistic workers become the spectacle to the

streets below. Furthermore, the workers are privy to

the theatre of the ever-changing streetscape below.

This structural extension traces itself through the

building as a narrow interstitial condition of research

carrels and resource libraries, and terminates at the

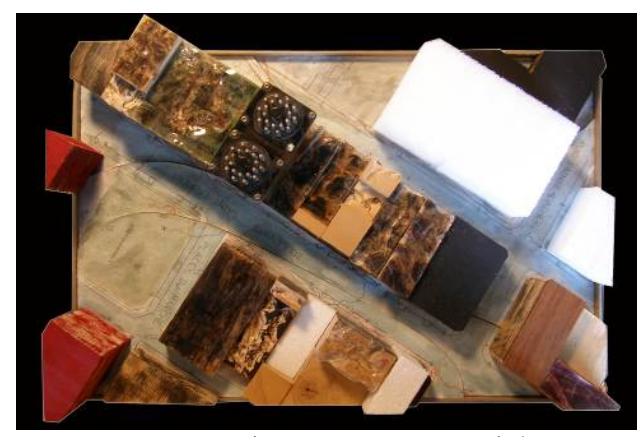

Fig. 29 Massing/Context site model, depicting new residential developments (red), lots to be developed according to the new development plan (white), and existing buildings to be re-developed (black).

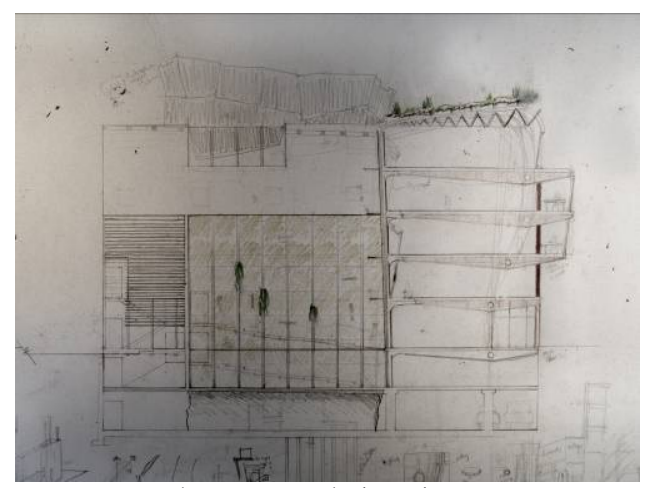

Fig. 30 Early sectional sketch.

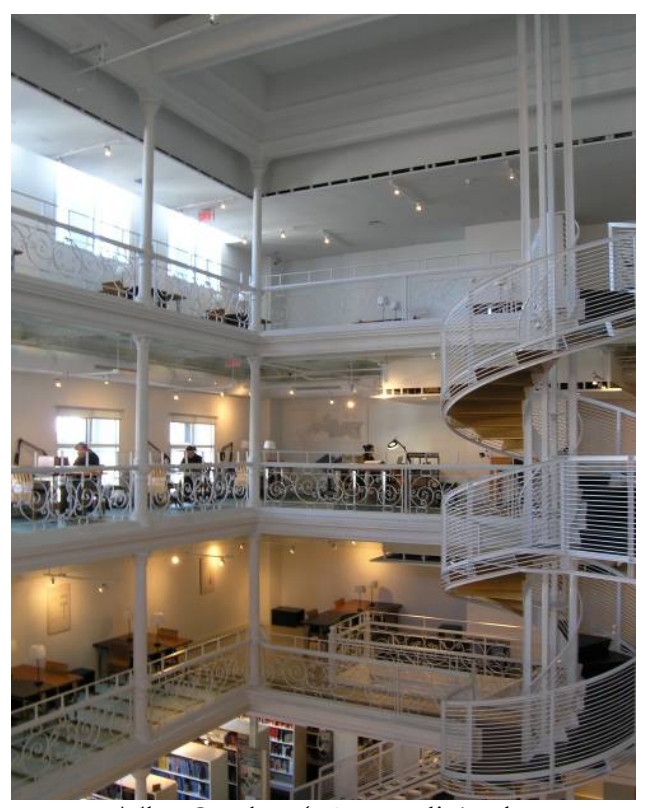

Fig. 31 The Québec 'National' Archives,

Montréal, Canada. Its glass floors date back to the original construction, at the turn of the 20th century. Photograph by the author. 
Clark St. elevation (which is angled inward to maximize solar reception), where the structure retains a fritted-glass wall of varying opacity. This glazing has a playful effect to the light passing against the court below, and on the passive-solar wall just beyond it. This condition creates unique opportunities for the passing workers to recognize the impact of the sun upon their environments. Tracing the structure upwards, a trellis is formed; against which flora grow as part of a roof-garden. This structure butts up against a nano-technology-based glazing surface ${ }^{3}$ on the foremost portion of the building, which changes its qualities of opacity according to varying solar movements or based upon a programmed algorithm. The effect is that of partially reducing direct solar radiation, much as clouds do on a partly cloudy day. The opportunities to generate a random pattern, or to completely obscure the sun rests within the scope of the programmers working below it, though the roof is conceived as a device to reveal their auto-referential tendencies.

These differing elements of technological control exist to contrast auto-referential instances with embodied experiences, thereby generating a duality of spaces; those which evince participatory heuristics by interrupting the ordinary, and those which deliberately mute such interruptive moments through their homogeneity. In such a way, symptomatic spaces of extension are contrasted with the quotidian, as a therapy to Autistic Culture.

The representations of this building have been generated in a similar manner, with a concession toward a client oriented around methods of extension. Subsequently, immersive vignettes are generated as collages imbued with building details contrasted against specific moments where participatory heuristics take place within the building. In representing the building as a duality of projective and immersive elements, imaginal possibilities are made present. 


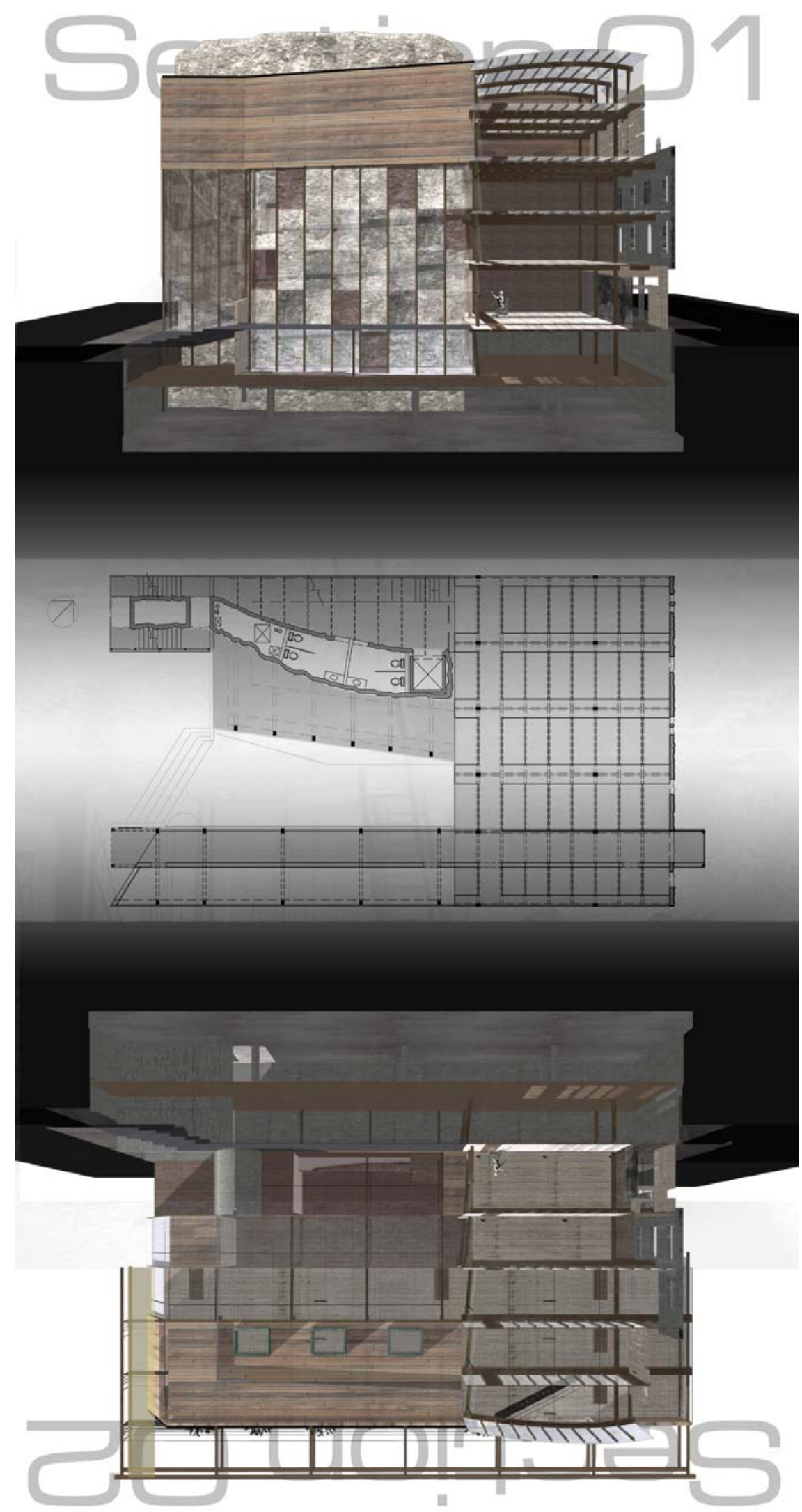

Fig. 32 Abstract of the proposed Laboratory. 


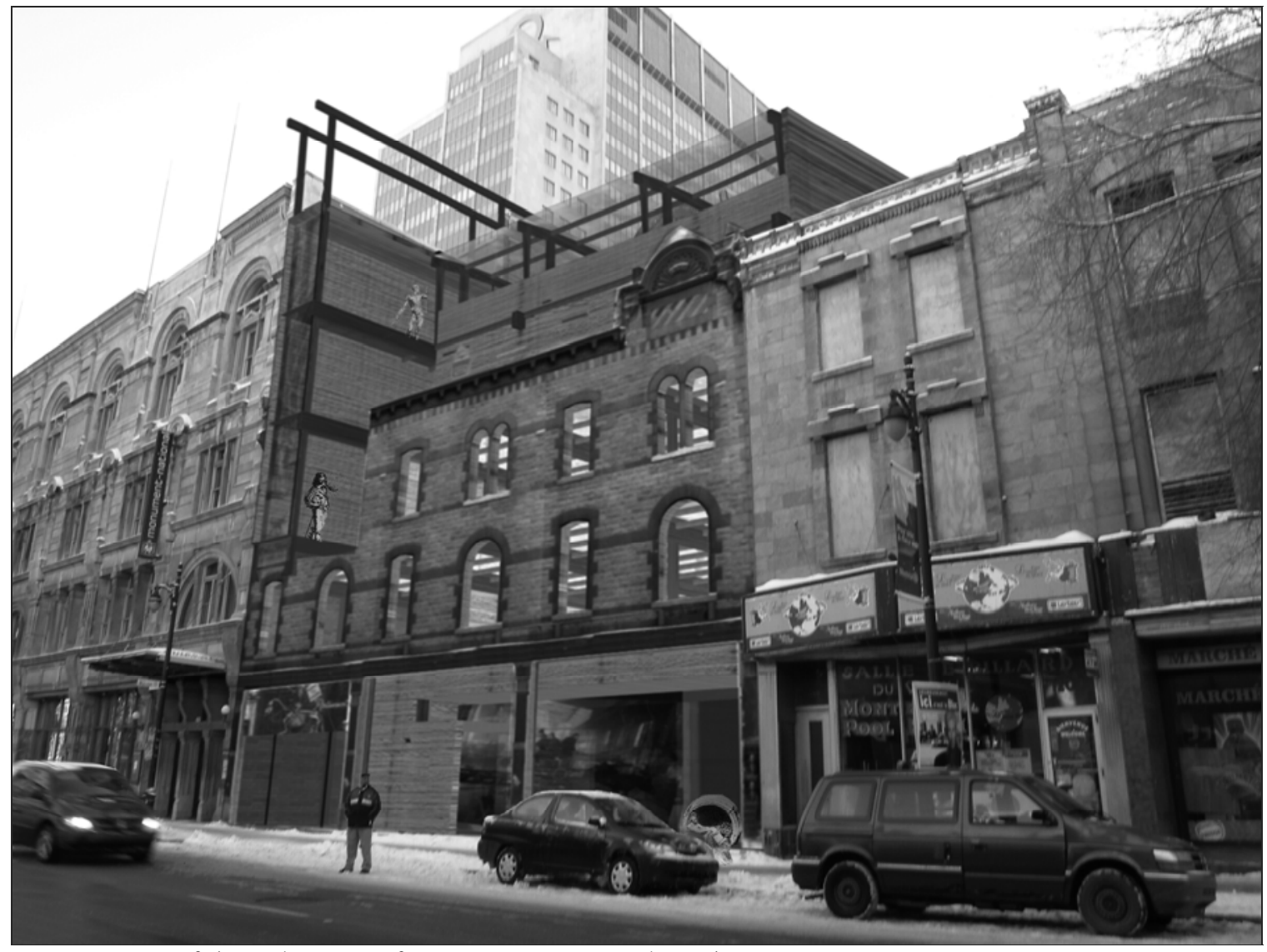

Fig. 33 View of the Laboratory from St-Laurent Boulevard. 


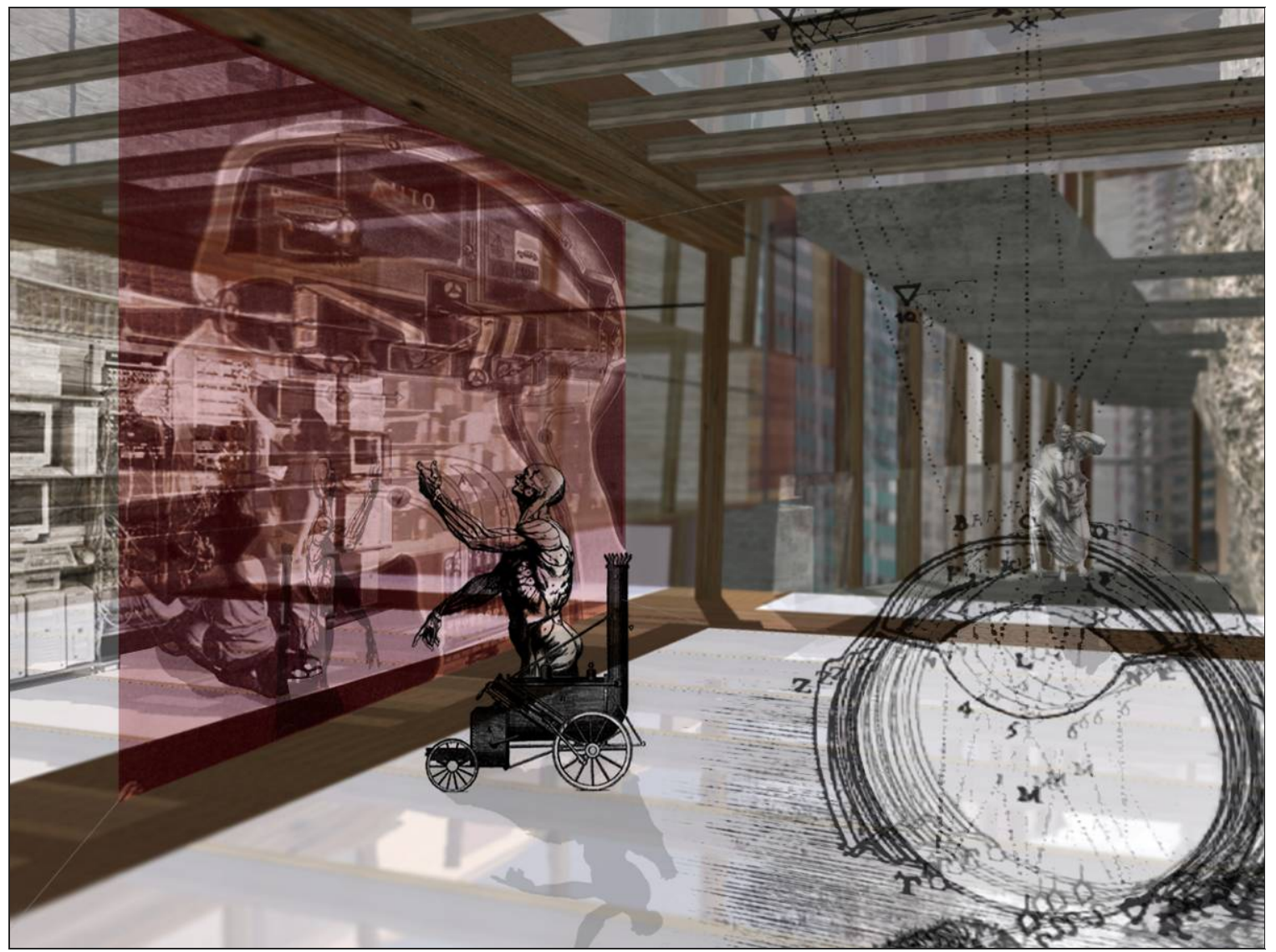

Fig. 34 Depiction of the Laboratory. 


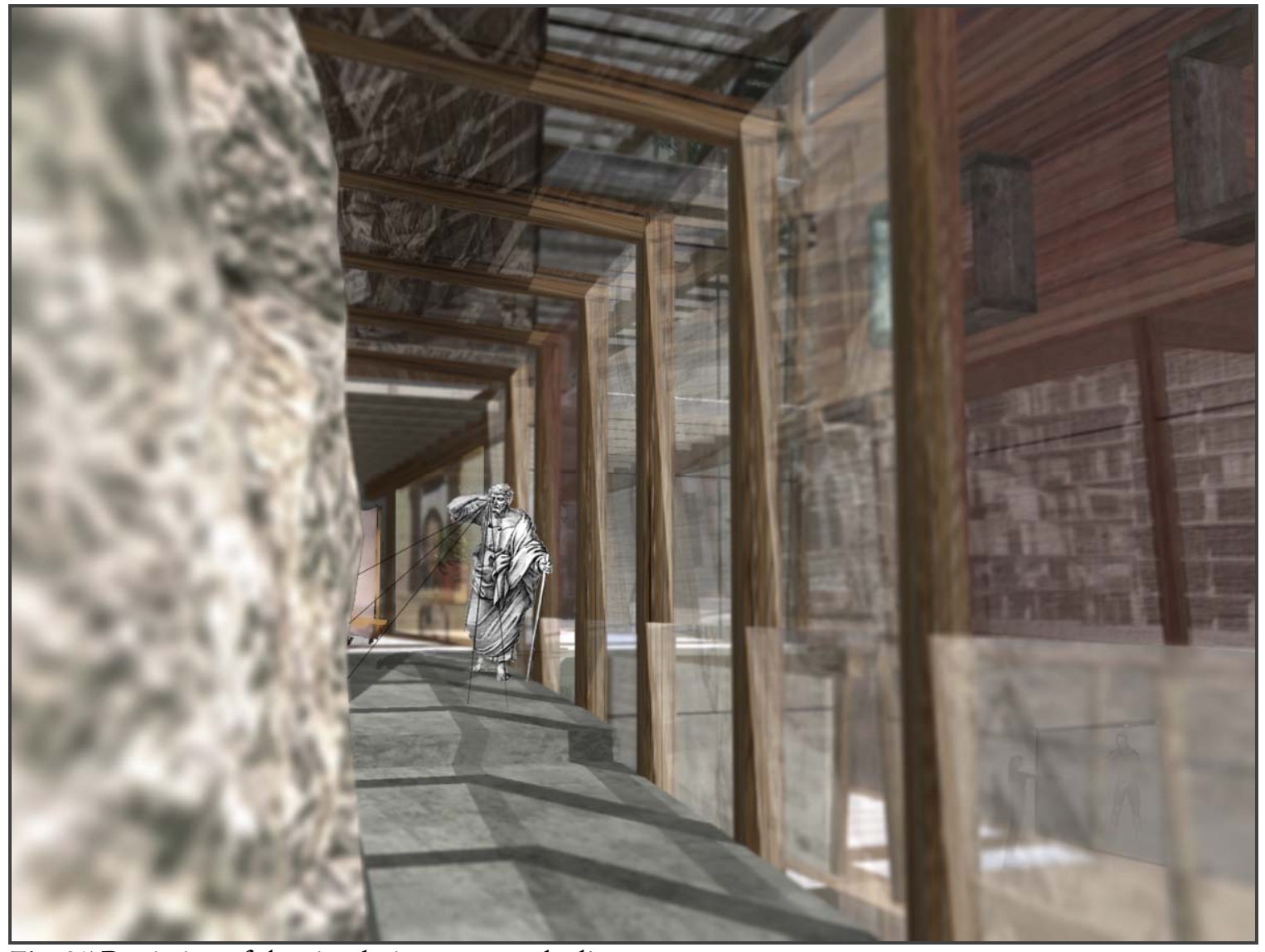

Fig. 35 Depiction of the circulation ramp and adjacent court. 


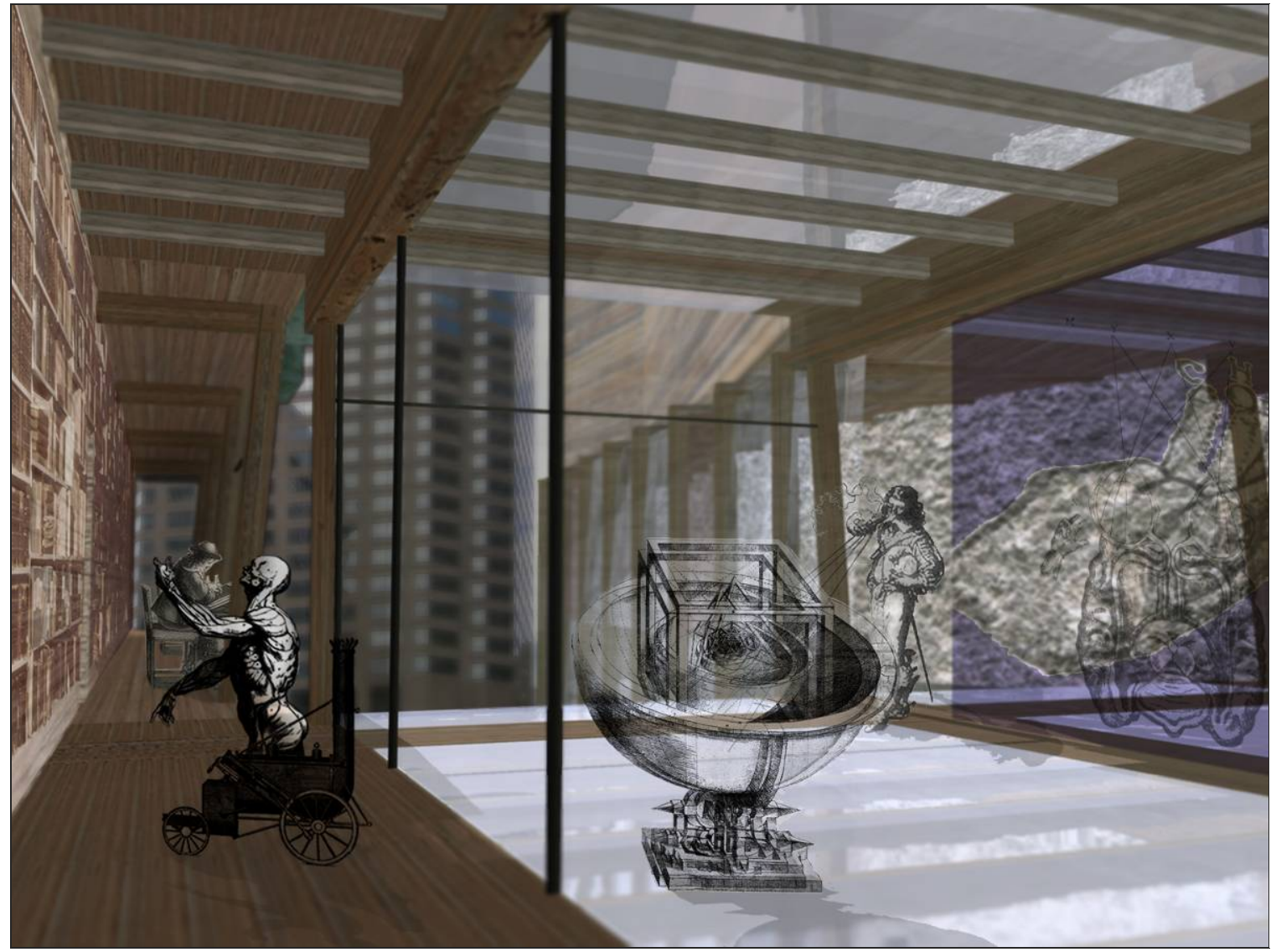

Fig. 36 Depiction of the interstitial resource library and research carrels, adjacent to the research laboratory. 


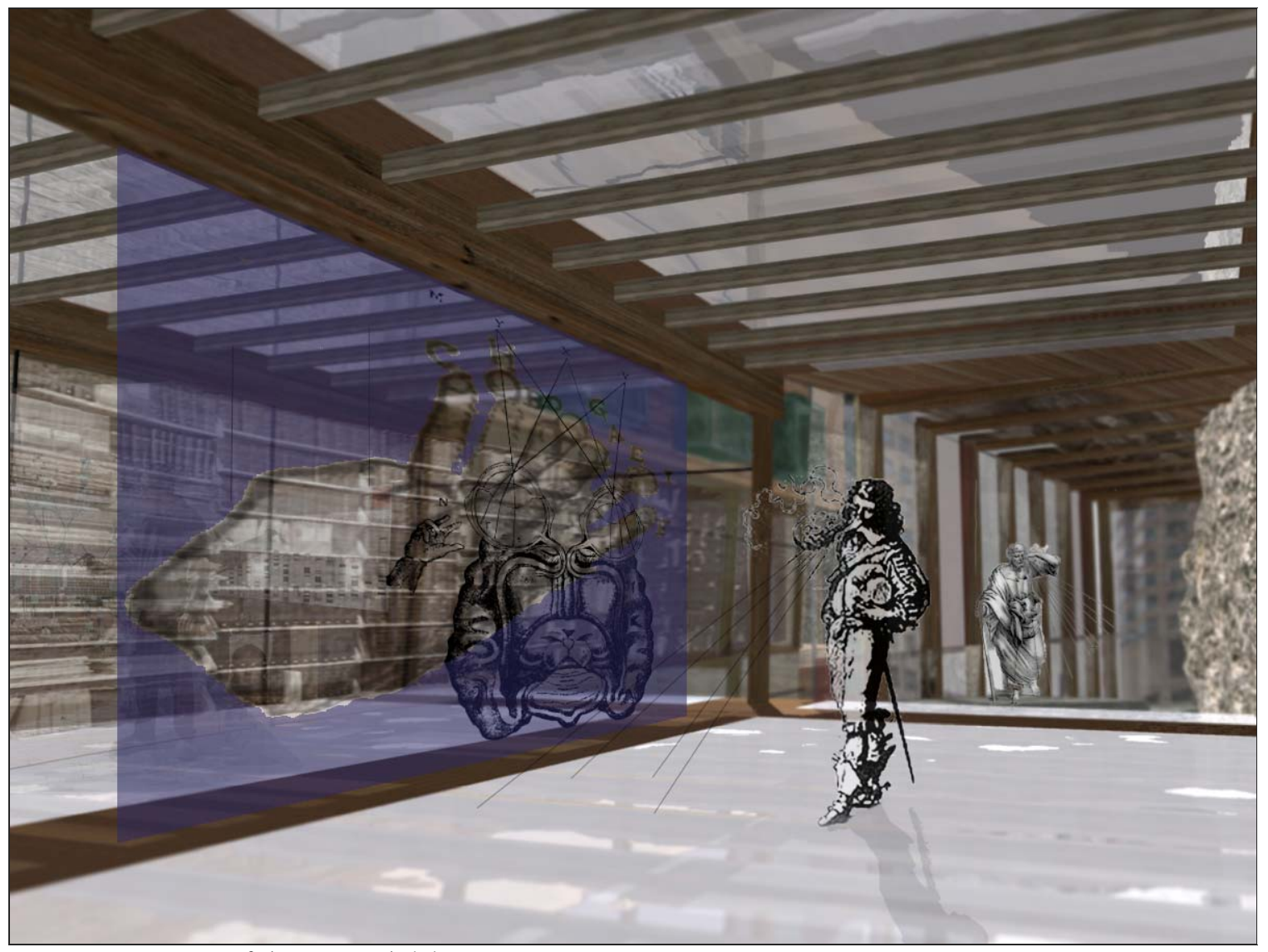

Fig. 37 Depiction of the research laboratory. 


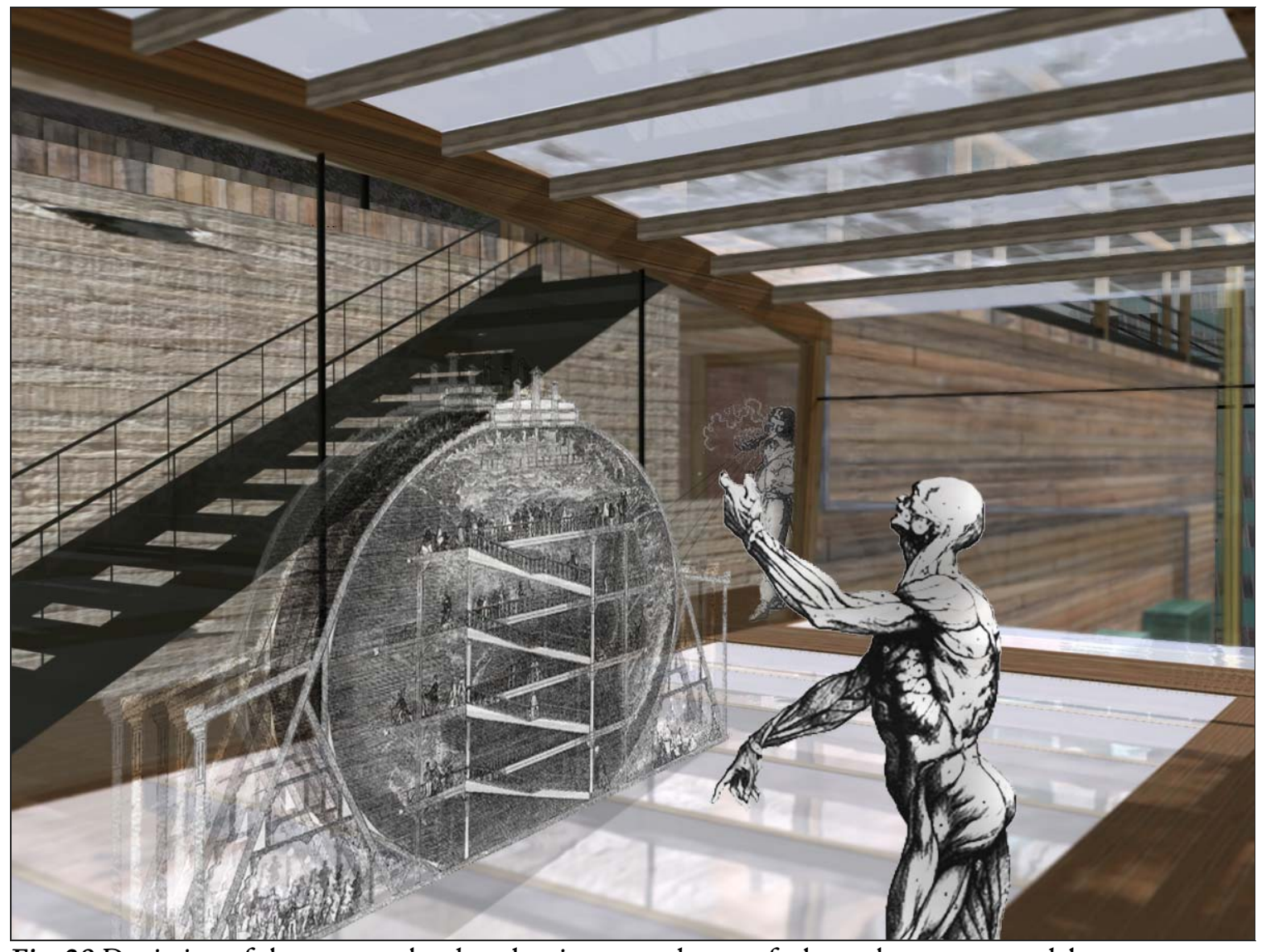

Fig. 38 Depiction of the nano-technology luminescent glass roof, above the uppermost laboratory. 


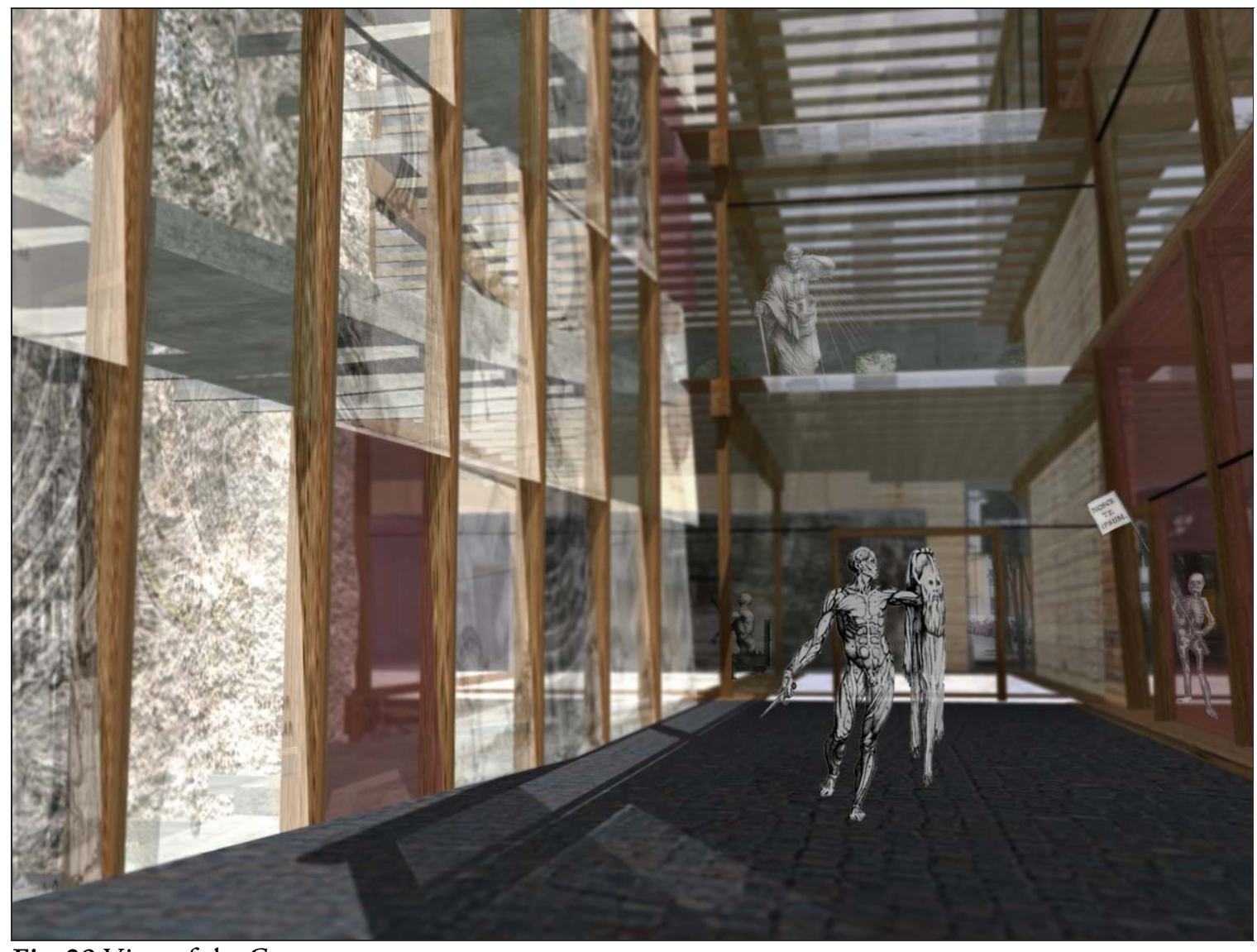

Fig. 39 View of the Court. 


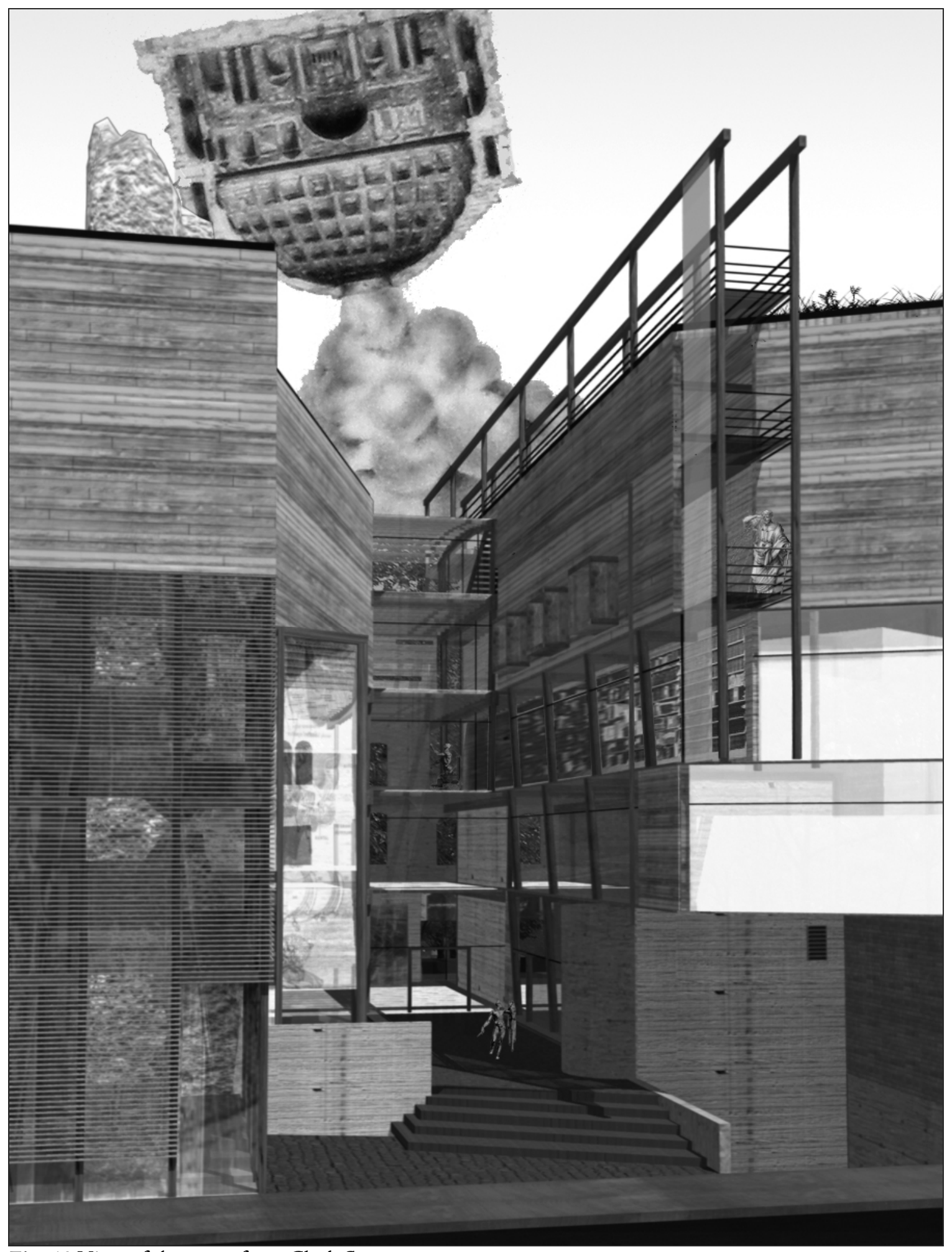

Fig. 40 View of the court from Clark St. 


\section{NOTES}

1. This scene is drawn after a classical painting by John William Waterhouse (see: http://en.wikipedia.org/wiki/Image:Waterhouse-Diogenes.jpg) in which Diogenes is depicted sitting in his tub, amongst his staple of onions and his lantern. He is said to have held his lantern in broad daylight as he walked through the agora. When asked about it, he would answer, "I am just looking for an honest man."

2. See the exhibition catalogue for Strangely Familiar: Design and Everyday Life, curated by Andrew Blauvelt.

3. See the University of Technology Syndey's research on applications of Nano-Technology: http://www.nano.uts.edu.au/ (last accessed: 2006-03-21) 


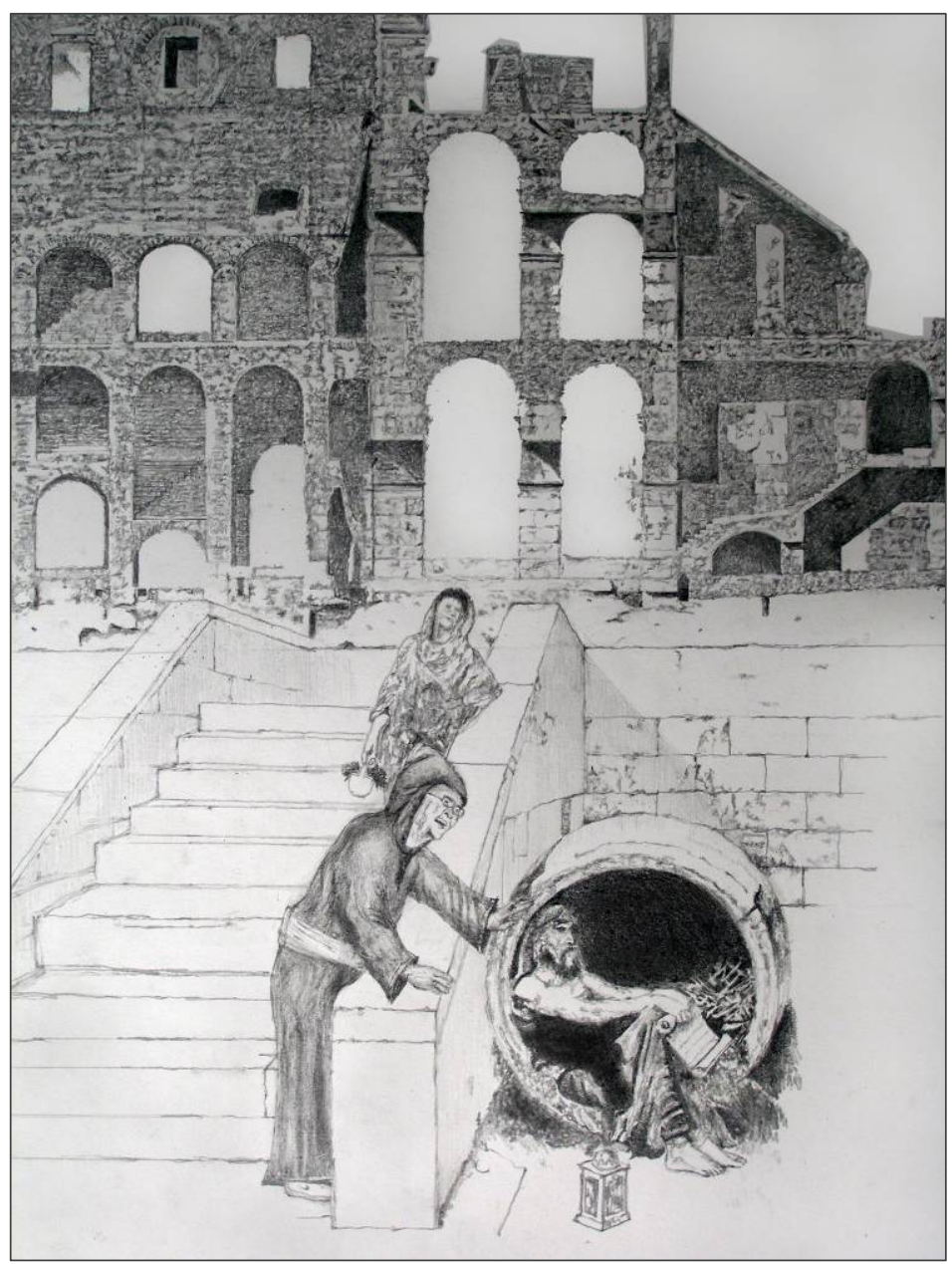

\section{${ }_{6.0}$ CONCLUSION}


Architecture stands as one of the major forces in the reconciliation of our terrestrial existence with the power of extension. In generating conditions of creative disclosure of the circumstances surrounding our existence, opportunities are created to allow individual narratives to negotiate the tenuous nature of appropriation, wherein the possibilities of the copula between language, action and thought in developing agency through heuristic fictions are made present. In representing our world, architecture - as a device for evincing - remains the most essential means of expressing the most fundamental (and most easily forgotten) aspects of our existence, precisely because it deals with the banal. However, the tendency of Autistic Culture of stripping the world of its dimensionality for the sake of control leaves architectural representation at the mercy of imperatives far beyond the circumstances of the quotidian. Thus, what seems most necessary in response to this situation is a circumstance which enacts the agency of those who participate in everyday architectural narratives, by contrasting the familiar aspects of edifices with a deliberate estrangement between the body and the spaces which conceive them; thereby allowing for aleatory interpretations based on metaphorical and metonymical associations to narratives, now commonly considered to be beyond the scope of architecture. This thesis suggests a possible means of generating such circumstances. It is an approach based on an understanding that technology can provide a dwelling, if we attend to it with a heuristic approach. On this fundamental level, this thesis seeks to negotiate the contested understanding of sustainability; it provides an account of the seminal acts of autoreferentiality which have come to define our world as a 'self-producing,' self-consuming entity, and provides an account of this development within a physiognomic condition embedded in cultural production. In doing so, the basis for questioning what sustains us is brought to the fore; here presented as a question of agency in the 'late-modern' age. 
The existence of Autistic Culture reveals a genetic propensity toward the instrumentalization of technology, and more fundamentally, a genetic underpinning for the conquering of space. This genetic inclination reveals possible circumstances far beyond the reach of this thesis, though definitely within its perspective. In a Darwinian sense, the prevalence of Autistic Culture - as a genetically-based condition - appears to be facilitated through environmental circumstances rendered specifically through technological systems of control, and suggests a potential vector of human relationality in the development of architecture that is as modular as light itself (such as those emulated in virtual and immersive environments). Within these environments, auto-referential conditions are implicit, as the familiar, standard, and recognizable are substituted for any auto-didactic conditions based on 'clumsy heuristics' of negotiation. This issue appears to parallel the current debate surrounding the veracity of autistic diagnoses; specifically those which place autism into any medically classifiable category whatsoever. According to some higher-functioning autistics, such as Michelle Dawson, autism is not a disorder, but a phenomenon which has existed since the origins of the human species - one which is considered by some to be an evolutionary trait in the species. ${ }^{1}$ This possibility appears only re-affirmed by the prevalence of autism under changing values and cultural phenomena, and places the symptoms - or traits, as they may be called - within an altogether different category of human beings with proclivities towards auto-referentiality. This theory, however, appears very divisive, particularly to those families beset with low-functioning autistics, who strongly believe in eradicating the autistic symptoms which have rendered their children incapable of performing the simplest of interactions, such as brushing their own teeth, without constant guidance and reference to pre-established structure. It is therefore important here to re-affirm the position of this thesis as referring to 
the phenomena of Autistic Culture (as an increasing incidence of auto-referentiality within cultural production), and not autism as defined by current medical diagnoses (keeping in mind the understanding of medicine as a cultural trope) ${ }^{2}$

As this thesis is based on a heuristic process, any conclusive remarks on the process which I undertook should only be made in hindsight. Therefore, the following remarks on the effectiveness of this thesis were made after the completion of the work of this thesis.

The intervention of a Laboratory for Human Prosthetics within the developing cultural district of Montréal was seen to provide a foil to the effects of gentrification in the area. The intervention embraces the cultural potential of its surroundings by creating a circumstance which implicates the protagonists of Autistic Culture in the communicative space of the area. These protagonists are further mediated through an architecture which is manifested by means of a twofold process; by one which engages the 'local technology' of its inhabitants, as a means of developing a relationality; and by another which deliberately engages their autistic tendencies, as a means of contrasting 'extension' with quotidian experience. These differing instances can begin to reveal the infra-ordinary aspects of their lives, allowing the realm of extension to become leveraged. Although the representations of the building may be seen to be quasi-acheiropoietic due to the nature of computer-generated representations, the insertion of classical precedents and perspectivalist figures lend characterization to the spaces, thereby skewing the implications of the representation as an acheiropoiesis; creating surrealistic allusions. Essentially, the representations were seen to be suggestive characterizations of the spaces, employing a narrative of classical medical and perspectivalist precedents as cues to the implications of the spaces upon the body.

Conceived as a device to reveal narratives based on heuristics of participation, the 
design of the building is inspired by the immediate subjective experience of its classical participants. This condition is then transcribed in the generation of a duality of spaces; those which evince participatory heuristics by interrupting the ordinary, and those which deliberately mute such interruptive moments through their homogeneity. In such a way, symptomatic spaces of extension are contrasted with the quotidian, as a therapy to Autistic Culture. 
6.0 CONCLUSION | IO6

NOTES

1. See Dawson, M.; Gernsbacher, M.A.; Goldsmith, H.H. Three Reasons Not to Believe in an Autism Epidemic, American Psychological Society. (Vol. 14, No. 2, 2005, 55-58).

2. See the chapter within this document entitled Use of Terms. 


\section{IMAGE APPENDIX}




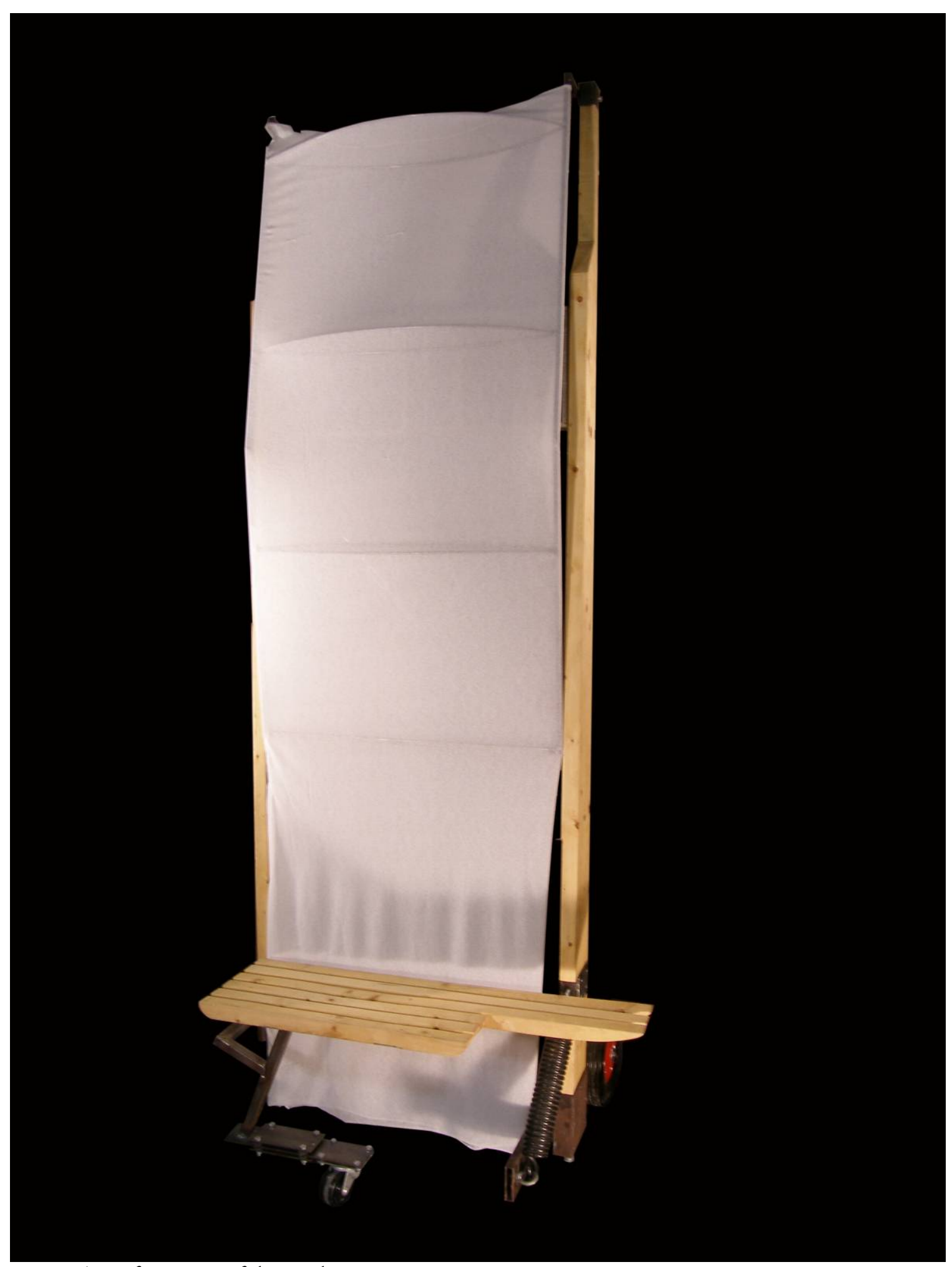

Fig. 41 A configuration of the mechanism. 


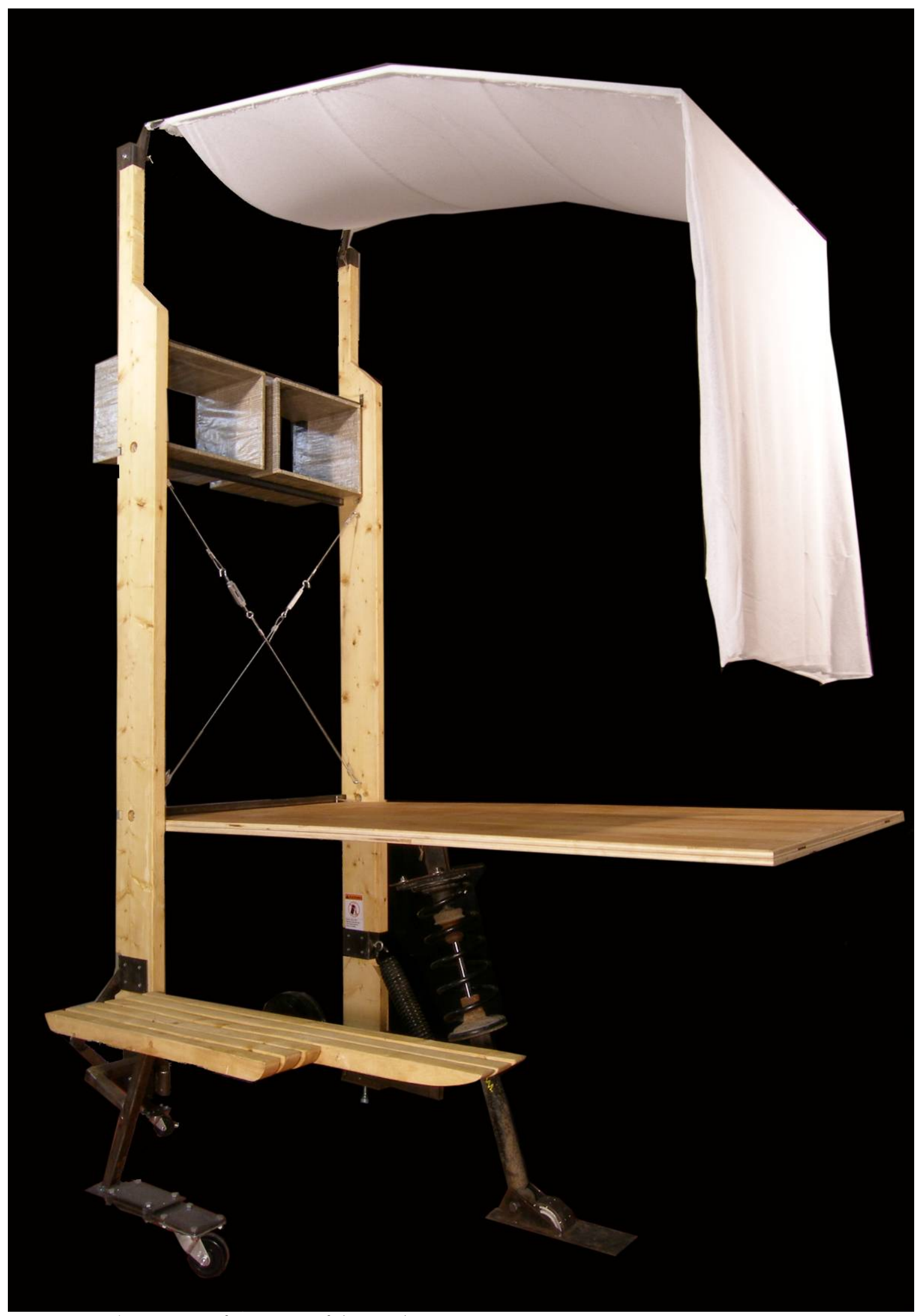

Fig. 42 An alternate configuration of the mechanism. 

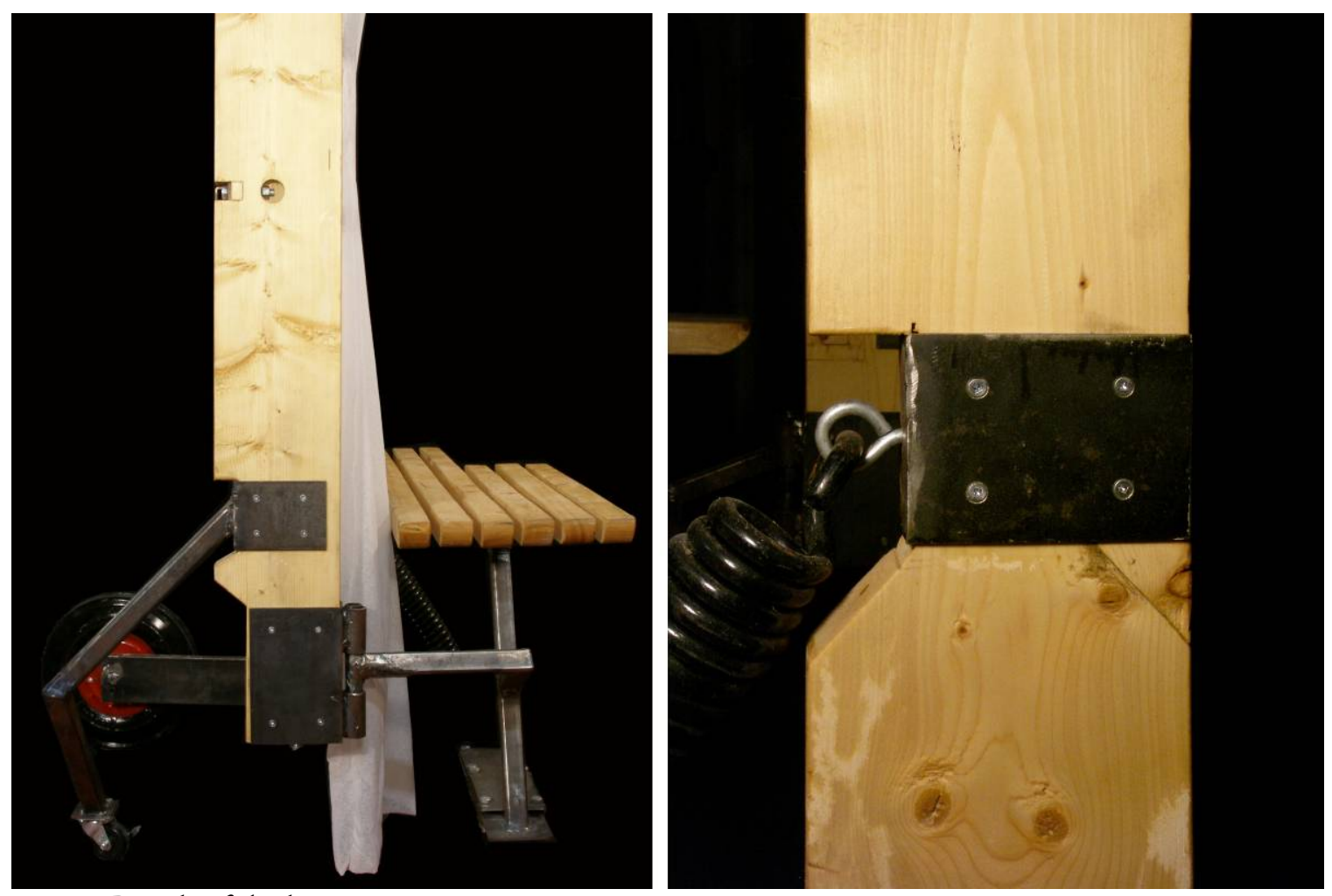

Fig. 43 Details of the lower connection points.

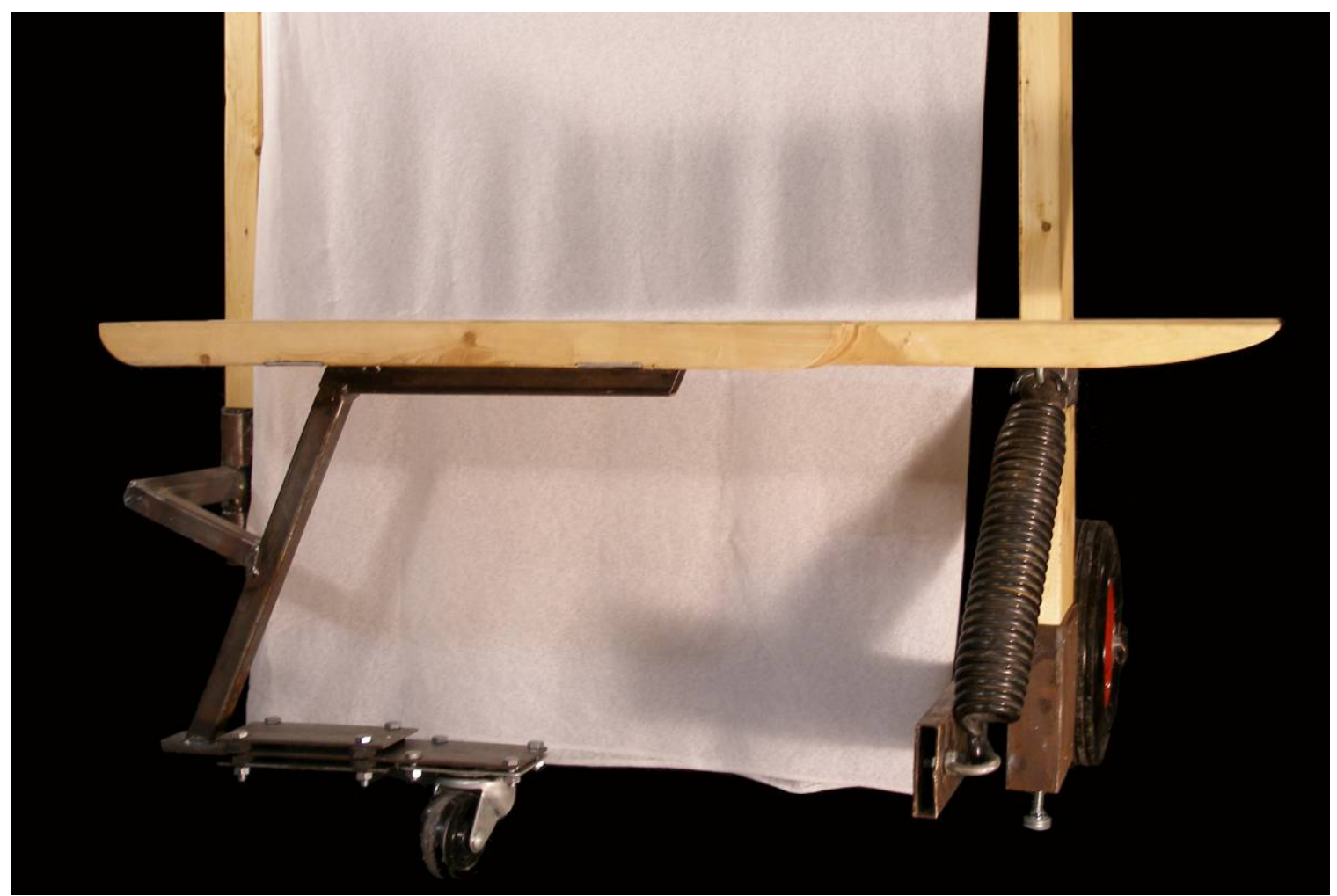

Fig. 44 Front view of the supports. 


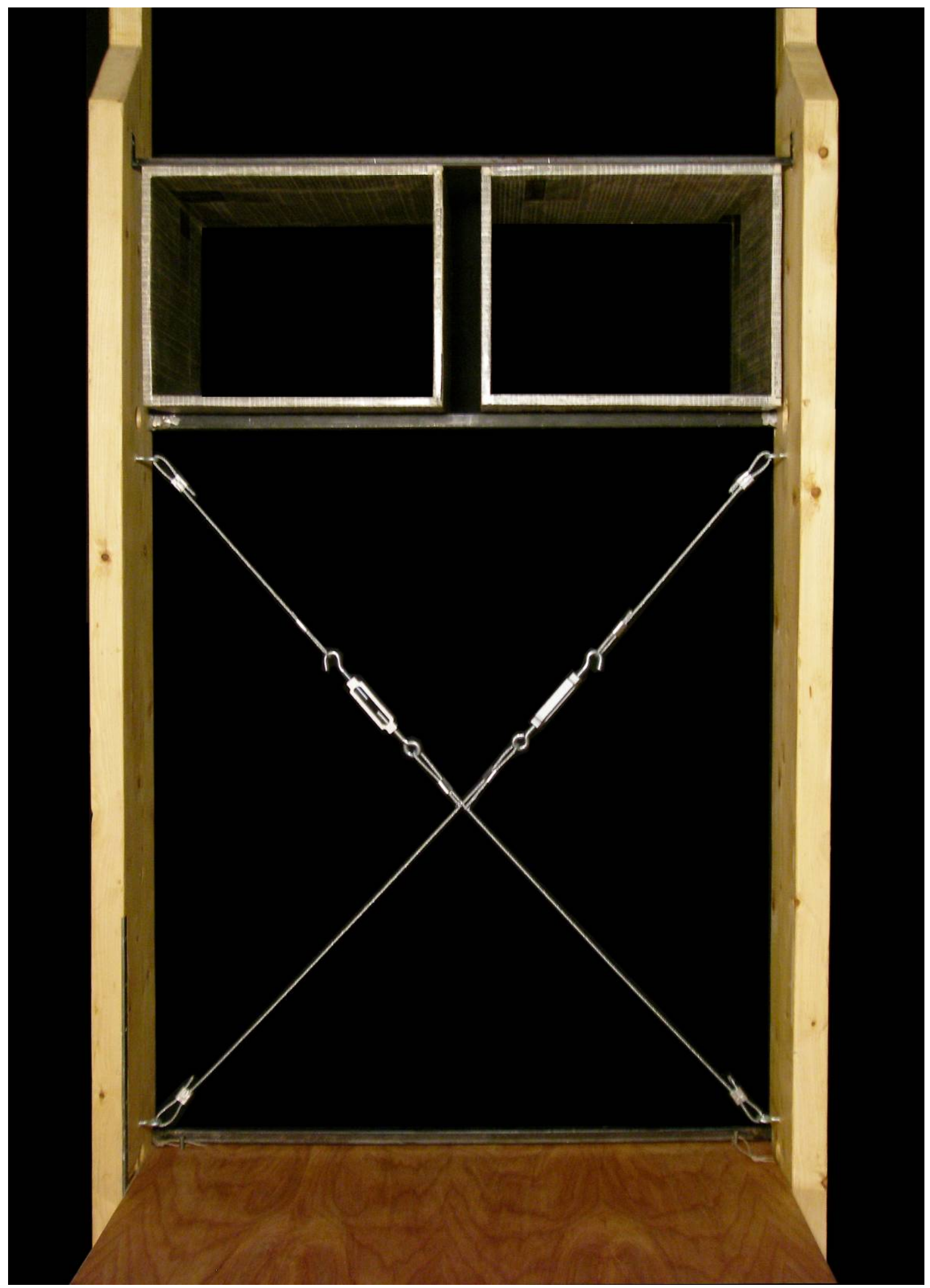

Fig. 45 Front view of the mechanism. 


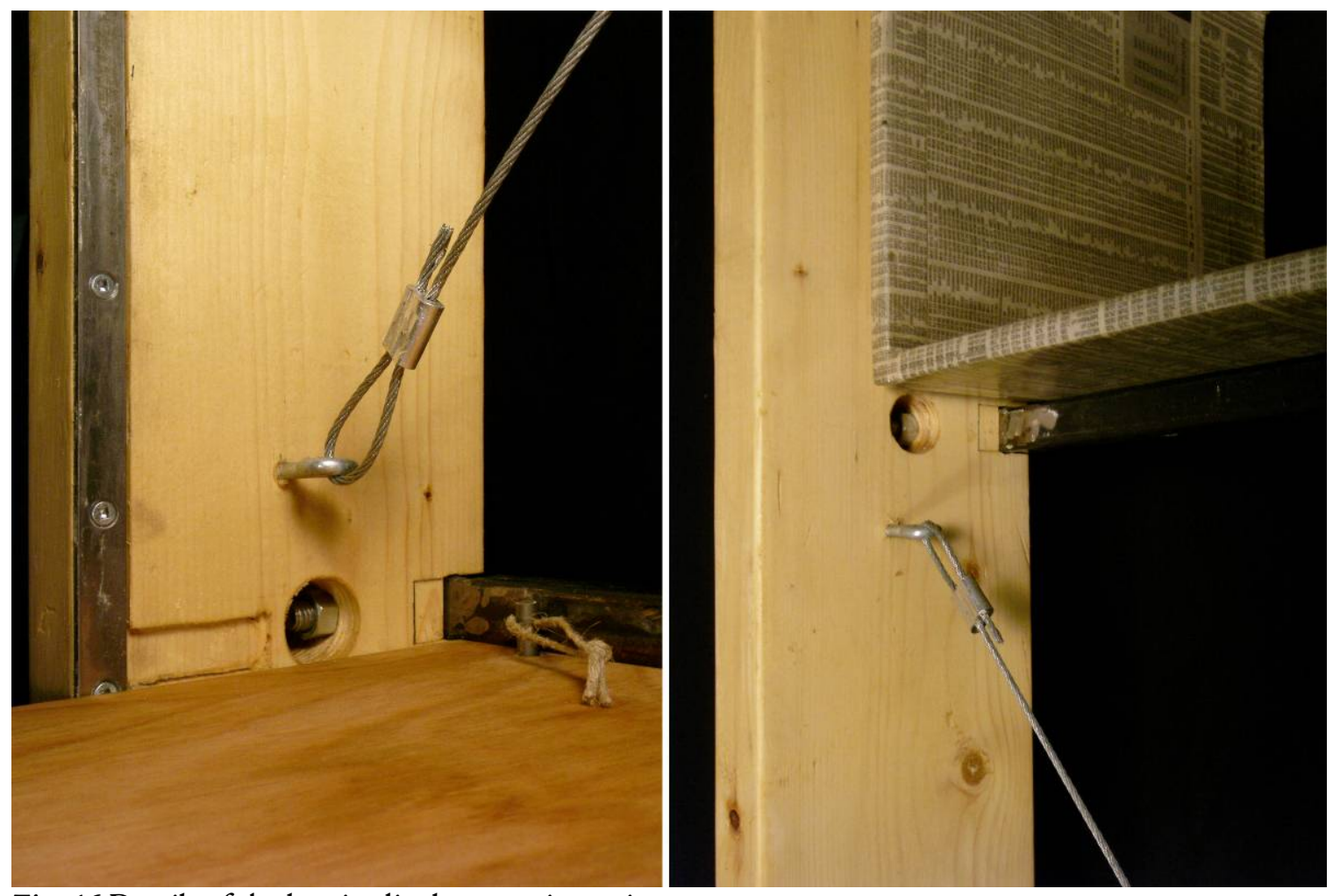

Fig. 46 Details of the longitudinal connection points.

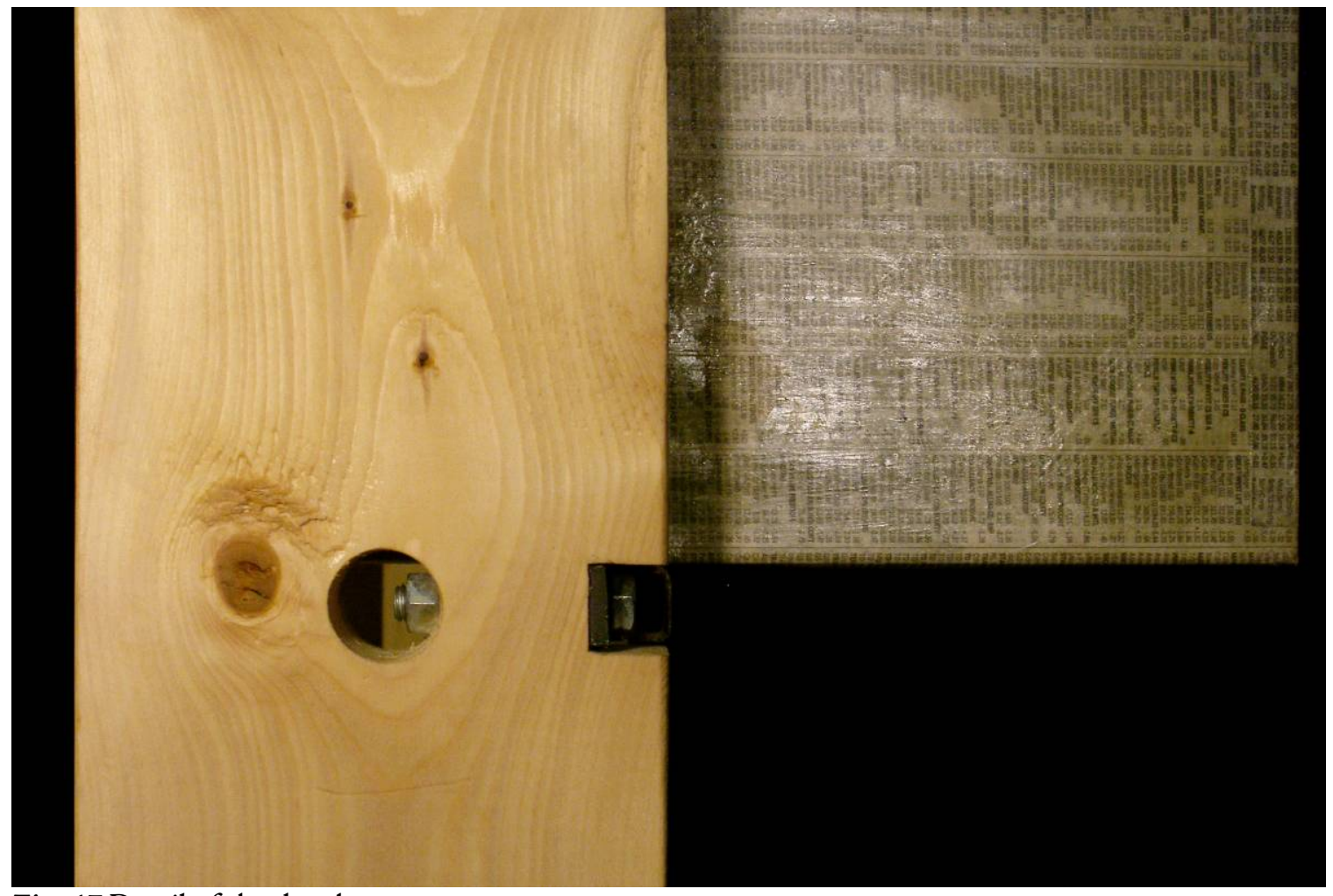

Fig. 47 Detail of the data box. 

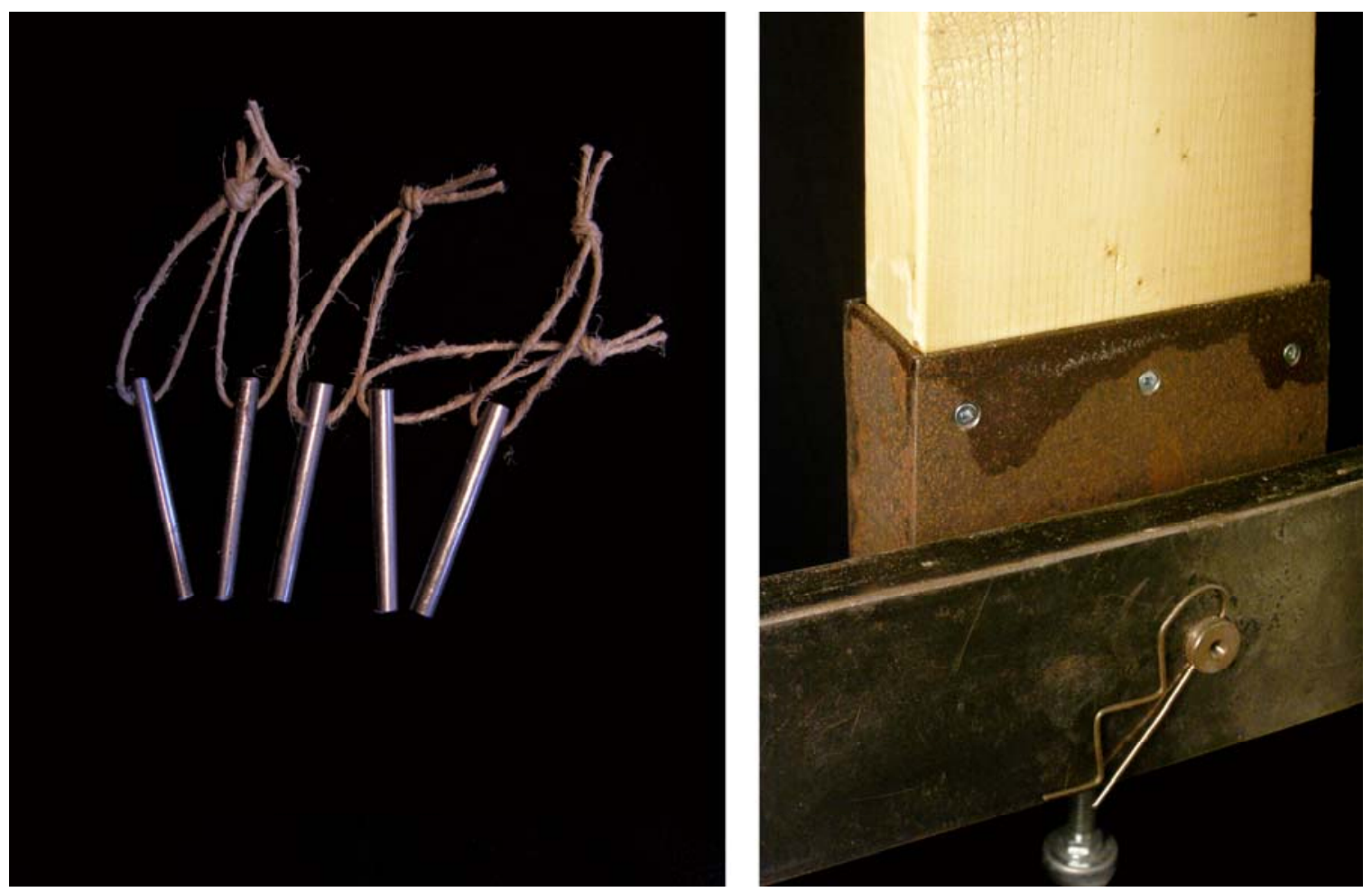

Fig. 48 Detail of the keys and lower joint.

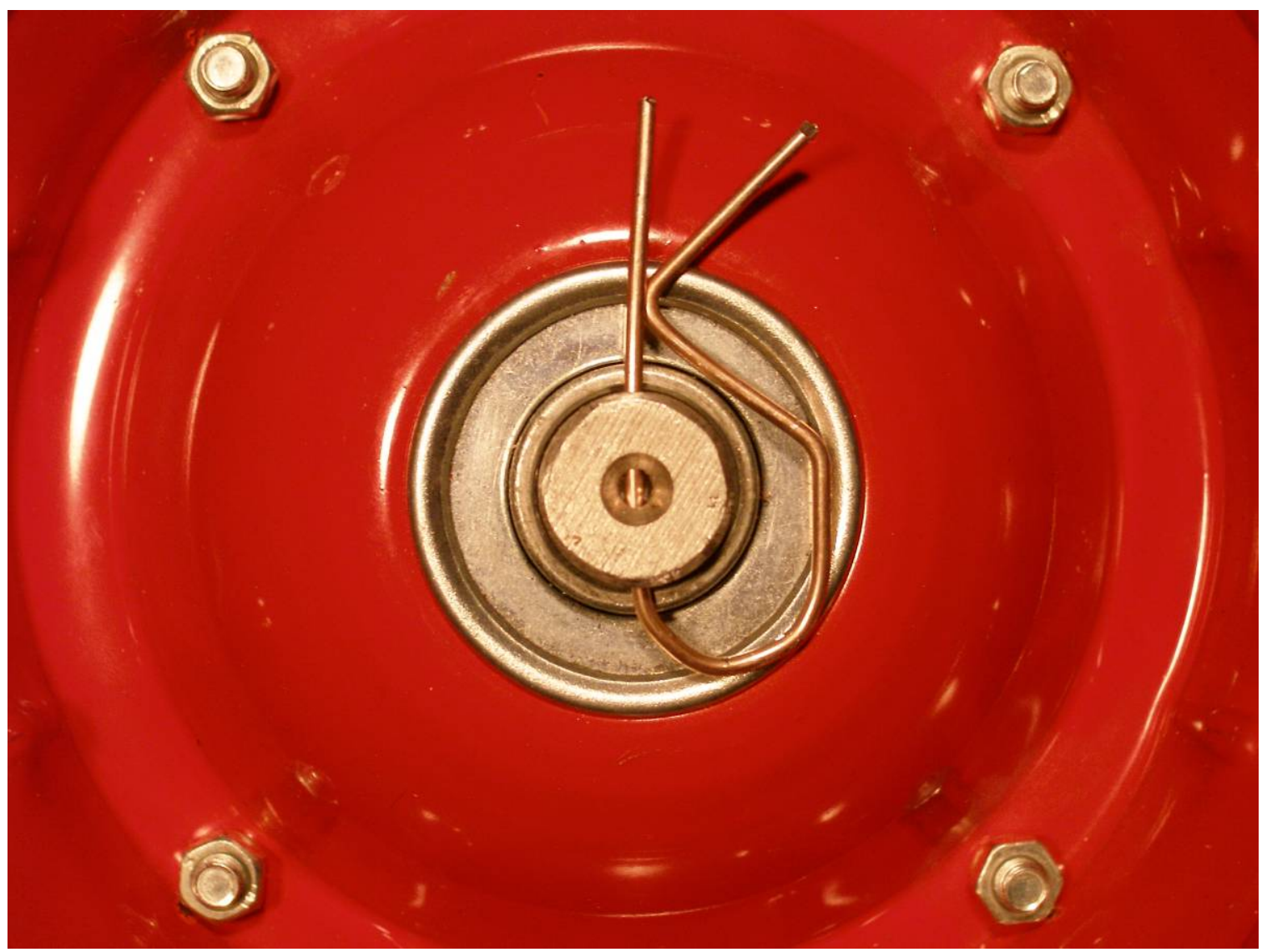

Fig. 49 Detail of the wheel hub. 


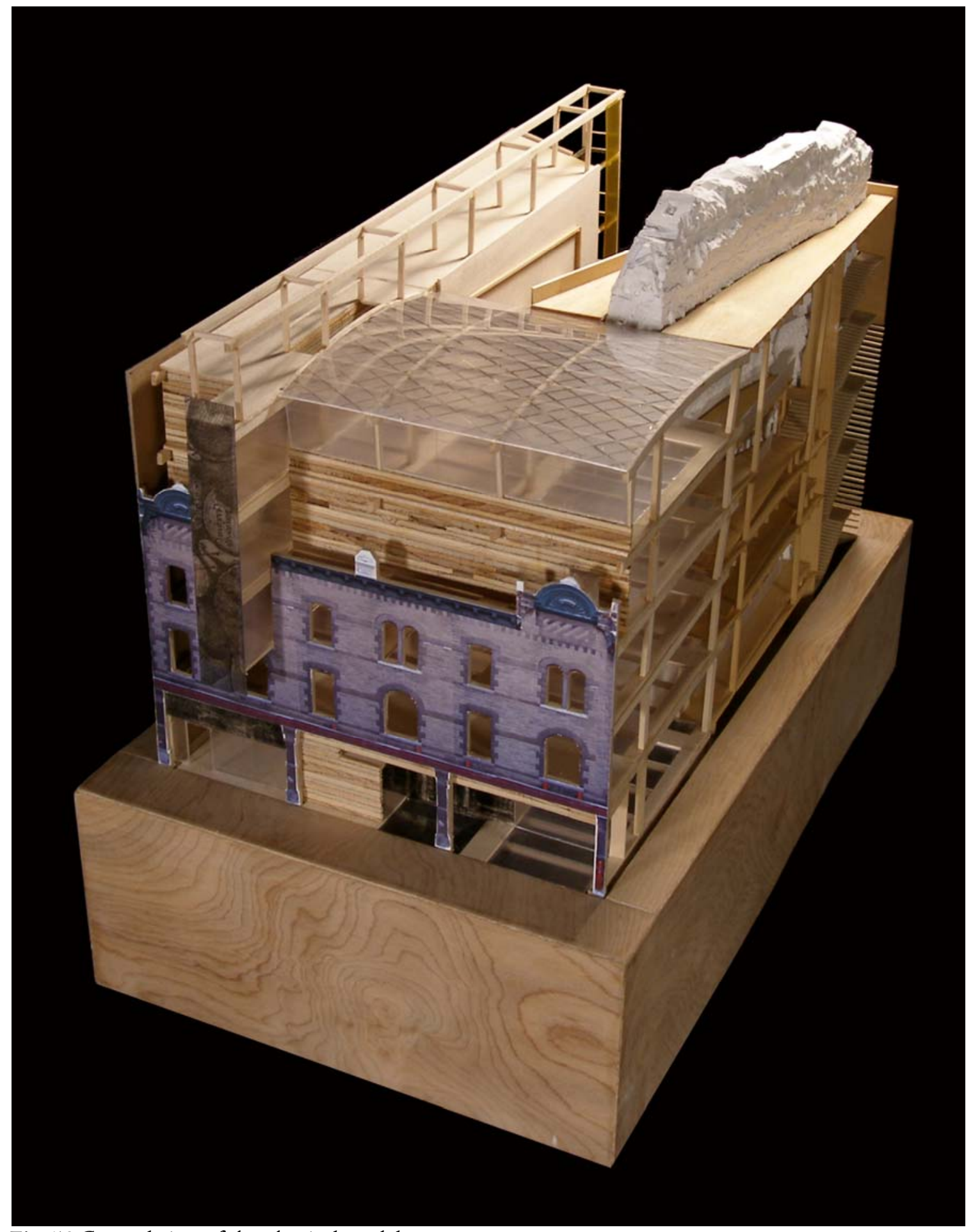

Fig. 50 General view of the physical model. 


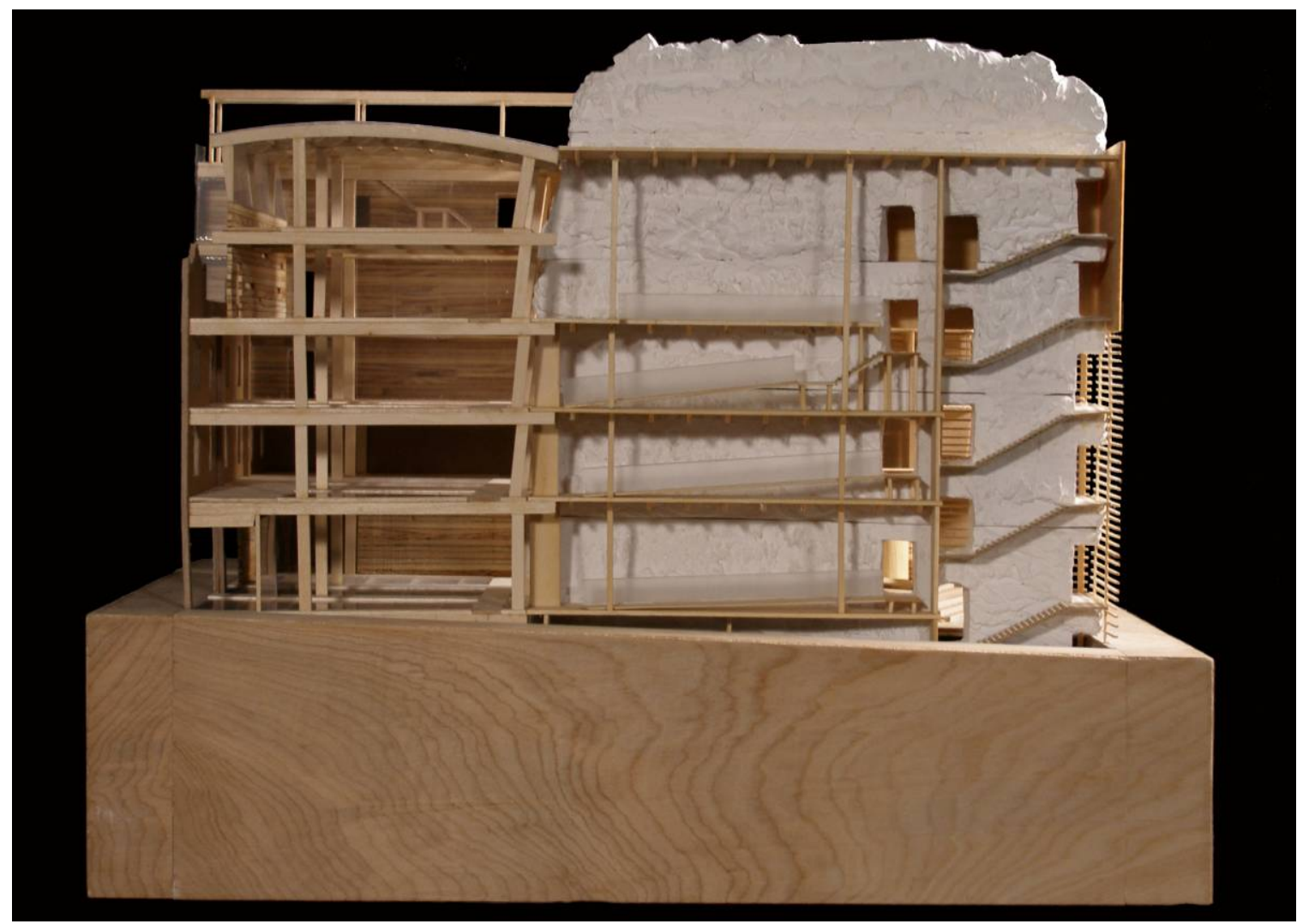

Fig. 51 Sectional view of the physical model; North-Eastern orientation.

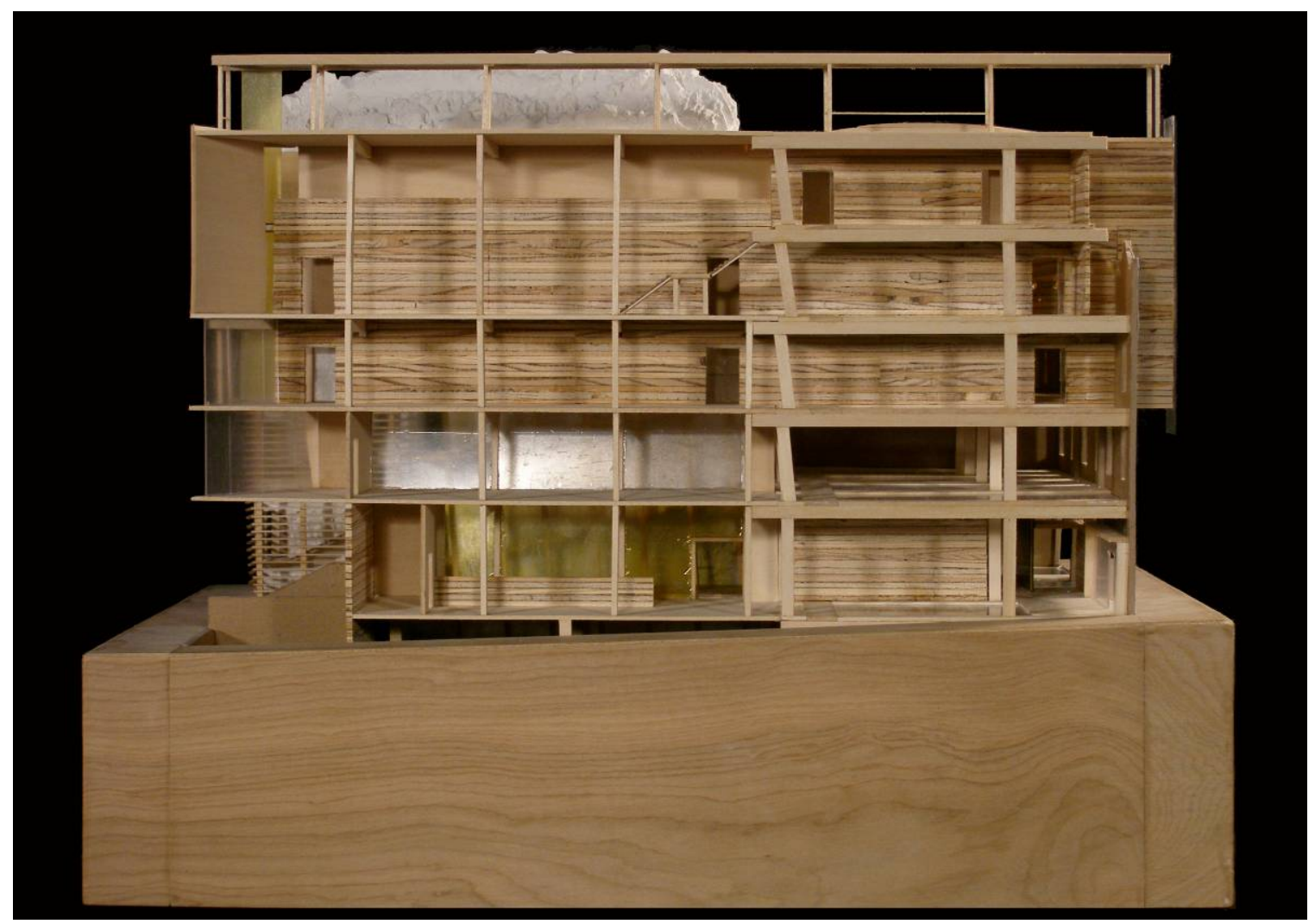

Fig. 52 Sectional view of the physical model; South-Western orientation. 


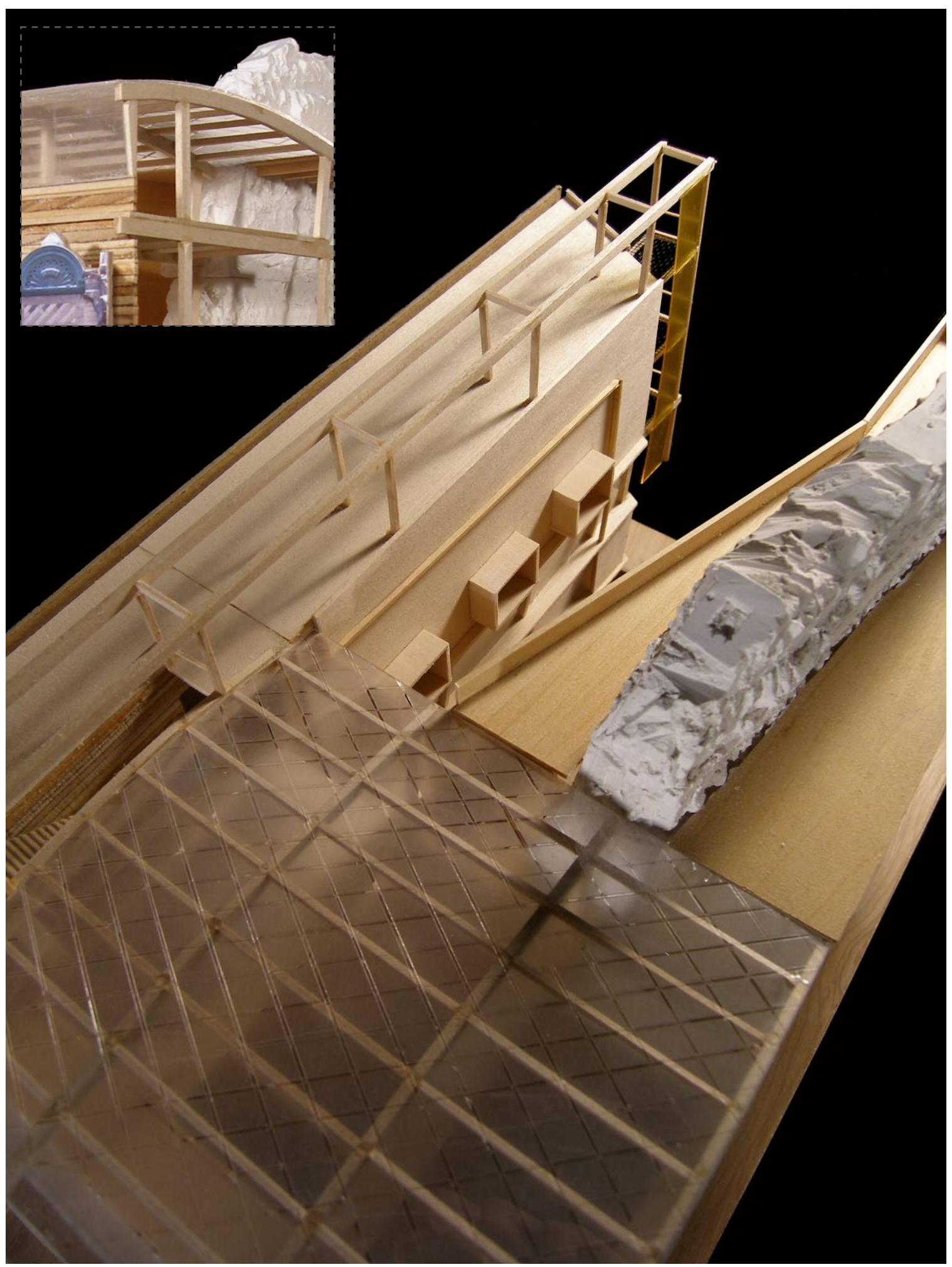

Fig. 53 Detail of the nano-technology-based glazing, and the emerging passive-solar mass. 


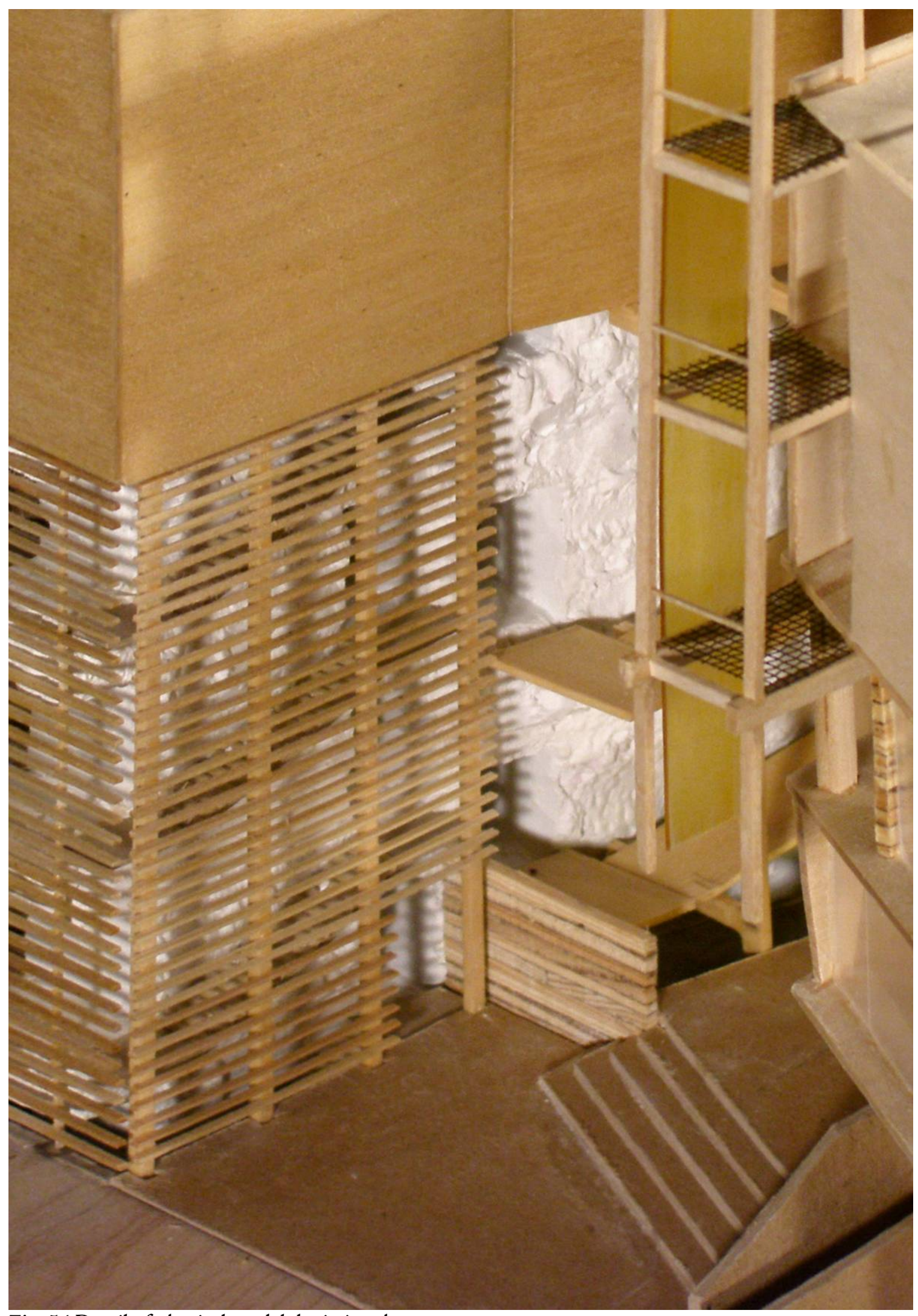

Fig. 54 Detail of physical model depicting the rear court. 


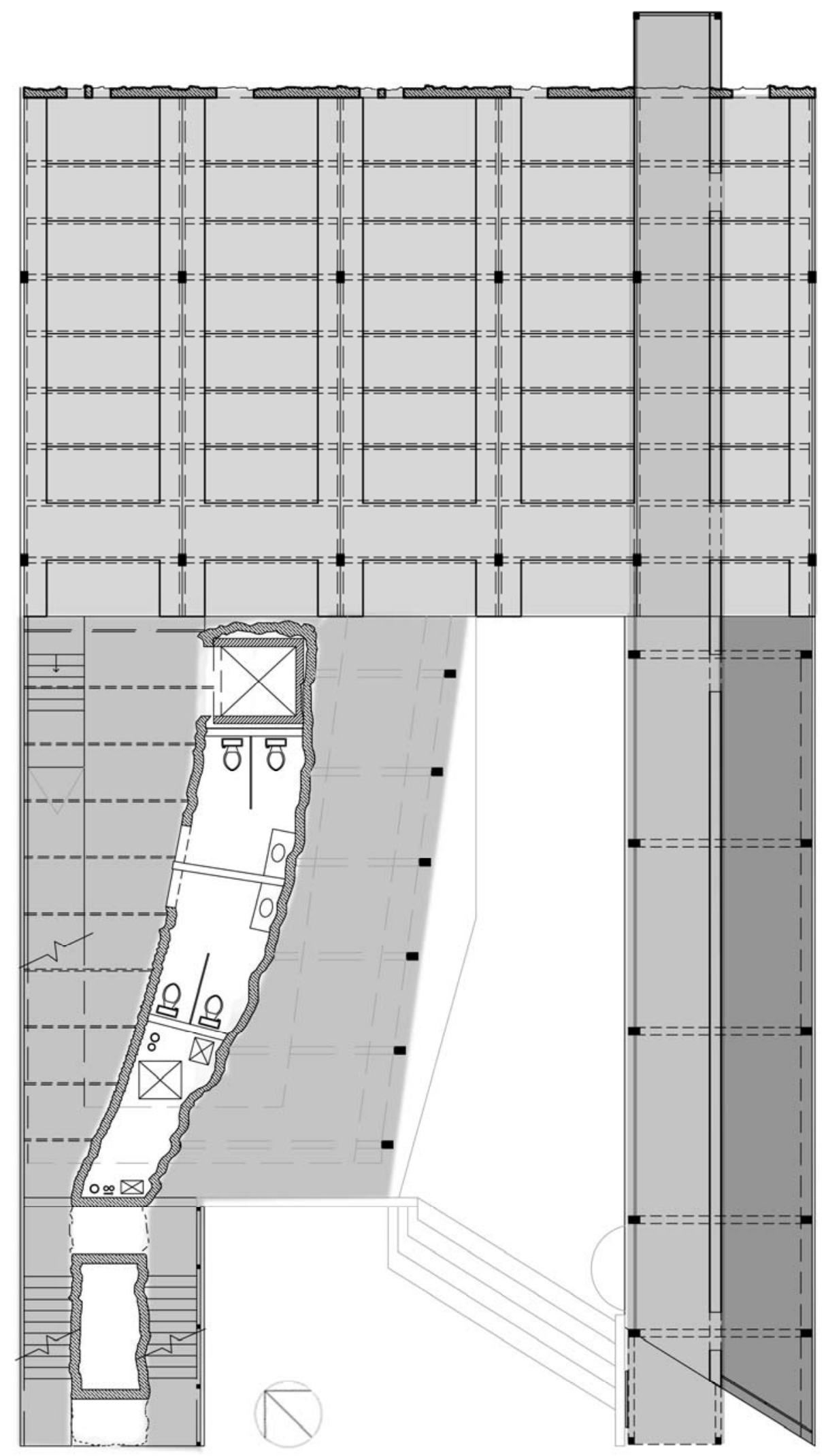

Fig. 55 Typical Plan of the Laboratory building. 


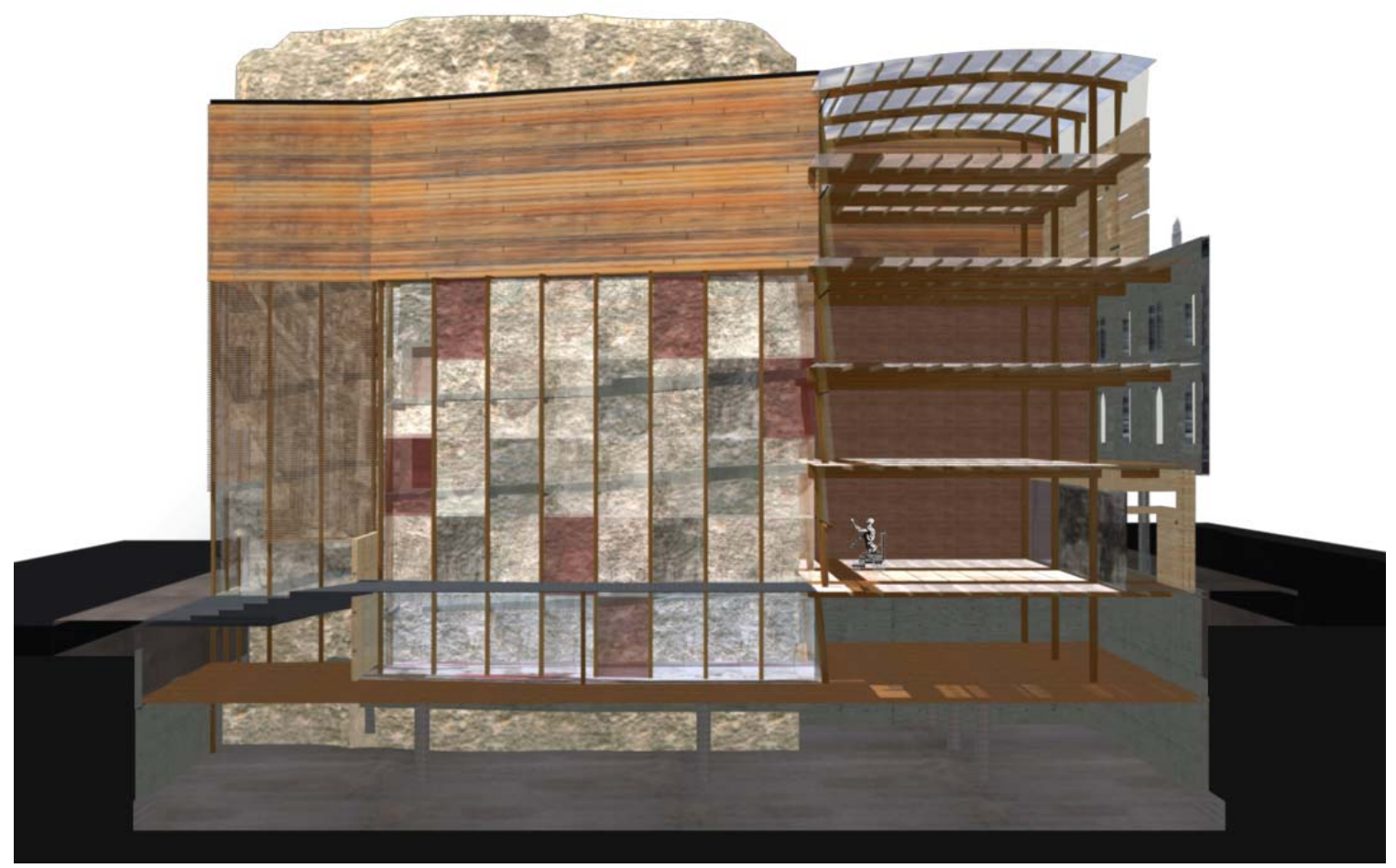

Fig. 56 North-Eastern Sectional diagram of the Laboratory.

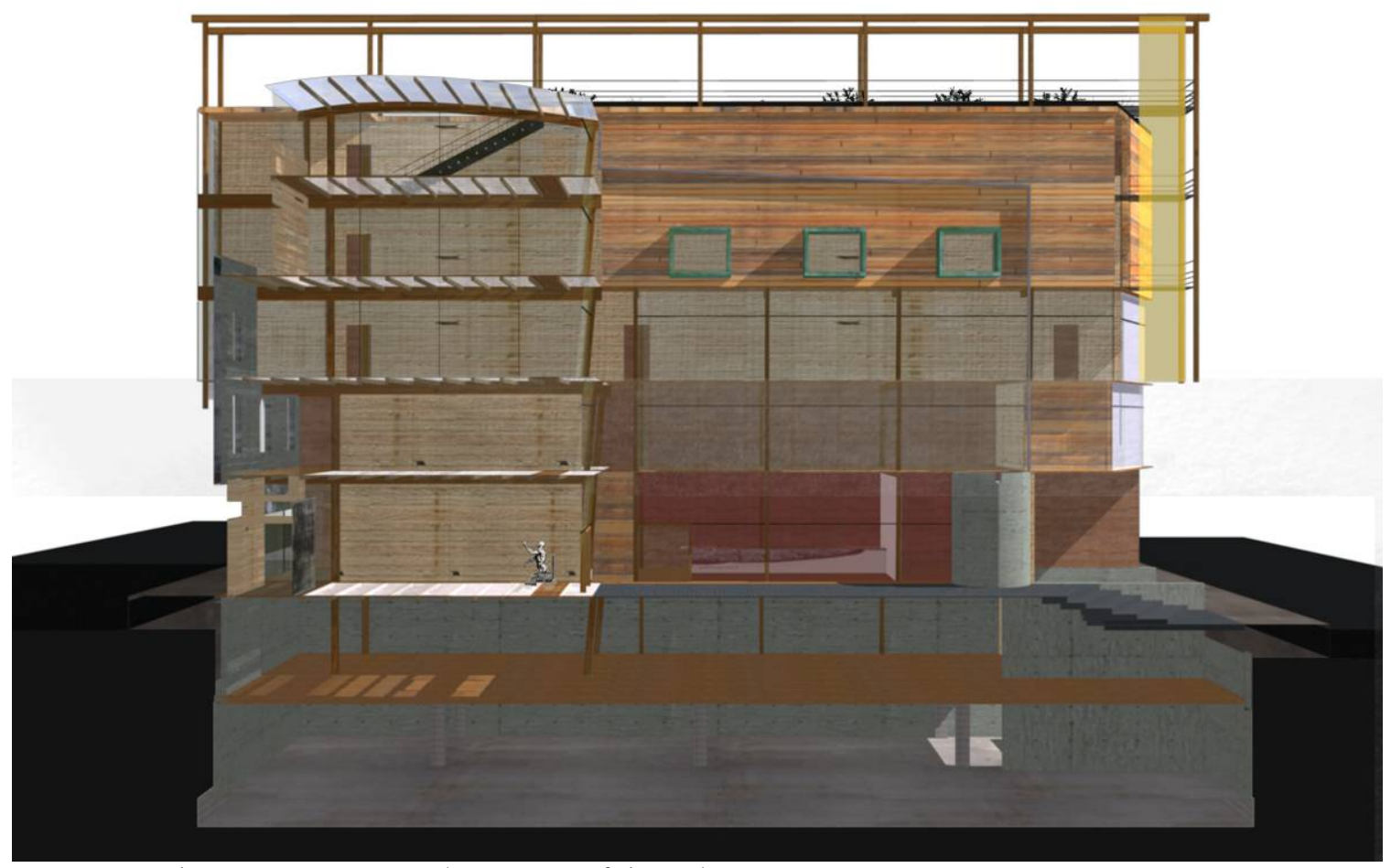

Fig. 57 South-Western Sectional Diagram of the Laboratory. 


\section{BIBLIOGRAPHY}

Baudrillard, Jean. Simulacra and Simulation. Ann Arbour: University of Michigan Press, 1994.

Beim, Anne. "Regio \& Mundus: an Inquiry into the World of Building Services," The Architectural Magazine, 2005: 72-86.

Capra, Fritjof. The Tao of physics: an exploration of the parallels between modern physics and Eastern mysticism. Boulder: Shambhala, 1983.

Cassanelli, Roberto... [et al.]. Ruins of Ancient Rome: the Drawings of French Architects Who Won the Prix de Rome, 1786 - 1924. Ed. by Massimiliano David. Los Angeles : J. Paul Getty Museum, 2002.

Certeau, Michel de. The Practice of Everyday Life. Website (last accessed: 2006-03-21): http $: / / w w w . u b u . c o m / p a p e r s / d e \_c e r t e a u . h t m l$

Coyne, Richard. Designing Information Technology in the Post Modern Age. Cambridge: The MIT Press, 1995.

Crowe, Norman. Nature and the Idea of a Man-Made World: An Investigation into the Evolutionary Roots of Form and Order in the Built Environment. Cambridge: The MIT Press, 1997.

Dal Co, Francesco; Giuseppe Mazzariol. Carlo Scarpa: the complete works. New York, Rizzoli., 1984

Darby, Thomas (ed.). Soujourns in the New World. Ottawa: Carleton University Press, 1986.

---. The Feast: Meditations on Time and Politics. Toronto: University of Toronto Press, 1982.

Davison, Aidan. Technology and the Contested Meanings of Sustainability. Albany: State University of New York Press, 2001. 
Dawson, M.; Gernsbacher, M.A.; Goldsmith, H.H. Three Reasons Not to Believe in an Autism Epidemic, American Psychological Society. Vol. 14, No. 2, 2005, 55-58.

Dodds, George (ed.) Body and Building: Essays on the Changing Relation of Body and Architecture. Cambridge: MIT Press, 2002.

Feenburg, Andrew. Alternative Modernity: The Technical Turn in Philosophy and Social Theory. Berkeley: University of California Press, 1995.

---. Questioning Technology. New York: Routledge, 1999.

Foucault, Michel, The Birth of the Clinic; an Archaeology of Medical Perception. New York: Pantheon Books, 1973.

Frank, Suzanne. Peter Eisenman's House VI - The Clients Response. New York: Whitney Library of Design, 1994.

Frampton, Kenneth. Studies in Tectonic Culture: the Poetics of Construction in Nineteenth and Twentieth Century Architecture. Cambridge, Mass.: MIT Press, 1995.

Frascari, Marco. Architectural Synaesthesia: a bypothesis on the makeup of Scarpa's modernist architectural drawings. Website (last accessed: 2006-05-24):

http://art3idea.psu.edu/synesthesia/documents/synesthesia_frascari.html

---. Monsters of Architecture: Anthropomorphism in Architectural Theory. Savage, Md.: Rowman, 1990.

Gubbay, Aline. A Street Called the Main. Montreal: Meridian Press, 1989.

Hamilton, Graeme. "The Main acknowledged as historic site." The National Post. Sect. A5. Sept. $28^{\text {th }} 2002$.

Hartoonian, Gevork. Ontology of Construction: on nibilism of technology in theories of modern architecture. New York: Cambridge University Press, 1994.

Harries, Karsten. The Ethical Function of Architecture. Cambridge: The MIT Press, 1998.

Heidegger, Martin. Poetry, Language, Thought. Trans. Albert Hofstadter. New York: Harper and Row, 1971.

Heidegger, Martin. The Question concerning Technology, and other essays. New York: London: Harper and Row, 1977.

Highmore, Ben. Everyday life and cultural theory: an introduction. New York: Routledge, 2002. 
---. The Everyday Life Reader. New York: Routledge, 2002.

Horwitz, Jamie; Singley, Pauline (ed). Eating Architecture. Cambridge: MIT Press, 2004.

Jacobson, Roman. Fundamentals of Language. New York: Mouton \& Co., 1956.

Kuhn, Thomas S. The Structure of Scientific Revolutions. Chicago: University of Chicago Press, 1996.

Kunze, Donald. "Prolegomena to any future dog architecture," Fifth Column, Vol. 7, No. 3 , 1989, 26-29.

Loverseed, Helga. "Property Report/Quartier des Spectacles." The Globe and Mail. Sect. B6. January $4^{\text {th }}, 2005$.

Lortie, André. "Montreal 1960: The Singularities of a Metropolitan Archetype." Montréal thinks big. Ed. by André Lortie. Montreal: Canadian Centre for Architecture, 2004.

Lyotard, Jean-François. The Post-Modern Condition. Minneapolis: University of Minnesota Press, 1984.

Merleau-Ponty, Maurice. The Phenomenology of Perception. Trans. Colin Smith. New York: Routledge, 1994.

Mesibov, Gary B. Autism: Understanding the Disorder. New York: Plenum Press, 1997.

Micklem, Niel. The Nature of Hysteria. New York: Routledge, 1996.

M.I.N.D. Institute. Report to the Legislature on the principal findings from The Epidemiology of Autism in California: A Comprehensive Pilot Study. Davis: University of California-Davis, 2002.

Oelschlaeger, Max. The Idea of Wilderness. Yale: Yale University Press, 1991.

Pallasmaa, Juhani. "Hapticity and Time," High Beam Research. Website: http://www.highbeam.com/library/docFree.asp?DOCID=1G1:64720968 (last accessed: 2006-09-05).

Perec, Georges. Species of Spaces and Other Pieces. Trans. and ed. John Sturrock. Harmondsworth, Middlesex: Penguin, 1997.

Pérez-Gómez, Alberto. Architecture and the Crisis of Modern Science. Cambridge: MIT Press, 1983.

---. "Chora: the space of architectural representation," Chora. Vol.1, 1994: 1-34. 
Preziosi, Donald. Architecture, Language, and Meaning. New York: Mouton Publishers, 1979.

Rykwert, Joseph. The Idea of a Town. London: Faber and Faber, 1976.

Solà-Morales Rubió, Ignasi. "Weak Architecture," Differences : topographies of contemporary architecture. Trans. by Graham Thompson, ed. by Sarah Whiting. Cambridge, Mass.: MIT Press, 1997. pp. 57-71

Tafuri, Manfredo. Architecture and Utopia: Design and Capitalist Development. Trans. Barbara Luigia La Penta. Cambridge: MIT Press, 1976.

Vesely, Dalibor. "Architecture and the Question of Technology," Educating Architects. London: Academy Editions, 1995: 44-53.

---. Architecture in the Age of Divided Representation. Cambridge: MIT Press, 2004.

Yutang, Lin. Wisdom of Lao-Tzu. New York: Modern Library, 1948.

Wilson, Frank R. The Hand. New York: Vintage Books, 1999. 